\title{
Performance of HALEU and HEU-Fueled Nuclear Thermal Propulsion Reactors
}

Nuclear Science and Engineering Division 


\title{
About Argonne National Laboratory
}

Argonne is a U.S. Department of Energy laboratory managed by UChicago Argonne, LLC under contract DE-AC02-06CH11357. The Laboratory's main facility is outside Chicago, at 9700 South Cass Avenue, Argonne, Illinois 60439. For information about Argonne and its pioneering science and technology programs, see www.anl.gov.

\section{DOCUMENT AVAILABILITY}

Online Access: U.S. Department of Energy (DOE) reports produced after 1991 and a growing number of pre-1991 documents are available free at OSTI.GOV (http://www.osti.gov/), a service of the US Dept. of Energy's Office of Scientific and Technical Information.

\author{
Reports not in digital format may be purchased by the public from the \\ National Technical Information Service (NTIS): \\ U.S. Department of Commerce \\ National Technical Information Service \\ 5301 Shawnee Rd \\ Alexandria, VA 22312 \\ www.ntis.gov \\ Phone: (800) 553-NTIS (6847) or (703) 605-6000 \\ Fax: (703) 605-6900 \\ Email: orders@ntis.gov
}

Reports not in digital format are available to DOE and DOE contractors from the Office of Scientific and Technical Information (OSTI):

U.S. Department of Energy

Office of Scientific and Technical Information

P.O. Box 62

Oak Ridge, TN 37831-0062

www.osti.gov

Phone: (865) 576-8401

Fax: (865) 576-5728

Email: reports@osti.gov

This report was prepared as an account of work sponsored by an agency of the United States Government. Neither the United States Government nor any agency thereof, nor UChicago Argonne, LLC, nor any of their employees or officers, makes any warranty, express or implied, or assumes any legal liability or responsibility for the accuracy, completeness, or usefulness of any information, apparatus, product, or process disclosed, or represents that its use would not infringe privately owned rights. Reference herein to any specific commercial product, process, or service by trade name, trademark, manufacturer, or otherwise, does not necessarily constitute or imply its endorsement, recommendation, or favoring by the United States Government or any agency thereof. The views and opinions of document authors expressed herein do not necessarily state or reflect those of the United States Government or any agency thereof, Argonne National Laboratory, or UChicago Argonne, LLC. 


\section{Performance of HALEU and HEU-Fueled Nuclear Thermal Propulsion Reactors}

prepared by

A. G. Nelson, A. A. Kasam-Griffith, M. I. Atz, F. Heidet

Nuclear Science and Engineering Division, Argonne National Laboratory

prepared for

National Aeronautics and Space Administration 


\section{Abstract}

Interplanetary spaceflight may be significantly improved by rockets that utilize nuclear thermal propulsion (NTP) instead of the chemically propelled rockets in use today. To be efficient, NTP reactors must be light, which presents unique design opportunities and challenges to reactor designers. One such opportunity is the enrichment of the nuclear fuel that powers the NTP reactor. The use of high-enriched uranium (HEU) instead of high-assay low-enriched uranium (HALEU) will result in a lower mass of fuel required but may present additional challenges beside the mass considerations, such as proliferation concerns, availability, public acceptance and autorization basis. Whether or not a NTP reactor fueled with HEU is significantly lighter than its HALEU counterpart is unclear and an assessment has been performed here as part of the Mars Transportation Assessment study.

This report assesses the impact of reducing the fuel enrichment fom HEU (93 wt.\% ${ }^{235} \mathrm{U}$ ) to HALEU fuel $\left(19.5 \mathrm{wt} . \%{ }^{235} \mathrm{U}\right)$ on reactor design outcomes for a conceptual NTP reactor. Two reactor designs, one fueled with HEU and the other with HALEU, were prepared based on a multi-stage design process. The neutronics and thermal-hydraulics characteristics of these reactors are compared and contrasted to illustrate the impacts of fuel enrichment. Despite differences in fuel and moderator mass, the overall mass difference between the HALEU and HEU cores was only 9\%. The required core size and assembly dimensions are nearly equivalent. This finding is based on a rapid design process that targeted core volume minimization. Each features some neutronics advantages - depletion is much less significant in the HEU core, but the Doppler reactivity feedback is stronger in the HALEU core. Additional discussions are made about the possible benefits of other design changes, including the possibility of utilizing a fast-spectrum reactor. Given the scope of this assessment the findings discussed in this report are not exhaustive and are only providing an initial comparison of the most obvious design and performance parameters. 


\section{Table of Contents}

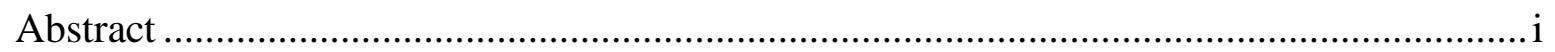

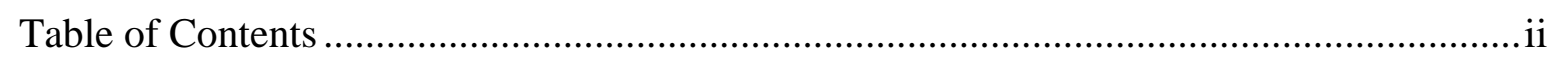

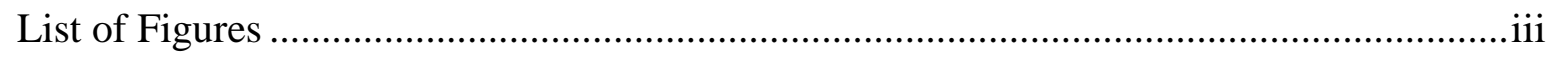

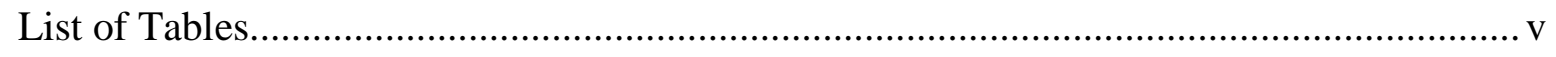

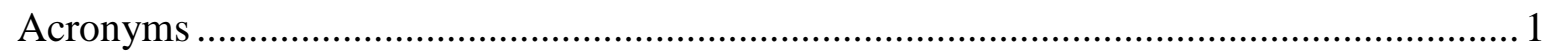

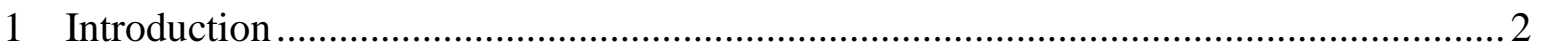

2 Fundamental Effect of Change in Enrichment .......................................................... 6

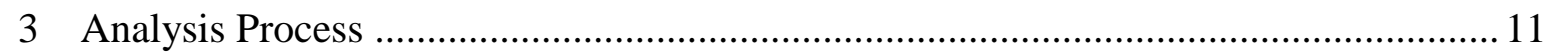

4 HALEU Core Design Description .................................................................. 25

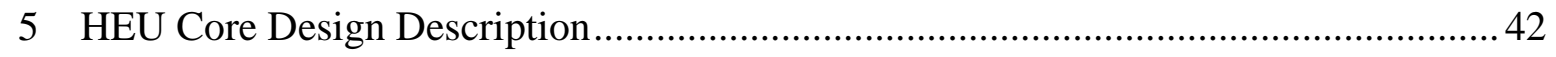

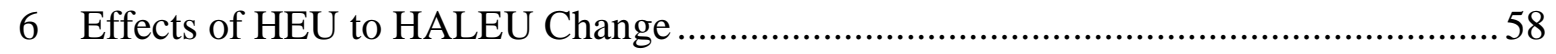

7 Anticipated Design Opportunities ........................................................................ 61

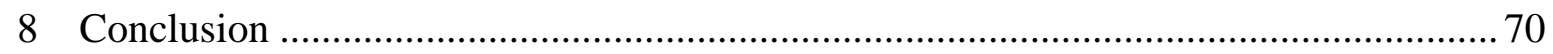

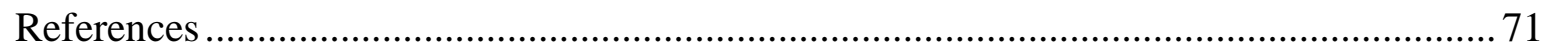

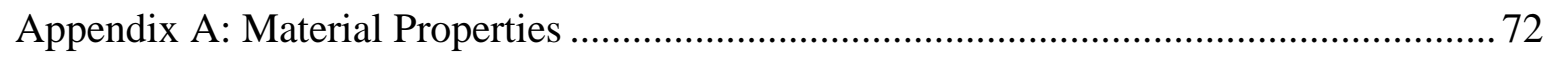

Appendix B: Neutronics Analysis Methodology ...................................................... 76

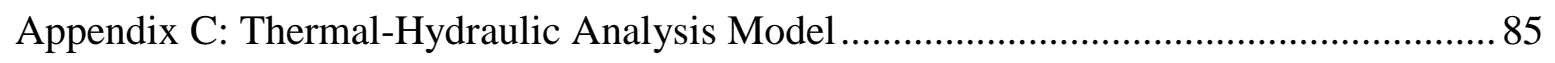




\section{List of Figures}

Figure 1. Coolant Flow Path .....................................................................................

Figure 2. Layout of NTP Assembly (left) and Core (right) …………………………........

Figure 3. ${ }^{235} \mathrm{U}$ (n,fission) and ${ }^{238} \mathrm{U}(\mathrm{n}, \gamma)$ Cross Sections ..................................................6

Figure 4. U Metal (left) and Aqueous Uranium Slurries (right) Subcritical Mass Limit Multiplicative Factor with Enrichment (courtesy TID-7016 [3]) ........................................ 8

Figure 5. HEU (left) and HALEU (right) Effect of H:U ratio on k-inf ..............................14

Figure 6. Reflector Worth (left) and Mass (right) with Thickness .....................................15

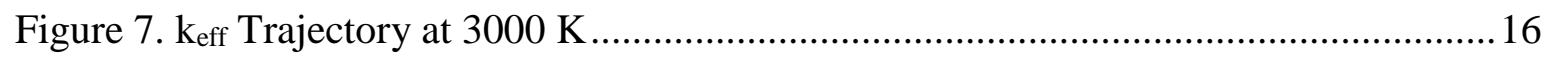

Figure 8. Total Fuel Volume vs. Fuel Radius and Fuel Height ...........................................19

Figure 9. Number of Rings vs. Fuel Radius and Fuel Height ............................................19

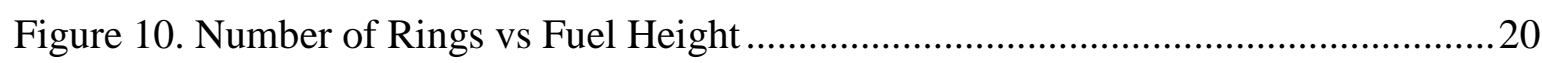

Figure 11. Number of Rings vs Number of Coolant Channels ..........................................21

Figure 12. $\mathrm{k}_{\text {inf }}$ with Moderator Thickness for HALEU ......................................................2

Figure 13. Fuel particle volume fraction selection for HALEU ……………………..........26

Figure 14. Reflector thickness evaluation for HALEU ......................................................2

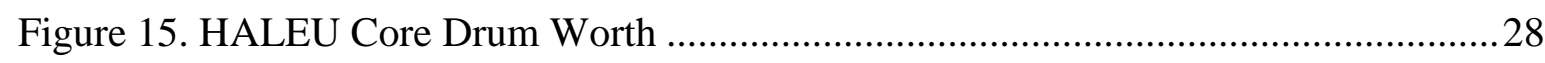

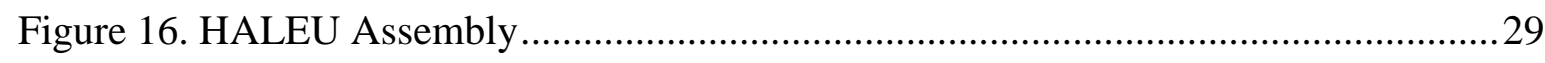

Figure 17. HALEU Full-Core Radial View .......................................................................30

Figure 18. HALEU Full-Core Elevation View ……………………………...................... 31

Figure 19. Normalized HALEU Intra-Assembly Power Distribution .....................................34

Figure 20. Axial Power Profile Used in Thermal Analysis for HALEU Core .....................35

Figure 21. Peak Hole Temperature Axial Profile for HALEU Core......................................35

Figure 22. Peak Hole Pressure Axial Profile for HALEU Core ……………………….......36

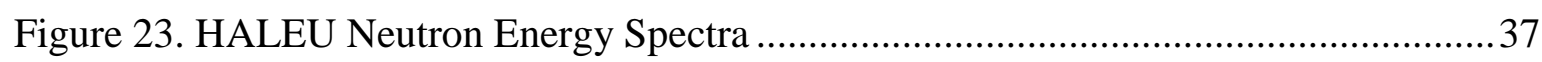


Figure 24. HALEU Assembly Power Distribution

Figure 25. Uncontrolled Core Reactivity during HALEU reactor operation and shutdown39

Figure 26. kinf with Moderator Thickness for HEU ...................................................42

Figure 27. HEU Core Drum Worth.....................................................................44

Figure 28. HEU Assembly ....................................................................... 45

Figure 29. HEU Full-Core Radial View ..............................................................46

Figure 30. HEU Full-Core Elevation View.........................................................47

Figure 31. Normalized HEU Intra-Assembly Power Distribution..................................50

Figure 32. Axial Power Profile Used in Thermal Analysis for HEU Core .......................51

Figure 33. Peak Hole Temperature Axial Profile for HEU Core ...................................51

Figure 34. Peak Hole Pressure Axial Profile for HEU Core ..........................................52

Figure 35. HEU Neutron Energy Spectra …............................................................53

Figure 36. HEU Assembly Power Distribution ........................................................54

Figure 37. Uncontrolled Core Reactivity during HEU reactor operation and shutdown.....55

Figure 38. Example Intra-Assembly Power Peaking (Left) and Thermal-to-Total Flux Ratio

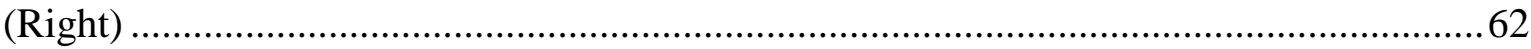

Figure 39. Example Radial Power Distribution .........................................................63 


\section{List of Tables}

Table 1. Core Characteristics to Determine, Part 1.........................................................12

Table 2. Core Characteristics to Determine, Part 2 2.........................................................12

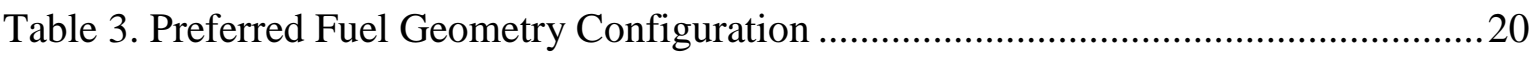

Table 4. Candidate HALEU Fuel Designs .........................................................................2

Table 5. HALEU Final Core Characteristics, Part 1 ............................................................32

Table 6. HALEU Final Core Characteristics, Part 2 …………………………………........32

Table 7. HALEU Core Component Masses …………………………………………..........33

Table 8. Doppler Reactivity Feedback in HALEU Core ......................................................40

Table 9. Pressure Reactivity Feedback in HALEU Core .......................................................40

Table 10. Summary of HALEU Performance Parameters ....................................................41

Table 11. HEU Final Core Characteristics, Part 1 …………………………………….....48

Table 12. HEU Final Core Characteristics, Part 2 …………………………………........48

Table 13. HEU Core Component Masses ..........................................................................49

Table 14. Doppler Reactivity Feedback in HEU Core........................................................56

Table 15. Pressure Reactivity Feedback in HEU Core ……………………......................56

Table 16. Summary of HEU Performance Parameters …………………..........................57

Table 17. HALEU vs HEU Mass Comparison …………….................................................58

Table 18. HALEU vs HEU Reactor Parameter Comparison ................................................59

Table 19. Fast vs Thermal HEU Core Mass Comparison .....................................................66 


\section{Acronyms}

BOL - Beginning-of-life

CERCER - Ceramic-ceramic (describing the material state of the nuclear fuel and the matrix in which it is embedded, respectively: ceramic fuel, ceramic matrix)

CERMET - Ceramic-metallic (ceramic fuel, metal matrix)

CZP - Cold zero power

DOE - United States Department of Energy

DOD - United States Department of Defense

HALEU - High-assay, Low-enriched uranium

HEU - Highly-enriched uranium

HFP - Hot full power

HZP - Hot zero power

NTP - Nuclear thermal propulsion

TRISO - Tristructural-isotropic fuel particles 


\section{Introduction}

Interplanetary spaceflight may be significantly improved by rockets that utilize nuclear thermal propulsion (NTP) instead of the chemically propelled rockets in use today. An NTP rocket reactor relies on nuclear fission to heat the propellant, which cools the fuel before being discharged from the nozzle. In essence, this is an open-coolant nuclear reactor. The primary advantage of NTP systems over chemical rockets is that they can deliver significantly greater specific impulse, a result of the fact that they require only a single, light propellant (hydrogen gas). This leads to improved efficiency and reductions in mass.

From a reactor design standpoint, an additional design criterion for NTP reactors beyond those already required for nuclear reactors that produce electricity is its mass. NTP-equipped spacecraft must be as light as possible in order to maximize the propulsion system efficiency. For the reactor designer, this presents unique design opportunities and challenges.

One such opportunity currently under consideration is the fissile content of the nuclear fuel to be used in an NTP reactor. Whereas most Earth-bound power reactors are fueled with reactorgrade low-enriched uranium (LEU), which has ${ }^{235} \mathrm{U}$ content of less than $5 \mathrm{wt} \%$, an NTP reactor will not be refueled and therefore must carry all the fissile material needed to accomplish its mission. Additionally, if the fuel has higher enrichment of fissile material, less fuel mass is required to achieve a fixed loading of fissile material. It is possible that increasing the enrichment of the fuel can substantially reduce reactor mass, but actual differences will also depend on other design constraints.

This study aims to assess the impact of HEU and HALEU enrichments on NTP reactor design goals. To that end, this work develops two NTP reactor core designs with different fuel enrichment. One reactor core is fueled with high-enriched uranium (HEU), defined in this study as $93 \mathrm{wt} \%{ }^{235} \mathrm{U}$. The other is fueled with high-assay low-enriched uranium (HALEU), defined in this study as $19.5 \mathrm{wt} \%{ }^{235} \mathrm{U}\left(19.7 \mathrm{at} \%{ }^{235} \mathrm{U}\right)$.

\subsection{HALEU vs HEU considerations}

Here, the HEU and HALEU enrichment options for NTP fuel are defined and a brief overview of non-technical considerations is provided.

The threshold below which uranium is considered low-enriched is $20 \mathrm{wt} \%{ }^{235} \mathrm{U}$. HALEU is more enriched than typical reactor-grade LEU but still below this high-enrichment threshold. It has received significant attention recently for its potential to power tadvanced nuclear reactors, which leverage its increased fissile content.

Currently, there is no infrastructure in place to produce HALEU but there are two possible production routes. First, HALEU may be produced by further enrichment of uranium beyond that required for reactor grade uranium, but would also result in a significant increase in separative work units. The initial steps in preparing HALEU in this way are the same as for LEU. Despite the potential for increased demand of HALEU in the future by next-generation nuclear reactors, it is anticipated that current production of uranium ore and enrichment feedstocks is adequate for the development of HALEU fuels [1]. Second, HALEU may be generated by downblending HEU with depleted uranium. This method requires access to existing stockpiles 
of HEU for which there is no anticipated use but may avoid possible competition for newly enriched HALEU.

Uranium with enrichment of $20 \mathrm{wt} \%{ }^{235} \mathrm{U}$ or greater is considered highly enriched. Highlyenriched uranium is generally only produced for nuclear weapons, naval reactors, and a few research reactors not yet converted to LEU. Under the NNSA Material Management and Minimization program, all research and experimental reactors have been or will be converted from using HEU to using LEU. Access to HEU will likely involve significant political hurdles due to the associated nonproliferation concerns. Further, facilities which can handle HEU have a higher degree of safeguards than lower uranium enrichments, leading to increased costs. These hurdles and costs are not the subject of this report.

\subsection{Conceptual Reactor Description}

The HEU and HALEU options investigated in this work share a conceptual design based on the historic Nuclear Engine for Rocket Vehicle Application (NERVA) reactor developed by the ROVER program in the 1960s [2]. The NERVA NTP concept is a thermal-spectrum reactor fueled by $\mathrm{HEU}(\mathrm{U}, \mathrm{Zr}) \mathrm{C}$-graphite composite assemblies, interspersed with moderating $\mathrm{ZrH}_{\mathrm{x}}$ assemblies.

The current NTP baseline design is a 540 MWth thermal-spectrum reactor, capable of operating for 180 minutes with multiple restarts. The fuel is a coated particle in either a ceramic (CERCER) or metallic (CERMET) matrix. The scoping calculations reported herein were performed for the CERCER-fueled design, consisting of $800 \mu \mathrm{m}$ UN kernels coated by $\mathrm{ZrC}$ and dispersed in a ceramic ZrC matrix. The NTP fuel blocks are right circular cylinders, penetrated by coolant channels and surrounded by a $\mathrm{ZrH}_{1.85}$ moderator block. Radial and axial reflectors surround the core, and control drum cylinders containing neutron-absorbing material are embedded in the radial reflector.

The NTP coolant and propellant is liquid hydrogen $\left(\mathrm{H}_{2}\right)$ with a designed exit temperature of $2700 \mathrm{~K}$. The coolant flow path through the core is shown in Figure 1. This coolant passes through the core twice before exit through the nozzle. In the first pass, the coolant is at its lowest temperature, rising from $30 \mathrm{~K}$ to $300 \mathrm{~K}$ and is used to cool the components with lower permissible temperatures, including the moderator block, the $\mathrm{SiC} / \mathrm{SiC}$ moderator insulator, the reflector, and the control drum materials. This first-pass flows from the $\mathrm{H}_{2}$ tanks to the bottom of the reactor, then up through the reactor internals. After this first pass, the coolant is at a temperature of around $300 \mathrm{~K}$. It then provides energy to related systems and enters the top of the fuel cylinders. This coolant travels axially downward out of the bottom of the fuel to the rocket nozzle entrance. The neutronics analyses within this work modelled the first-pass pressure at 1 $\mathrm{MPa}$ and the second-pass pressure at $3 \mathrm{MPa}$; this lower first-pass pressure has negligible effect on results or conclusions as the majority of first-pass coolant was not modelled explicitly in this work and was instead treated as an uncertainty. 


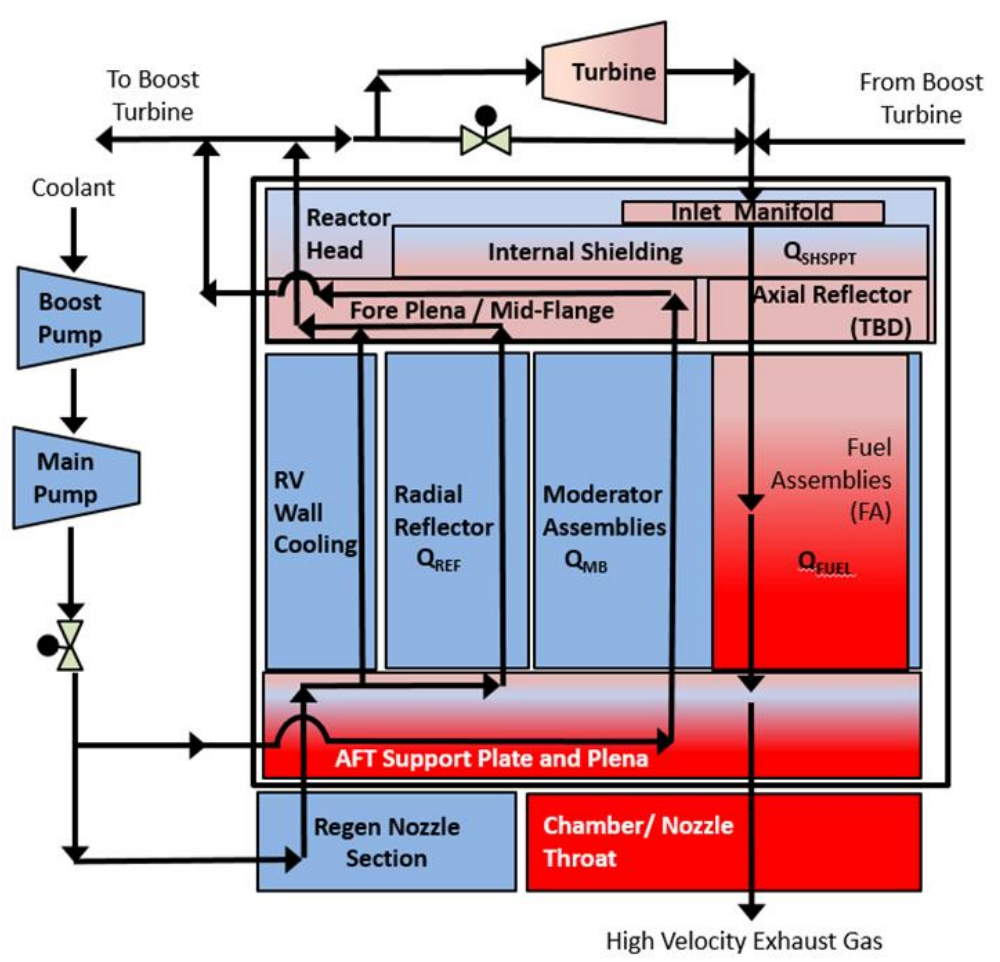

Figure 1. Coolant Flow Path

Figure 2 shows the assembly and full-core layout as modeled in the present study. While the fuel blocks will realistically be arranged in a circular lattice, a hexagonal lattice has been modeled here to reduce the number of degrees of freedom at the current design stage. In the assembly model, the CERCER fuel is shown in red and coolant channels in blue. Outside the outer coolant channel is an outer coolant gap (containing second-pass coolant), a low-density ZrC insulator, a second-pass coolant channel gap, $\mathrm{SiC} / \mathrm{SiC}$ moderator insulator, first-pass coolant, and finally the moderator in yellow. In the full-core model, the reflector is shown in green, and the neutronabsorbing material within control drums is shown in purple. Properties of these materials are given in Appendix A. 


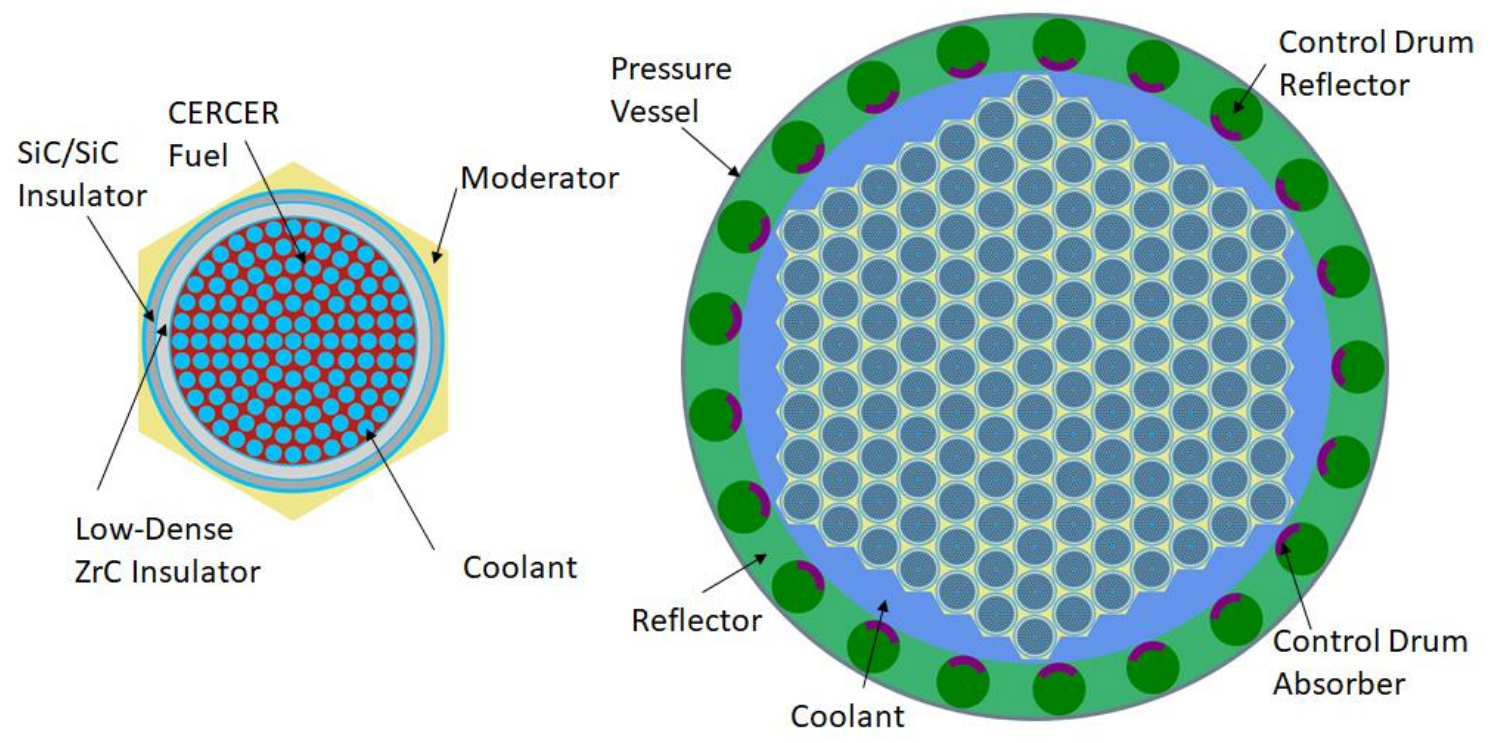

Figure 2. Layout of NTP Assembly (left) and Core (right)

\subsection{Report Scope and Organization}

These core layouts were produced as the result of a rapid, multi-stage design process. The initial phases consisted of scoping calculations to probe the design space and make choices about key variables. The later phases refined and iterated on the initial designs to produce two reactor designs that could be compared and contrasted to assess the impact of enrichment on the resulting NTP system.

This report describes the concepts, reactor design approach, the NTP systems produced by that design approach, and outcomes as they pertain to the difference in enrichment. Section 2 introduces a first-principles assessment of the effect of changing enrichment on reactor design goals. In Section 3, the multi-step analysis process by which the two reactor designs were produced in parallel is described. The final HALEU and HEU reactor designs themselves are presented in Sections 4 and 5, respectively. In Section 6, the reactors are compared and contrasted to demonstrate the impact of enrichment. Finally, Section 7 provides some brief insights into possible opportunities to enhance future NTP designs. 


\section{Fundamental Effect of Change in Enrichment}

In this work, the HEU fuel is uranium composed of 93 percent ${ }^{235} \mathrm{U}$ by weight and the HALEU is 19.5 percent ${ }^{235} \mathrm{U}$ by weight. Relative to HALEU, HEU includes significantly more fissile material $\left({ }^{235} \mathrm{U}\right)$ and smaller amounts of fertile material $\left({ }^{238} \mathrm{U}\right.$, and to a much lesser extent ${ }^{234} \mathrm{U}$ and ${ }^{236} U$, depending on the uranium source). Therefore, reducing the enrichment from HEU to HALEU, if preserving the total ${ }^{235} \mathrm{U}$ content, requires an increase in the total uranium mass by a factor of approximately 4.8. This results in the same ${ }^{235} \mathrm{U}$ content but increases the total content of ${ }^{238} \mathrm{U}$ by a factor of approximately 55 .

As shown in Figure 3, the ${ }^{238} \mathrm{U}(\mathrm{n}, \gamma)$ cross section indicates strong neutron absorption at neutron energies below approximately $1 \mathrm{keV}$. Increasing the ${ }^{238} \mathrm{U}$ loading in a reactor by a factor of 55 will reduce the reactivity of a thermal neutron reactor, barring any other changes. Further, capture in ${ }^{238} \mathrm{U}$ will increase the build-up of transuranics compared to an HEU-loaded core.

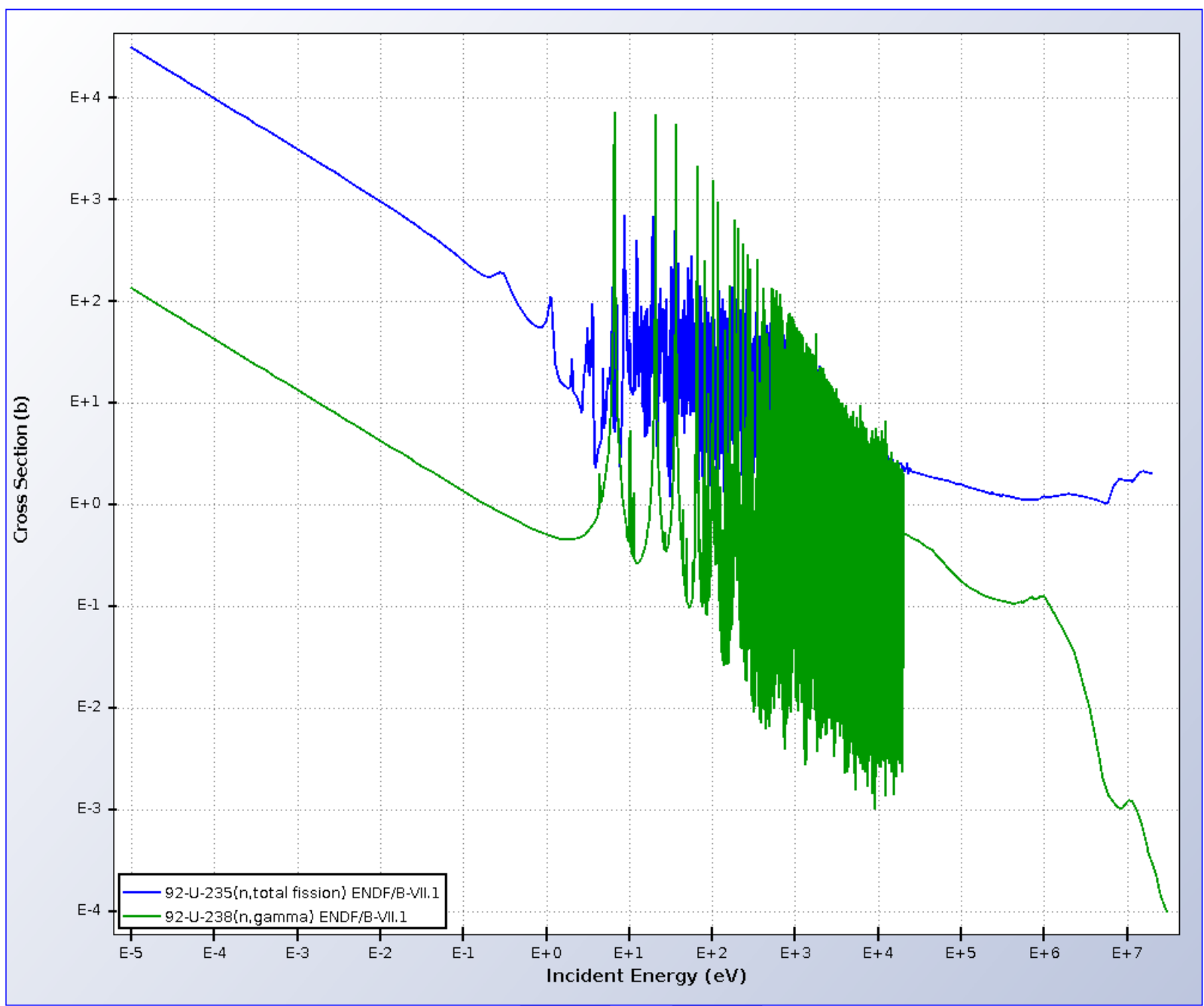

Figure 3. ${ }^{235} \mathbf{U}\left(\mathbf{n}\right.$,fission) and ${ }^{238} \mathrm{U}(\mathrm{n}, \gamma)$ Cross Sections

From the above, it is clear that a reduction in enrichment will lead to the following first-order changes: (1) the reactor core will require a larger total uranium mass; (2) the reactor performance 
characteristics will change due to the increased ${ }^{238} \mathrm{U}$ content; and (3) reactor operation will result in a greater inventory of transuranics.

The principles behind the effects of these three first-order changes are discussed further in the sub-sections that follow.

\subsection{Effect of Reduced Enrichment on Reactor Mass}

Reducing enrichment from HEU to HALEU fuel while preserving the ${ }^{235} \mathrm{U}$ loading will increase the uranium loading by a factor of 4.7. However, this total uranium change alone is not enough to describe the practical change in the total reactor mass. Specifically: (1) more ${ }^{235} U$ mass in the HALEU case may be necessary to counteract the negative reactivity effect of the increased ${ }^{238} \mathrm{U}$ loading, and (2) more non-fuel mass will be necessary if the change in enrichment results in additional core components or an increase in core dimensions.

The effect on the mass due to the parasitic capture of ${ }^{238} \mathrm{U}$ is exemplified best in nuclear safety criticality evaluations that desire a simplified mass control limit for various fuel forms and enrichments. A suitable example is the Nuclear Safety Guide written by Oak Ridge National Laboratory for the Nuclear Regulatory Commission [3]. This guide provides isotopic mass limits to ensure subcriticality for fast and thermal systems, including those that primarily fission via ${ }^{235} \mathrm{U}$. These limits are not exactly applicable to reactor design concepts; however they do clearly identify the sensitivity of reactivity to enrichment and neutron energy spectrum.

First, Figure 3.3 of ref. [3] is provided in this document as the left image of Figure 4. This figure provides a multiplicative factor to apply to the ${ }^{235} \mathrm{U}$ mass limit for uranium metal (i.e., a fast neutron spectrum system). This analysis shows that switching from HEU to HALEU fuel leads to an increase in the mass limit by a factor of approximately 15 . This increase in the total uranium mass required for a certain reactivity level is driven by the significant increase in the ${ }^{238} \mathrm{U}$-to${ }^{235} \mathrm{U}$ ratio and the commensurate increase in the parasitic capture of neutrons in ${ }^{238} \mathrm{U}$.

This same information for thermal systems is provided in Figure 3.4 of ref. [3]; this is provided in this document as the right image of Figure 4. The "mass" line of this figure shows that switching from HEU to HALEU fuel will require an increase in the total uranium loading for a given reactivity level by a factor of approximately six. This again is driven by the significant increase in the ${ }^{238} \mathrm{U}-\mathrm{to}_{-}{ }^{235} \mathrm{U}$ ratio but is smaller than the effect in the fast spectrum system because the ${ }^{235} \mathrm{U}$ fission cross section is significantly larger than the ${ }^{238} \mathrm{U}(\mathrm{n}, \gamma)$ cross section (Figure 3) at thermal energies compared to fast energies.

These ref. [3] findings for fast and thermal systems show that a significant increase in the uranium mass will be necessary to maintain reactivity. The specific differences for a given application and non-homogenous geometry will not necessarily follow these results exactly, but this gives a simplistic view of the mass change expected in total uranium loading needed to maintain reactivity while reducing enrichment. 

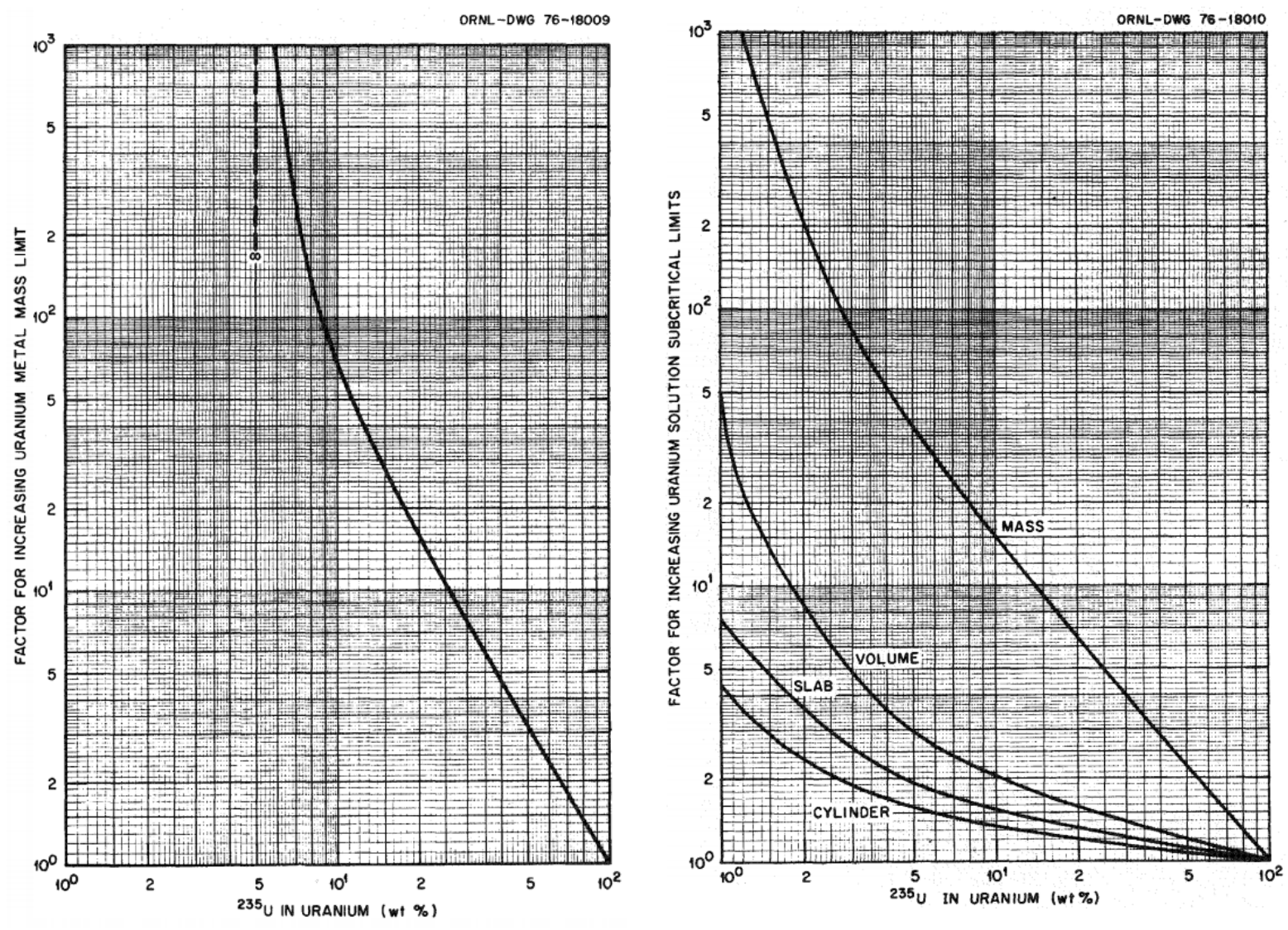

Figure 4. U Metal (left) and Aqueous Uranium Slurries (right) Subcritical Mass Limit Multiplicative Factor with Enrichment (courtesy TID-7016 [3])

The above descriptions become more complicated when factoring in realistic reactor applications, in which components other than fuel contribute to total mass. In this case, the change in total reactor mass must also consider how the masses of other components are affected by the change in enrichment. To explain this, consider two categories of reactor applications: an energy-dense reactor design and a power-dense reactor design.

An energy-dense reactor is one that requires power generated over a long reactor core lifetime. In this case, a major driver in the reactor design process is to load as much fuel (and poison) as needed to meet the long lifetime goals. This results in a reactor designed with uranium loading as high as achievable in the selected fuel-bearing material, given applicable burnup limits. Since reducing the enrichment in such a system would require increasing the uranium loading further, then it is likely that the uranium loading density would exceed the uranium loading limit of the fuel material. Therefore the core volume must be increased, increasing the core mass significantly.

Conversely, a power-dense reactor is one that requires the reactor to generate high powers for significantly shorter times than the energy-dense reactor. Design constraints drive these core types to larger heat generation volumes and heat transfer areas to avoid reaching excessively high material temperatures. Since the core size (volume) will be driven by heat removal, reaching criticality does not necessarily requires the highest allowable uranium loading in the selected 
fuel-bearing material. Therefore, reducing the enrichment can be accommodated by increasing the uranium loading of the fuel-bearing material. In this case, if the increased uranium loading required is still lower than the maximum uranium loading of the fuel-bearing material, then no change is needed to the reactor core geometry and dimensions. Therefore, a power-dense reactor design may have a significantly smaller increase in the total core mass than an energy-dense reactor design when going from HEU to HALEU fuel.

The above paragraphs highlight how the targeted reactor application can determine the degree to which a reduction in enrichment requires an increase in total reactor core mass. As there are many factors involved, an analysis of the actual change in the core mass therefore must be informed by the specific design and the limitations of the fuel system.

In this work, the NTP reactor design is expected to be a power-dense application and therefore the mass change may be minimal. The exact amount, however, depends on how much underloaded the fuel-bearing material is in the HEU case and if it can completely accommodate the increased uranium loading needed for HALEU or even lower enrichments.

\subsection{Effect of Reduced Enrichment on Reactor Performance}

The increase in ${ }^{238} \mathrm{U}$ content that occurs with the reduction in enrichment will alter reactor performance. The primary effect is that more neutrons will be absorbed in ${ }^{238} \mathrm{U}$ instead of ${ }^{235} \mathrm{U}$. Although this effect can be countered by design so that reactivity can be maintained, the response, or feedback, of the reactor to changes in core conditions will be affected. Most of these feedback mechanisms are primarily affected by leakage and so will only be slightly impacted by the change of enrichment.

A parameter that is strongly impacted by the change in enrichment is the Doppler reactivity feedback. This feedback represents how the reactivity of the reactor changes with the material temperature and is important for reactor control and safety considerations. For example, during a reactor startup the core reactivity is increased, and the reactor power and temperatures respond by increasing at an exponential rate. In this case, if the Doppler reactivity feedback coefficient is negative, then the increase in temperature will reduce the rate of exponential rise in power or even stop the increase altogether. Conversely, if this Doppler feedback coefficient is positive, then the increase in temperatures will lead to a greater rise in the exponential rate of change of power. Generally, the negative feedback is preferred in reactor design.

This sign and magnitude of the Doppler feedback is driven by broadening of the neutron cross section resonances with increasing temperature. At a high-level, the Doppler feedback of fissile material (e.g., ${ }^{235} \mathrm{U}$ ) can be slightly positive or negative. For fertile material (e.g., $\left.{ }^{238} \mathrm{U}\right)$, this is always negative. Therefore, a thermal reactor with significant ${ }^{238} \mathrm{U}$ loading will have significant negative Doppler feedback, and so a HALEU-fueled reactor will have a more negative Doppler feedback than an HEU-fueled reactor.

As stated, the Doppler reactivity feedback is important for reactor control and safety considerations. Since an HALEU-fueled reactor will have a more negative Doppler coefficient, then this could be used to simplify the operations, instrumentations and control systems, and/or the overall safety posture compared to an HEU-fueled design 


\subsection{Effect of Reduced Enrichment on Transuranic Buildup}

As can be seen by inspection of the chart of the nuclides ([4]), an amount of ${ }^{238} \mathrm{U}$ present at the beginning-of-life (BOL) will create significantly more transuranics for a given fluence level than an equal amount of ${ }^{235} \mathrm{U}$. This can be attributed to the significantly greater capture-to-fission ratio at thermal energies of ${ }^{238} \mathrm{U}$ relative to ${ }^{235} \mathrm{U}$. The increased inventory of transuranic isotopes in irradiated HALEU fuel causes significantly higher $(\alpha, n)$ and spontaneous fission decay rates, resulting in greater neutron production in irradiated HALEU relative to irradiated HEU. This primarily affects the shielding considerations core disposal, but may also affect operations depending on the strength of the installed neutron source used for startup.

Since the NTP cores studied in this report undergo relatively little depletion, these transuranic inventory differences are expected to be minimal. Additionally, shutdown reactor maintenance and disposal is outside the scope of this analysis. Therefore, this effect will not be discussed further in this report. 


\section{Analysis Process}

As stated in Section 2, reducing the enrichment in power-dense reactors that are limited by thermal margin may result in a smaller change in mass than in energy-dense reactors. The extent of this change in mass primarily depends on the extent that additional uranium can be loaded in the fuel-bearing material. Therefore, a simplified core design process is necessary to determine the effect of enrichment on total core mass. This section details the process used to identify HEU and HALEU reactor designs that will form the basis of the comparison presented in Section 6.

\subsection{Core Design Parameters}

The parameters to determine for each of the HEU and HALEU CERCER-fueled and $\mathrm{ZrH}_{1.85-}$ moderated reactors are shown in Table 1 and Table 2. In these tables, the parameters are split among the fuel assembly (the cylindrical fuel piece), moderator block and its thermal insulators, reflectors, control drums, and overall core parameters. In total, there are 27 parameters that must be determined to establish the design. A 27-dimensional design process is not feasible within the scope of this work. Where possible, parameters are set as given. The remaining parameters must be determined as a result of this work.

Based on engineering judgment, the authors identified and determined constant parameters that would have minimal effect on the final conclusions. Although these values are assumed for now, they should be subject to further scrutiny in any post-conceptual design phases. These fixed parameters are denoted as "Fixed" in the "Approach" columns in Table 1 and Table 2. This reduction in scope leaves 14 of the original 27 parameters to be determined through an iterative design approach.

The fixed parameters that require discussion are those that characterize the axial reflectors and the fuel temperature limit. In Table 2, the axial reflectors include $30 \%$ of their volume as $\mathrm{H}_{2}$ gas to take into account that the coolant needs to enter and exit the core. The $30 \%$ coolant volume is assumed to be near the realistic value; however, this will need to be refined at later stages. Next, the top reflector material is chosen as beryllium metal and the bottom reflector as Inconel 718. The top reflector is 5-cm thick and the bottom reflector is $1-\mathrm{cm}$ thick. These values were chosen because less reflection will be needed at the bottom of the core than the top, to reduce the power produced in the fuel near the outlet and to reduce the shielding requirement above the top of the core. The coolant outlet temperature is $2700 \mathrm{~K}$, only $100 \mathrm{~K}$ less than the fuel temperature limit discussed in Appendix A, so the heat produced there must be minimized. Thus, the purpose of the bottom axial reflector is only to attach the reactor to the nozzle, and the material is not chosen for its reflector worth.

Finally, the total mass flow rate required was estimated a priori using the given core power, the hydrogen properties (from Appendix A), and a constant pressure of $3 \mathrm{MPa}$, the assumed secondpass inlet pressure. 
Table 1. Core Characteristics to Determine, Part 1

\begin{tabular}{|l|c|c|}
\hline \multicolumn{1}{|c|}{ Parameter } & Approach & Final Value \\
\hline Fuel Radius & Fuel Assembly & \\
\hline Coolant Channel Thickness & Free variable & $0.01 \mathrm{~cm}$ \\
\hline Fuel "cladding" thickness & Fixed & $0.01 \mathrm{~cm}$ \\
\hline Fuel "cladding" material & Fixed & ZrC \\
\hline Fuel Cylinder Coolant vol frac & Fixed & \\
\hline Number of holes & Free variable & \\
\hline CERCER particle vol frac & Derived to obtain $\mathrm{k}_{\text {eff }}$ & \\
\hline & Moderator & \\
\hline Moderator web thickness & Free variable & \\
\hline Insulator Materials & Fixed & low dense ZrC and SiC \\
\hline Insulator Dimensions & Fixed & $0.2 \mathrm{~cm}$ each \\
\hline $\begin{array}{l}\text { Insulator Coolant Gap } \\
\text { Thicknesses }\end{array}$ & Fixed & $0.02 \mathrm{~cm}$ each \\
\hline
\end{tabular}

Table 2. Core Characteristics to Determine, Part 2

\begin{tabular}{|c|c|c|}
\hline Parameter & Approach & Final Value \\
\hline \multicolumn{3}{|c|}{ Reflector } \\
\hline Axial reflector materials & Fixed & Be top, Inconel 718 bottom \\
\hline Axial reflector thicknesses & Fixed & $5 \mathrm{~cm}$ top, $1 \mathrm{~cm}$ bottom \\
\hline Axial reflector coolant fraction & Fixed & $30 \%$ \\
\hline Radial reflector material & Free variable & \\
\hline Radial reflector thickness & Derived to obtain $\mathrm{k}_{\mathrm{eff}}$ & \\
\hline Radial reflector coolant fraction & Fixed & $15 \%$ \\
\hline \multicolumn{3}{|c|}{ Control } \\
\hline Control material & Free variable & \\
\hline Control material thickness & Free variable & \\
\hline Control material span & Free variable & \\
\hline Number of drums & Free variable & \\
\hline \multicolumn{3}{|c|}{ Overall } \\
\hline Number of Rings & Free variable & \\
\hline Core flow rate & Derived for outlet temperature & $13.6 \mathrm{~kg} / \mathrm{s}$ \\
\hline Fuel Height & Free variable & \\
\hline Power & Fixed & $540 \mathrm{MW}$ \\
\hline Coolant Inlet Pressure ( $1^{\text {st }}$ Pass) & Fixed & $1 \mathrm{MPa}$ \\
\hline Coolant Inlet Pressure ( $2^{\text {nd }}$ Pass) & Fixed & $3 \mathrm{MPa}$ \\
\hline Coolant Inlet Temperature & Fixed & $300 \mathrm{~K}$ \\
\hline Target Outlet Temperature & Fixed & $2700 \mathrm{~K}$ \\
\hline Maximum Fuel Temperature & Fixed & $2800 \mathrm{~K}$ \\
\hline
\end{tabular}




\subsection{Core Design Process}

At the highest level, the design process applied in this work consists of five phases, which are described in the sub-sections that follow. In short, these phases were divided into initial scoping to down-select design variables and acquire information for later use (Phase 1); application of initial scoping insights to make final decisions on certain parameters (Phases 3-4); and evaluation of the final core performance (Phase 5).

In these phases the neutronics analyses is performed using the OpenMC software [5] with ENDF/B-VII.1 nuclear data [6]. This software, the associated nuclear data, and the usage for this work is discussed in Appendix B: Neutronics Analysis Methodology. The thermal-hydraulics analysis was performed semi-analytically using solvers developed specifically for the purposes of this work. This model is detailed in Appendix C: Thermal-Hydraulic Analysis Model.

The remainder of this section will present the process used to perform the design and analysis of the HEU and HALEU designs. While many computations were performed, especially in the early phases, only those important for the final design are highlighted herein.

\subsubsection{Phase 1: Initial Scoping}

In the first phase, initial neutronics analyses were performed to generate a core design for each enrichment type, which could be used to perform sensitivity studies. Many of the computations in this phase did not yield any final values but they were useful to identify key core characteristics. This phase included lattice optimization studies to narrow down the range of optimum neutronics parameters, estimate the core size and loading necessary from a reactivity perspective, evaluate reflector types and control materials, and identify reasonable ranges of excess reactivity and temperature defects to set both design reactivity and required control swing.

First, the lattice optimization studies were used to identify the range of optimum ${ }^{1} \mathrm{H}$ to ${ }^{235} \mathrm{U}$ isotopic inventory ratios (referred to hereafter as "H:U ratio"). This hydrogen inventory included the hydrogen in the $\mathrm{ZrH}_{1.85}$ moderator and the $\mathrm{H}_{2}$ coolant. In moderated reactors, this ratio is used to find the ratio that hydrogen transitions from the role of moderator (under-moderated) to neutron poison (over-moderated). In systems with a fluid moderator, the goal is to ensure the reactor is under-moderated to yield a negative moderator temperature reactivity feedback coefficient. In the case of the NTP designs that are the subject of this report, the hydrogen moderator is a solid (as $\mathrm{ZrH}_{1.85}$ ) and thus the majority of the hydrogen inventory is relatively constant in temperature. Variations in the temperature and density of the hydrogen gas coolant introduce a small moderator temperature reactivity feedback effect, but it will be substantially lower than in a typical liquid-moderated reactor. The major motivator for selecting an undermoderated design is to reduce neutron absorption by hydrogen, which will in turn increase the magnitude of the Doppler reactivity coefficient, the expected primary means of control.

To evaluate the effect of the $\mathrm{H}: \mathrm{U}$ ratio, parametric studies in OpenMC were performed to investigate the effect of fuel cylinder radius, moderator thickness, and coolant volume fraction on the $k_{\text {infinite }}$ of an 2D infinite assembly. The volume fraction of UN particles in the CERCER fuel was set to a large bounding fraction of $40 \%$ in all these Phase 1 analyses for both enrichment levels. The $40 \%$ fraction, as discussed in Appendix A, is estimated to be an upper limit of the 
fuel particle volume fraction that can be feasibly manufactured. For simplicity, these analyses were performed without including the two insulator layers and their hydrogen coolant in the model.

This analysis produced a suite of results; an example result is shown in Figure 5 for a coolant volume fraction of $60 \%$. In this figure, the left is the HEU result and the right is the HALEU result. The $\mathrm{x}$-axis is the moderator thickness (moving right increases the $\mathrm{H}: \mathrm{U}$ ratio); the $\mathrm{y}$-axis is the fuel cylinder radius (moving up decreases the $\mathrm{H}: \mathrm{U}$ ratio). The plotted color represents the value of kinfinite. These results show that the optimum $\mathrm{H}: \mathrm{U}$ ratio for $\mathrm{HEU}$ fuel is generally at thin moderator thicknesses, whereas for HALEU fuel, the optimum H:U ratio follows a diagonal.
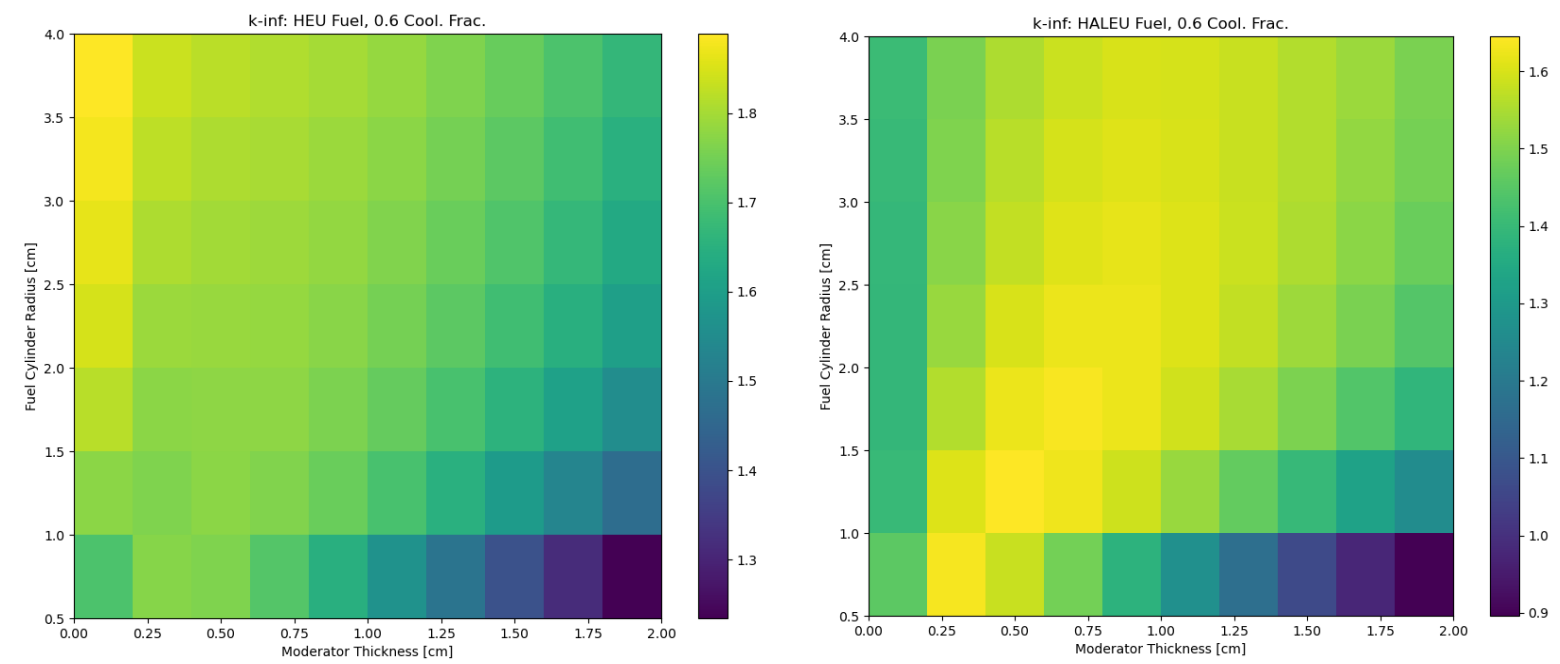

Figure 5. HEU (left) and HALEU (right) Effect of $H: U$ ratio on k-inf

Since both enrichment levels show that the $\mathrm{k}_{\text {inf }}$ values at low moderator thicknesses are supercritical, a fast reactor may be possible if the core is large enough to counteract its increased leakage. However, since the $\mathrm{k}_{\mathrm{inf}}$ for the HEU infinite assembly is significantly more supercritical than that for the HALEU infinite assembly, an HEU-fueled fast reactor will be significantly smaller than an HALEU-fueled fast reactor.

These results were then used to develop a limited set of full-core 3D models of near-optimum unit cells for each enrichment type. For each case, the critical radius was estimated using simple diffusion theory estimates. This critical radius was converted into a number of rings of fuel assemblies in the hexagonal lattice; since the diffusion theory estimates are inexact, both the predicted number of rings and one less were analyzed in subsequent steps. These full-core cases were modeled with a length-to-diameter ratio of 1.0. Each was computed in OpenMC to determine the unreflected $\mathrm{k}_{\text {eff. }}$. Cores with $\mathrm{k}_{\text {eff }}$ values between 0.8 and 1.0 were selected for further analysis with a radial reflector. This range of $\mathrm{k}_{\mathrm{eff}}$ was chosen because it is judged that active reactor control will be via control drums located in the radial reflector to minimize system complexity. Such a system can only control reactivity by modifying the reflection worth, and therefore the maximum control drum worth is set by the value of $\mathrm{k}_{\mathrm{eff}}$ for an unreflected core. 
The set of reactor designs with $\mathrm{k}_{\mathrm{eff}}$ in this range was then used to evaluate the reactivity and mass worth of a variety of radial reflector materials. Figure 6 shows these reflector reactivity and mass worths for the listed reflector types. These results are specific to a particular HALEU core but are representative of both HALEU and HEU cores. At this stage, analysis was performed assuming fully dense reflectors, as opposed to later calculations that assumed that the radial reflector contains $15 \%$ by volume of hydrogen gas for cooling.

Figure 6 shows that the beryllium metal reflector is the most effective, and based on densities, is also the least massive. Note that the $\mathrm{ZrH}_{1.85}$ reflector worth saturates at around $6 \mathrm{~cm}$. This is due to the relatively high thermal neutron absorption of the hydrogen that minimizes the number of neutrons that can return to the core after thermalization at the outer edges of the reflector. All work going forward will assume a beryllium metal radial reflector. An additional key result from this analysis is that the beryllium reflector can increase $\mathrm{k}_{\text {eff }}$ by around $18 \%$, depending on the leakage rate from the unreflected core. Note that the usage of a beryllium reflector will require encasing or cladding the reflector. This will have a downstream effect on reactivity that will have to be addressed in subsequent design phases.

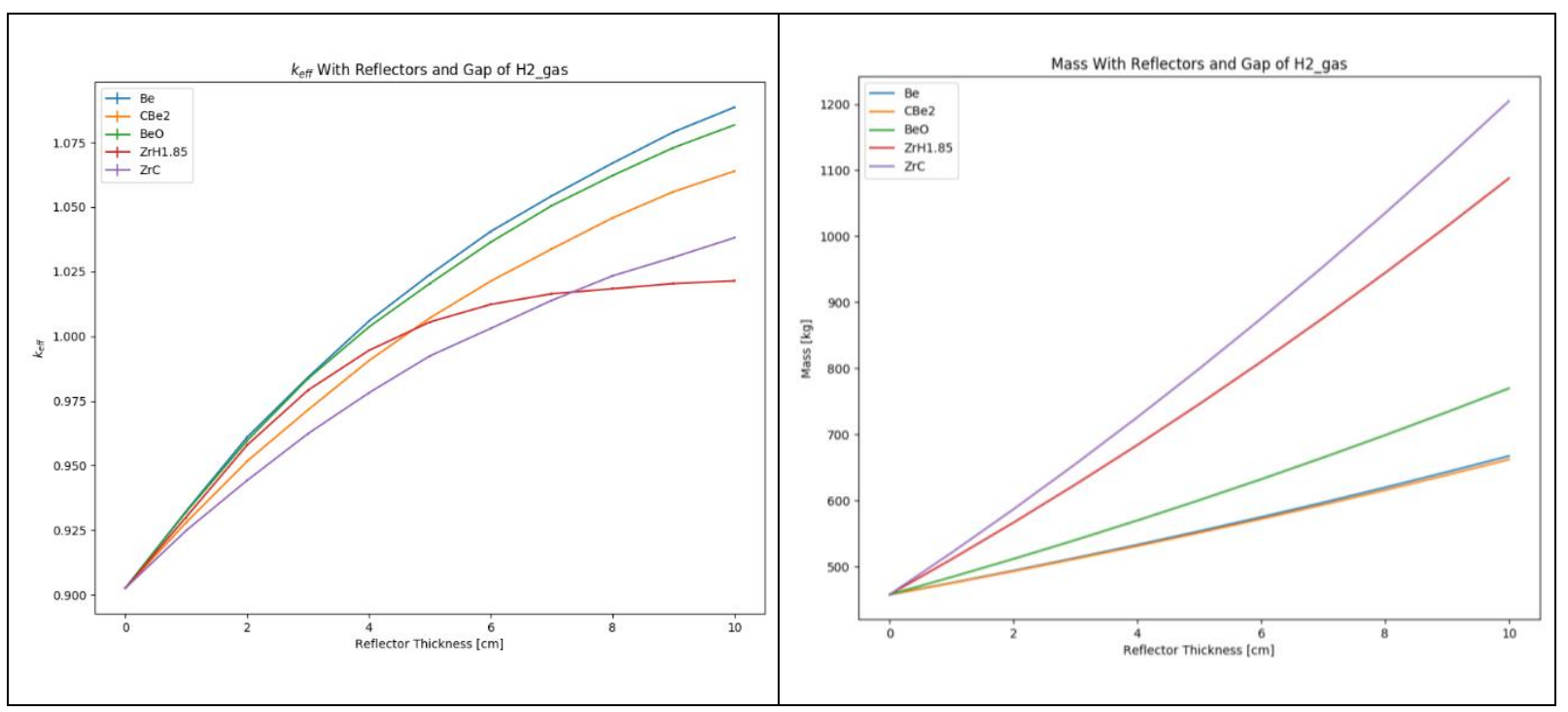

Figure 6. Reflector Worth (left) and Mass (right) with Thickness

The final study in this early phase is an evaluation of the desired BOL excess reactivity to meet the lifetime and temperature reactivity compensation needs of the reactor (i.e., the "temperature defect").

The excess reactivity requirements were evaluated for a set of reactor cores by performing depletion calculations to assess xenon buildup. The reactors were depleted continuously for the three hours of operation, and then for 11 hours after the shutdown so that peak ${ }^{135} \mathrm{Xe}$ conditions could develop in the reactor. These peak conditions are anywhere between 0 hours and around 11 hours after shutdown based on the pre-shutdown magnitudes of ${ }^{135} \mathrm{I}$ and ${ }^{135} \mathrm{Xe}$ and the halflives of these isotopes (6.57 hours for ${ }^{135} \mathrm{I}$ and 9.1 hours for $\left.{ }^{135} \mathrm{Xe}\right)$. A continuous period of operation is modeled instead of the more realistic power history because thermal reactors generally experience an increase in core reactivity after shutdown periods as short-lived fission products (including, but not only, ${ }^{135} \mathrm{Xe}$ ) decay. Continuous operation will therefore 
conservatively increase the rate of reactivity reduction. Similarly, the xenon peak is evaluated at the end of the 3-hour operational window because longer pre-shutdown operations increase the amount of xenon present at the peak (for operations less than 30 hours) and the peak xenon reactivity worth grows with fuel burnout.

This depletion history was applied to one of the cores of interest with the resultant $\mathrm{k}_{\text {eff }}$ trajectory shown in Figure 7. The change in $\mathrm{k}_{\text {eff }}$ during the first 3 hours of operation in Figure 7 is worth approximately $1.5 \% \Delta \mathrm{k} / \mathrm{kk}$ ' in reactivity. This was found to be roughly constant when evaluating cores of other enrichments and sizes. This behavior indicates linear reactivity burnout, which shows that 1) the power distribution is not migrating with fuel burnup and thus core size impacts will not play a significant role, and 2) 3 hours of $540 \mathrm{MWth}$ of power does not produce enough fission products to increase the rate of reactivity reduction. This $1.5 \%$ excess reactivity reduction is therefore expected to be representative and will be used when making design choices through the remainder of this work. This parameter is re-evaluated for the final designs in the Phase 5 analyses.

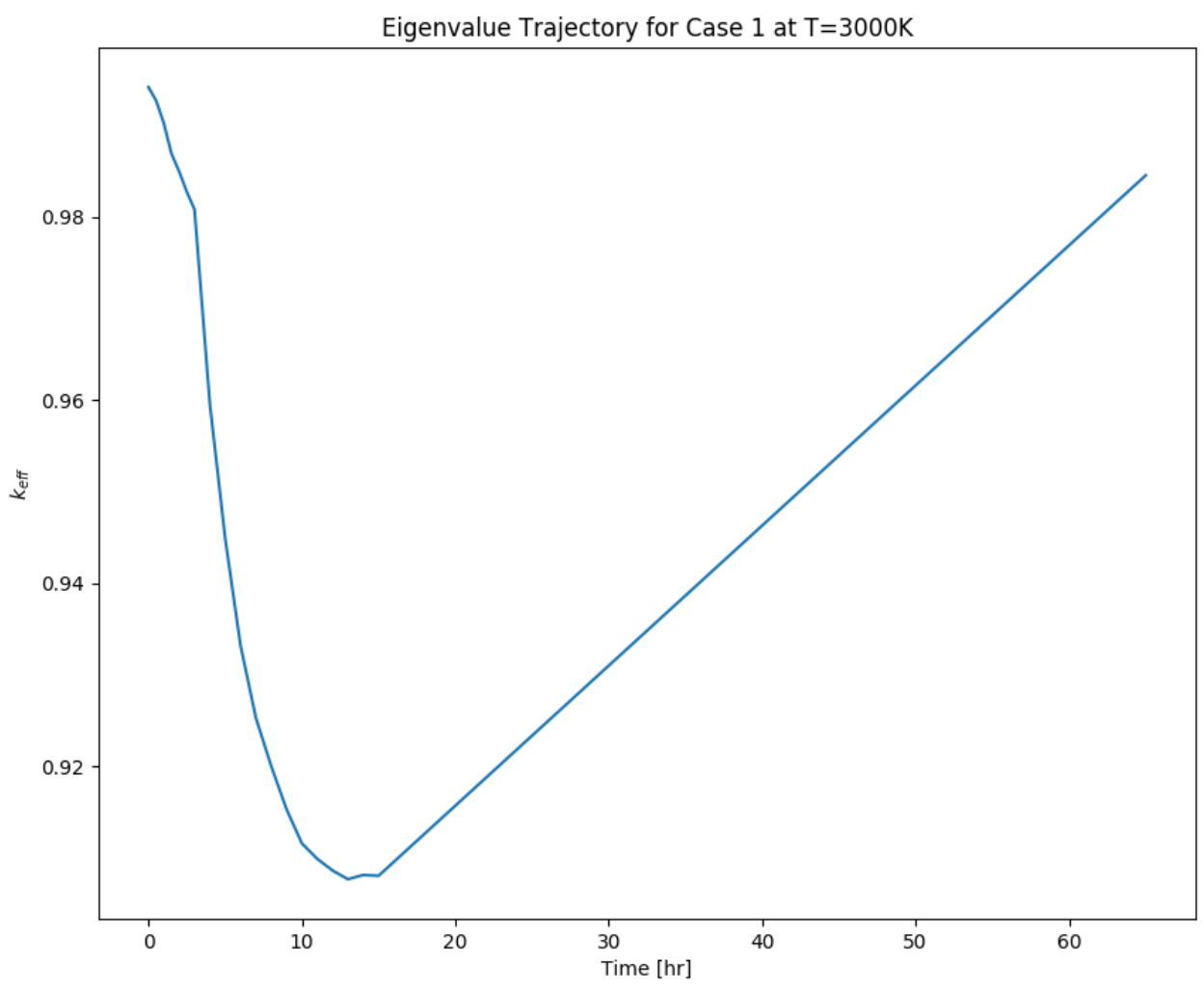

Figure 7. keff Trajectory at $3000 \mathrm{~K}$

The xenon peak is readily apparent after the shutdown at 3 hours. This occurs because the reactor is shut down and the ${ }^{135} \mathrm{I}$ that is present is decaying in to the ${ }^{135} \mathrm{Xe}$ without a neutron flux present to remove the ${ }^{135} \mathrm{Xe}$ inventory. As seen in Figure 7, this is worth as much as $8 \%$ in reactivity, which would require substantial excess reactivity to counteract. The operational requirements of this reactor were discussed with the customer, revealing that the current expected operational requirement is that the only planned restart within 11 hours after a long period of operation would come after a thirty-minute period of operation. Because the magnitude of the peak for these short 
operational times is roughly proportional to the time at power, this reduces the total xenon peak needed to be overcome by a factor of one-sixth (30 minutes / 180 minutes). Therefore, the $8 \%$ maximum peak xenon reactivity can be reduced to a peak of $1.3 \%$ excess reactivity for xenon override.

The temperature reactivity defect accounts for the variation in reactivity between cold (isothermal $250 \mathrm{~K}$ in this case) and hot (isothermal $3000 \mathrm{~K}$ ) temperatures. This temperature range was chosen to be reasonably bounding with a lower bound at the lowest available nuclear data temperature and an over-estimate of all temperatures as the upper bound. These temperature evaluations were performed at BOL, after 3 hours continuous operation, and during the xenon peak transient. The resultant range of $\mathrm{k}_{\mathrm{eff}}$ was then used to establish the temperature reactivity defect. This $\mathrm{k}_{\text {eff }}$ range varied with the $\mathrm{H}: \mathrm{U}$ ratio of the core design analyzed, but the bounding effect is an additional $1.5 \%$ swing in reactivity from cold to hot conditions.

In summary, the excess reactivity evaluation found that a total of $1.5 \%$ (burnup) plus $1.3 \%$ (30minute xenon override) excess reactivity was required in a core at hot full power conditions. This yields a total excess reactivity of $2.8 \%$. This was increased further to allow for later reductions in reactivity due to the addition of structural material and to accommodate power shaping, each assumed to be worth $1 \%$ reactivity. The net effect indicated a target BOL $\mathrm{k}_{\text {eff }}$ of 1.048 . The control drums were then required to offset this $4.8 \%$ of excess reactivity as well as an additional $1.5 \%$ due to the temperature defect.

\subsubsection{Phase 2: Thermal-Hydraulics and Core Size Selection}

The second phase focuses on the application of a thermal-hydraulics hot-channel model specific to the reactor design concept of interest. Such a model can be used to determine the heat generation volume and heat transfer surface area if it is dictated by thermal-hydraulics considerations alone. As such, the impact of fuel enrichment is not explicitly considered in the analysis performed for this phase. The neutronics core size information from the first phase and the thermal-hydraulics core size information produced in this phase was enough to support selection of core size parameters. Specifically, the output of this phase was the selection of the core height, the core total hydrogen gas flow rate, the number of rings of fuel assemblies, and the fuel cylinder radius.

The process used herein focuses on minimizing the total fuel cylinder volume in the core and not specifically the core mass. This volume is analyzed in terms of both the fuel height, the fuel cylinder radius, and the number of assembly rings. This approach is taken because some significant mass components like the reflector and moderator block are not yet determined, but will scale with the number of assembly rings and height.

Thermal-hydraulics analysis was performed over a sweep of reasonable fuel assembly radii, coolant volume fractions, number of coolant holes, fuel lengths, and fuel assembly power to determine the fuel temperature and available thermal margin. This evaluation was performed using the conservative analysis methodology detailed in Appendix C: Thermal-Hydraulic Analysis Model. For completeness, and to ensure viable designs of slightly different geometry were not neglected, the model was applied both to the reference block-type fuel form described 
in Section 1.2, and to an alternate pin-type fuel form with equivalent coolant volume fraction, number of pins/holes, fuel assembly radius, and fuel assembly height.

Previous work has demonstrated that for a given fuel volume fraction, lower peak fuel temperatures can be achieved in a block-type geometry compared to a pin-type geometry, because of more favorable surface area-to-volume ratios [7]. In this work, the thermal-hydraulics analysis methodology was used to compare peak fuel temperatures between the two geometries to determine whether one type of fuel form is clearly preferable. Results showed that while the pin-type geometry may be preferable for very small coolant volume fractions, in general the block-type geometry maintains smaller peak temperatures. The remaining analysis therefore focused on the results of the thermal-hydraulics sweep for the block-type cases.

Next, the block-type cases were down-selected to those that resulted in peak fuel temperature of $2800 \mathrm{~K}$ and a Mach number less than 1, since larger Mach numbers correspond to supersonic flow, which is outside the valid range of the model. This subset of cases included over 1000 combinations of the fuel geometry parameters; these were then further processed and organized to determine the most attractive combinations of fuel geometry parameters.

The list of cases was further reduced to those that would result in 12 or fewer rings of fuel assemblies in a hexagonal lattice core arrangement. This was determined by adjusting the nominal cell power by the assumed peaking factors. The product of intra-assembly radial peaking and core radial peaking factors was assumed to be 2.6, and the nominal (peak) cell power was divided by this factor to estimate the average cell power. The target core power, $540 \mathrm{MW}$, was then divided by the average cell power to determine the number of assemblies needed, and from that the number of rings was identified. All cases that required more than 12 rings to produce $540 \mathrm{MW}$ were eliminated from further consideration because they would lead to large core volume and therefore system mass.

For the remaining 175 cases, the number of required assemblies and the fuel geometry parameters were used to calculate the total volume of fuel in the core. Both the fuel volume and number of rings are related to the core mass, so both parameters should be minimized. Figure 8 shows the variation of total fuel volume with fuel height and fuel assembly radius, for coolant volume fractions of 0.2 to 0.6 . As the fuel radius increases, the surface area-to-volume ratio generally decreases, requiring a lower linear heat generation rate and larger total fuel volume. As height increases, the total fuel volume generally increases, though the correlation is weak at larger coolant volume fractions. It should be noted that the number of coolant holes and cell power also vary somewhat between some cases, and can affect the required fuel volume within a subset of a given radius and height.

From Figure 8, numerous configurations with coolant volume fraction of 0.6 and radii of $3.0 \mathrm{~cm}$ or less result in a total fuel volume around $2.5 \mathrm{E} 5 \mathrm{~cm}^{3}$ or less. However, Figure 9 shows that only one of these, with a $3.0 \mathrm{~cm}$ radius, results in the smallest number of assemblies, corresponding to 8 rings. The radius is small enough to accommodate a high linear heat rate, but not so small that an excessive number of assemblies is required. 


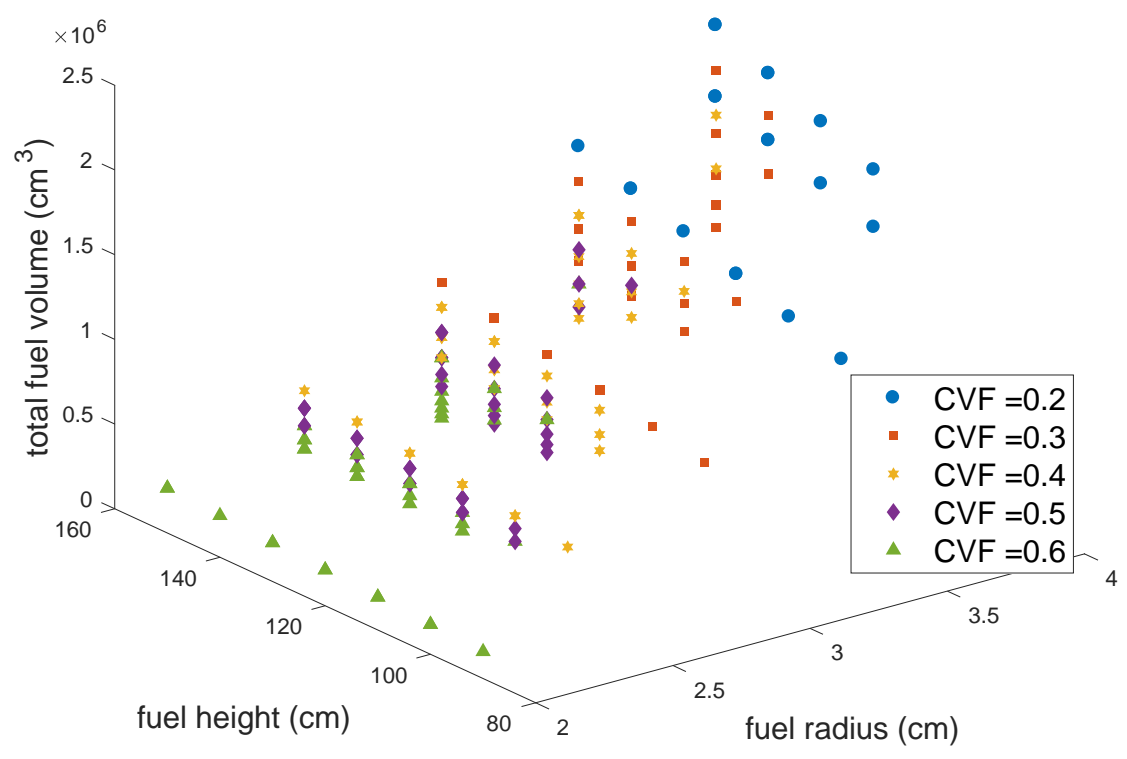

Figure 8. Total Fuel Volume vs. Fuel Radius and Fuel Height

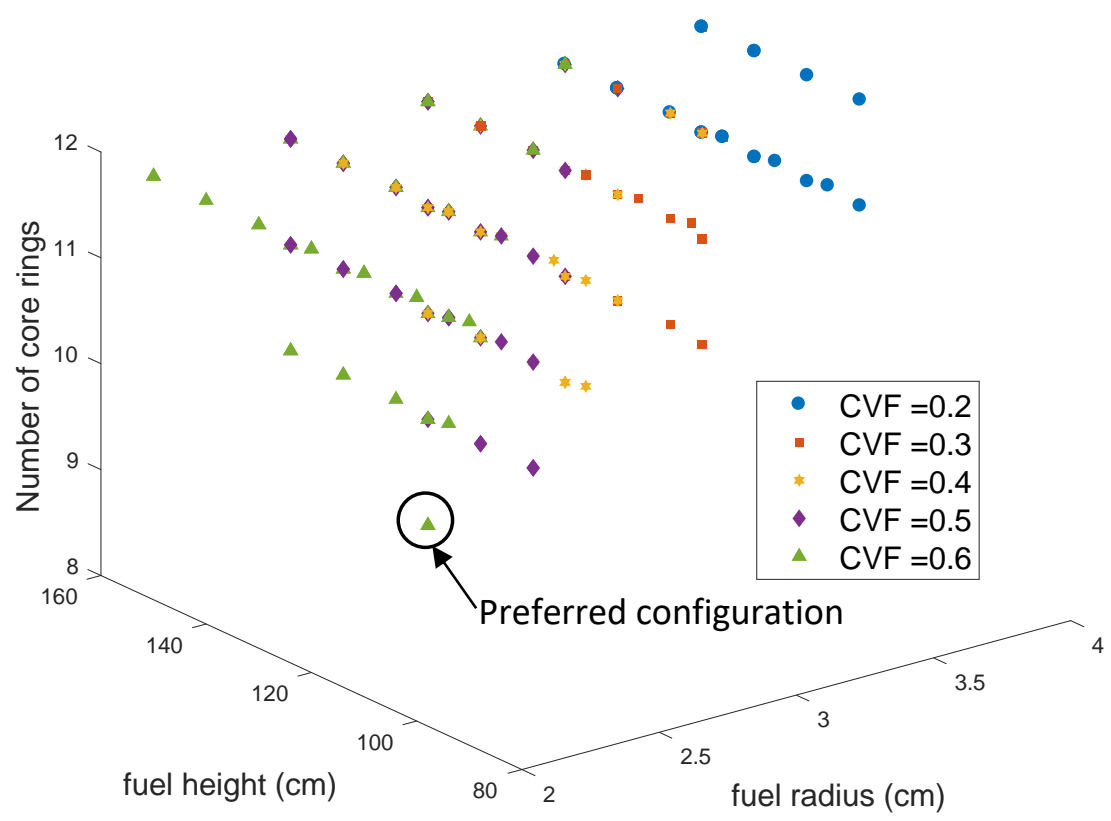

Figure 9. Number of Rings vs. Fuel Radius and Fuel Height 
For the assumed radial peaking factor, eight rings is the minimum number that can be achieved, with the fuel geometry parameters given in Table 3. This fuel geometry is selected as the preferred configuration for the neutronics analyses of the next phase.

\section{Table 3. Preferred Fuel Geometry Configuration}

\begin{tabular}{|l|r|}
\hline Fuel radius (cm) & 3.0 \\
\hline Coolant volume fraction & 0.6 \\
\hline Fuel height $\mathbf{( c m )}$ & 150 \\
\hline Number of assemblies & 140 \\
\hline Number of rings & 8 \\
\hline Number of coolant holes & 217 \\
\hline Total fuel volume $\left.\mathbf{( c m}^{\mathbf{3}}\right)$ & $2.4 \mathrm{E} 5$ \\
\hline
\end{tabular}

Although the fuel height of the selected geometry is larger than desired, for the most compact core configurations there is a trade-off between height and the number of assemblies required to generate $540 \mathrm{MW}$. Reducing the height also requires reducing the cell power to maintain a safe linear heat rate, so the number of assemblies and therefore the number of rings increases, as shown in Figure 10. The number of coolant holes per assembly, while potentially difficult to manufacture, also cannot be easily reduced from 217. This trend is shown in Figure 11, where 169 coolant holes per assembly corresponds to 10 rings of fuel assemblies, even for the same coolant volume fraction. Since fewer holes results in less heat transfer surface area, the cell power must be reduced and so the required number of assemblies increases. This parameter will be finalized in Phase 4 with the final peaking factors.

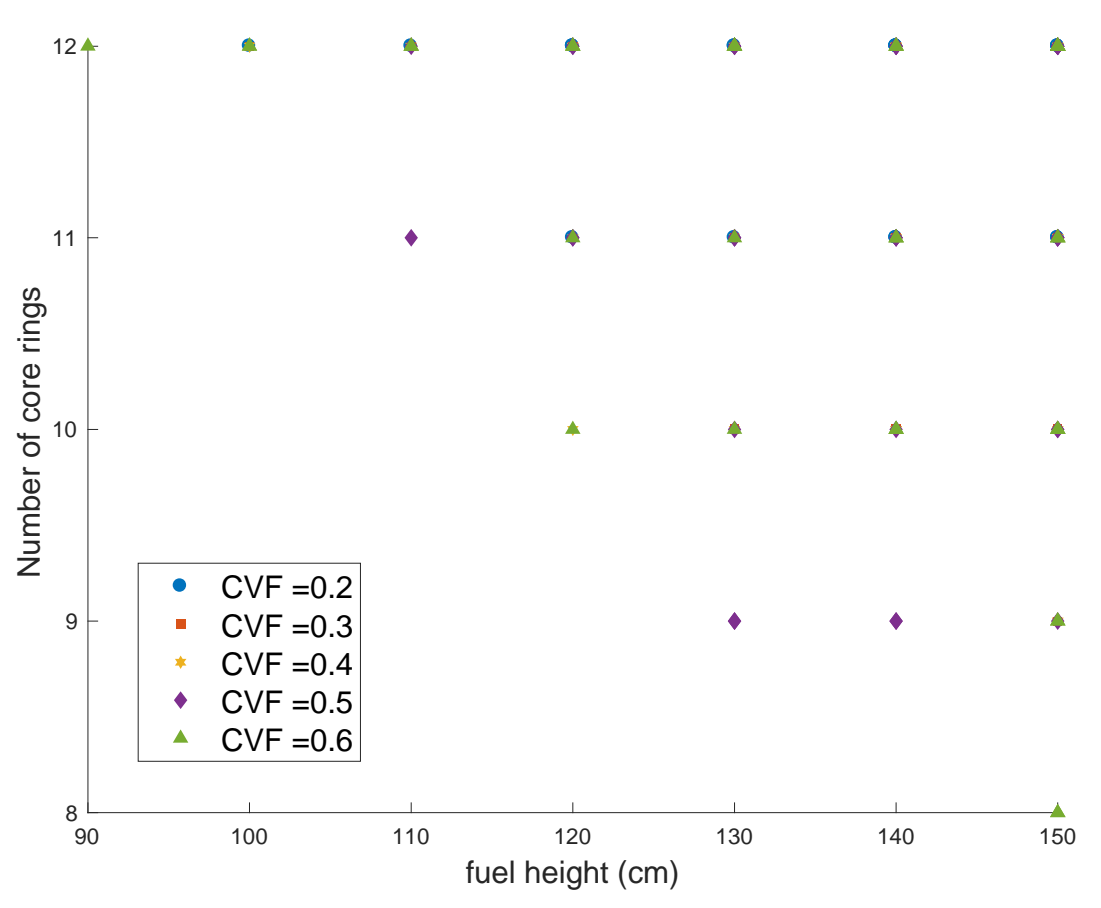

Figure 10. Number of Rings vs Fuel Height 


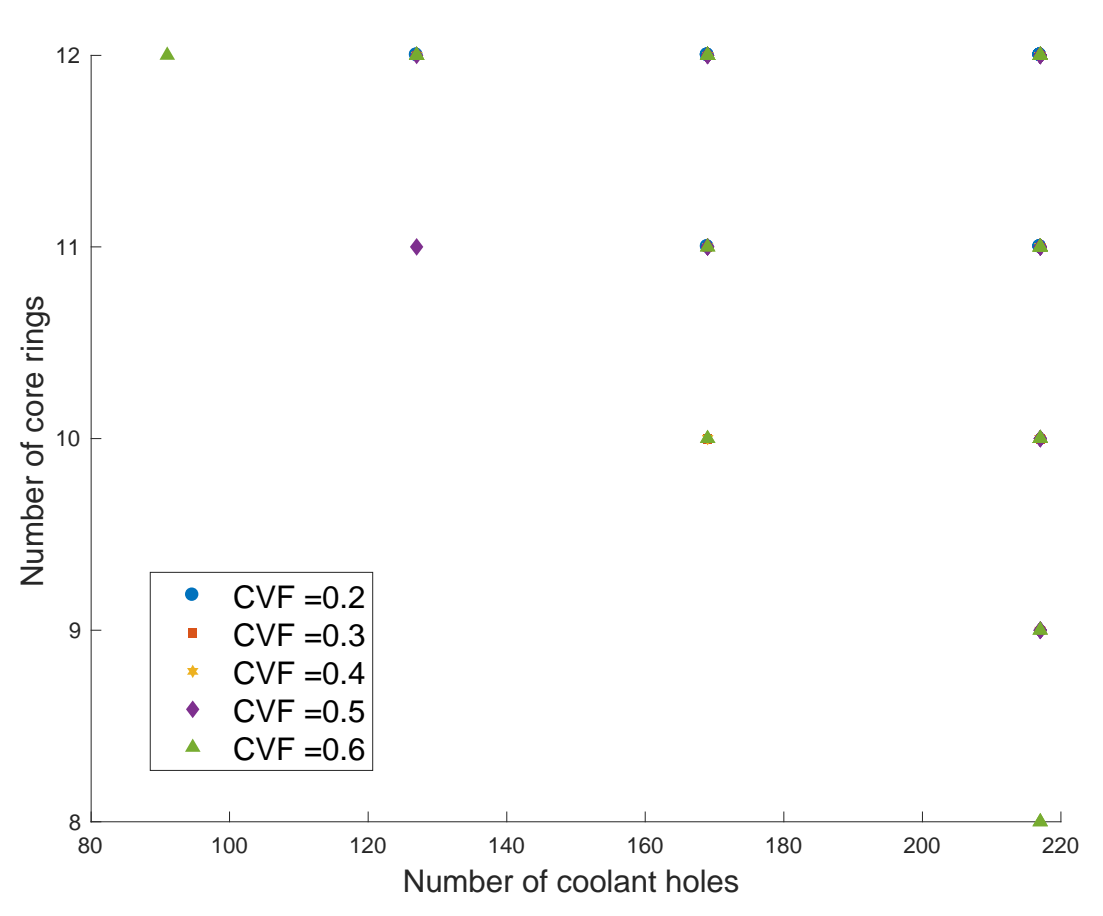

Figure 11. Number of Rings vs Number of Coolant Channels

It may be possible to use only seven rings of fuel assemblies if the radial power peaking factor can be reduced. This will be determined in the Phase 3 analysis, which includes evaluating the required moderator thickness and reflector thickness to produce the desired core reactivity characteristics. The moderator thickness impacts the intra-assembly peaking factor, and the reflector thickness impacts the core radial peaking factor. In this analysis, the product of these two values was assumed to be 2.6; the results shown here indicate that if this product is less than 2.3 , only seven rings are needed with the selected fuel geometry.

\subsubsection{Phase 3: Final Neutronics Parameters}

The third phase uses the core size parameters from the second phase to finalize the remaining parameters. This was achieved via iterative neutronics analyses with OpenMC and guided by the results from Phase 1. For example, in Phase 3 the targeted excess reactivity from Phase 1 was used in lieu of explicitly depleting each potential design, saving significant computational time. The goal of this stage is to establish the volume fraction of fuel particles in the CERCER fuel, the moderator thickness, the radial reflector thickness, and the control drum parameters.

These evaluations were performed as described herein for each enrichment type of interest. Although they are presented in a linear fashion, the reader should recognize that the process was necessarily iterative.

First, the moderator web thickness and fuel particle volume fraction were reduced until the value of keff had a value of between 0.8 and 0.94 . This keff range increases the reactor mass because a thick reflector is required. However, it was found that significant neutron leakage is necessary for the control drums to have sufficient control worth. 
In this analysis, the moderator thicknesses and fuel particle volume fractions were reduced such that the $\mathrm{H}: \mathrm{U}$ ratio was kept as constant as possible to maintain the under-moderated starting point. This objective could not be kept for all fuel particle volume fractions, however. As the fuel particle volume fraction became low, the moderator thickness could not be reduced any further without changing the assembly arrangement from a hexagonal to circular lattice. This lattice change was not performed. Therefore in these cases, the $\mathrm{H}: \mathrm{U}$ ratio would increase over the desired starting point. This will have an impact on the Doppler reactivity coefficient, the hydrogen absorption fraction, and the hydrogen pressure reactivity coefficient. This is considered acceptable for this work as the original $\mathrm{H}: \mathrm{U}$ ratio can be restored as the $\mathrm{ZrH}_{1.85}$ is reduced in volume to incorporate structural material and coolant channels.

After identifying the fuel particle volume fraction and moderator web thicknesses, the next step is to evaluate the reflector thickness needed to create the desired excess reactivity. The target keff was 1.048 with an additional $0.005 \Delta \mathrm{k}$ of margin to accommodate the reduction in reactivity when the control drums are present and rotated out, based on the Phase 1 analyses. In this Phase 3 analysis, the beryllium metal reflector, as was identified in Phase 1, is homogeneously mixed with $15 \%$ by volume $\mathrm{H}_{2}$ gas at $300 \mathrm{~K}$ and $1 \mathrm{MPa}$.

The final step of this phase was to take the reflected core design and add control drums of varying control material $\left(\mathrm{B}_{4} \mathrm{C}\right.$ - with natural ${ }^{10} \mathrm{~B}$ enrichment - or Hafnium metal), number of degrees (out of 360) that the control material covers of the drum (the "span"), control material thicknesses, and number of control drums. For this effort, the control drums were designed such that the drum contained mostly reflector material (beryllium metal homogenously mixed with $15 \% \mathrm{H}_{2}$ gas), with an outer layer of control material. The control drums were modeled as the full height of the fueled region of the reactor, with the radius of each control drum slightly less than half the thickness of the reflector.

These control drums must be able to ensure the reactor is subcritical by some margin when the reactor is at the most reactive time-in-life and most reactive temperature. This means that the uncontrolled hot-full power reactor with $\mathrm{k}_{\text {eff }}$ of 1.048 must be able to be reduced to a $\mathrm{k}_{\text {eff }}$ of less than 0.99. Note this subcriticality margin is an estimate and does not account for uncertainties, anticipated operational occurrences, or any other margin to criticality that may be required by the regulator. Further, the control drums must also reduce reactivity by another $1.5 \%$ for subcriticality at cold temperatures. This control window sets the required control drum worth to approximately $6,300 \mathrm{pcm}$.

The specific results of this phase are discussed in Sections 4 and 5. However, it is worth noting now that this design process revealed that the radial peaking factors were sufficiently low in both the HEU and HALEU designs that the number of rings could be reduced from the eight identified in Section 3.2.2 (Phase 2 analysis) to seven. This result was implemented during this phase and carried forward.

\subsubsection{Phase 4: Final Thermal Hydraulics Parameters}

The fourth phase involves iterating between the neutronics and thermal-hydraulics analyses to settle on the remaining parameters of interest. Specifically, the first step is to identify the critical control drum rotations. This was necessary since the control drum contains a strong neutron 
absorber that significantly affects the radial neutron flux distribution by capturing neutrons returning from the reflector.

With the drums at the critical position, a whole-core neutronics evaluation was performed to compute the axial and radial power distributions of the $3 \mathrm{D}$ core and an individual $2 \mathrm{D}$ fuel assembly in an infinite lattice. The core power distribution and intra-assembly power peaking results were used to identify the axial and assembly-wise radial peaking factors. These peaking factors were then used with the thermal-hydraulics model described in Appendix C: ThermalHydraulic Analysis Model to identify the number of coolant channel holes needed in the hottest fuel assembly. Finally, the axial temperature distributions were compared to the temperature distributions assumed in the OpenMC model for hot-full-power conditions to verify whether assumed distributions still hold, and if not, to update the distributions and re-run the OpenMC analyses for this phase.

The specific results of this phase are discussed in Sections 4 and 5 for the HALEU and HEU cores, respectively.

\subsubsection{Phase 5: Final Evaluation}

The fifth and final phase of this analysis was to perform any remaining evaluations of HALEU and HEU core performance needed to support the conclusions of this report. Specifically, this includes the generation of the final reactor geometries; an evaluation of the control worth, the excess reactivity with depletion, and the reactivity worth of ${ }^{135} \mathrm{Xe}$; and the determination of the Doppler reactivity and hydrogen pressure coefficients of reactivity.

The depletion and xenon reactivity evaluations were performed simultaneously in a manner similar to the excess reactivity calculations performed in Phase 1. Here, however, the control drums are present at the critical position and slight modifications are applied to the power history to evaluate the history that produces the greatest xenon reactivity worth

The control drums are placed at their critical position at BOL and held there through life for this analysis. This increases the power generated in the center of the reactor, where the power is already peaked. This should increase the burnup of fuel in the central region of the core compared to rotating the drums as needed to maintain criticality and thus exacerbate the reactivity burnup rate. This also forces the peak xenon reactivity worth to be more negative in magnitude, as the xenon is concentrated in the center and will push power towards the edges of the core, where more leakage will reduce reactivity even further.

This reactivity evaluation will differ from that performed in Phase 1 as the Phase 5 analysis is less interested in scoping-level analyses. The power history applied to the core in this phase is: (1) 2.5 hours of full power (540 MW) operation; (2) a 50-hour shutdown period; (3) the remaining 0.5 hours of the mission's lifetime; (4) zero-power decay to determine the peak xenon reactivity and later when a negligible amount of ${ }^{135} \mathrm{Xe}$ is present (a total of 72 hours later). This power history provides the reactivity depletion over the 3-hour period as the difference in reactivity between BOL and after the first 3 hours of at-power operation. This is feasible, despite the 50-hour shutdown period before the last half hour of operation, because the xenon is far from equilibrium and in very small quantities during operation. 
The final half hour and peak xenon reactivity determination is used to make sure the reactor can restart after a 30-minute period of operation. The first 50-hour period to achieve xenon-free conditions is intended to remove all the ${ }^{135} \mathrm{I}$ and ${ }^{135} \mathrm{Xe}$ from the system before starting the final run. Since the peak xenon reactivity worth grows with fuel depletion, the inclusion of this 30minute period at the end of the 3-hour operation window is conservative from the standpoint of maximizing peak xenon reactivity worth. The final xenon decay period is included as a sanity check to gauge xenon inventory during the at-power conditions.

The Doppler coefficients of reactivity are computed by comparing the reactivity at cold-zeropower conditions (assumed $100 \mathrm{~K}$ ), at hot-zero-power conditions (assumed $1000 \mathrm{~K}$ ), and hotfull-power conditions (the temperature distribution obtained at $540 \mathrm{MW}$ ). These computations are performed changing only the temperatures of materials; no densities, pressures, or dimensions are modified. In this way, the computation is a true Doppler reactivity coefficient, but should not be confused for the total temperature coefficient of reactivity.

The pressure coefficients of reactivity are determined by taking the hot-zero-power case used in the Doppler coefficient determination, reducing $\mathrm{H}_{2}$ pressure to $1 \mathrm{MPa}$, then to $0.01 \mathrm{MPa}$, and finally to void conditions. This is repeated for the cold-zero-power case. Again, only pressure is modified in these cases; the starting temperatures are maintained at their original values (i.e., at the hot-zero-power or cold-zero-power values).

The specific results of this phase are discussed in Sections 4 and 5 for the HALEU and HEU cores, respectively. 


\section{HALEU Core Design Description}

The design of the HALEU core builds upon the general core design insights gained from Phases 1 and 2, described in Sections 3.2.1 and 3.2.2. This section focuses on the HALEU core design analysis performed in Phases 3, 4, and 5. While the Phase 3 analysis was initially performed for a core with 8 rings (including the center assembly) as identified in Phase 2, intermediate results indicated that the core radial peaking factor is sufficiently low that thermal-hydraulic requirements can be satisfied with only 7 rings. Therefore, this section presents the design analysis only for the 7-ring core.

\subsection{Design Process}

Figure 12 shows $\mathrm{k}_{\mathrm{inf}}$ as a function of moderator thickness from the Phase 1 scoping calculations described in Section 3.2.1, for the preferred fuel geometry (from Phase 2, Table 3) with HALEU and at the assumed maximal fuel particle volume fraction of $40 \%$. An attractive H:U ratio, with respect to being slightly under-moderated, for the HALEU design was taken to be at $0.6 \mathrm{~cm}$ moderator thickness, as marked in the figure. This value is slightly to the left of the peak shown in Figure 12.

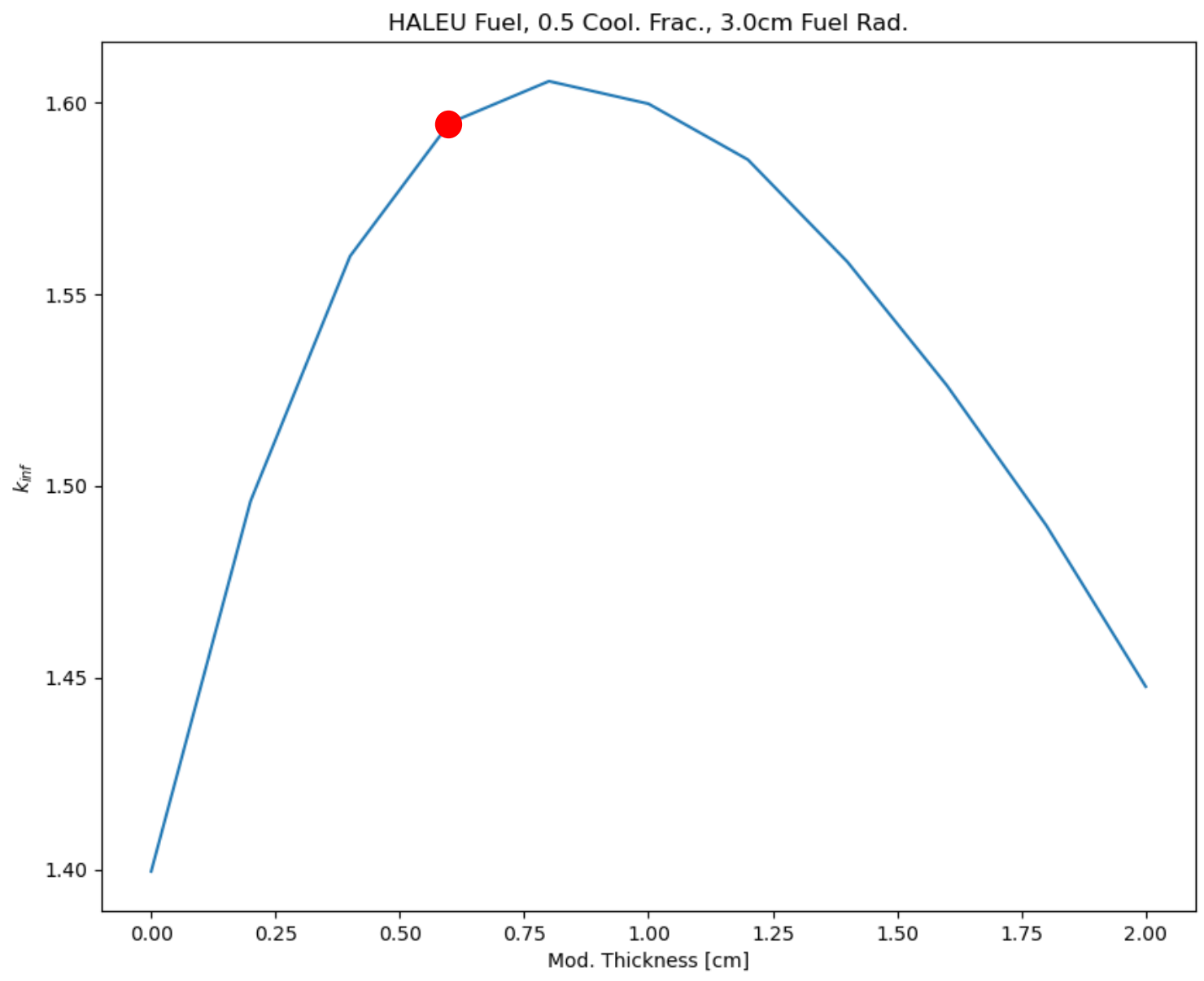

Figure 12. $\mathrm{k}_{\text {inf }}$ with Moderator Thickness for HALEU 
The HALEU fuel configuration was then determined by maintaining this identified $\mathrm{H}: \mathrm{U}$ ratio. The fuel particle volume fraction was reduced, varying the moderator thickness accordingly, as described in Section 3.2.3. Figure 13 shows that fuel particle volume fractions of $12-15 \%$ produce the target unreflected $\mathrm{k}_{\mathrm{eff}}$, between 0.8 and 0.94 .

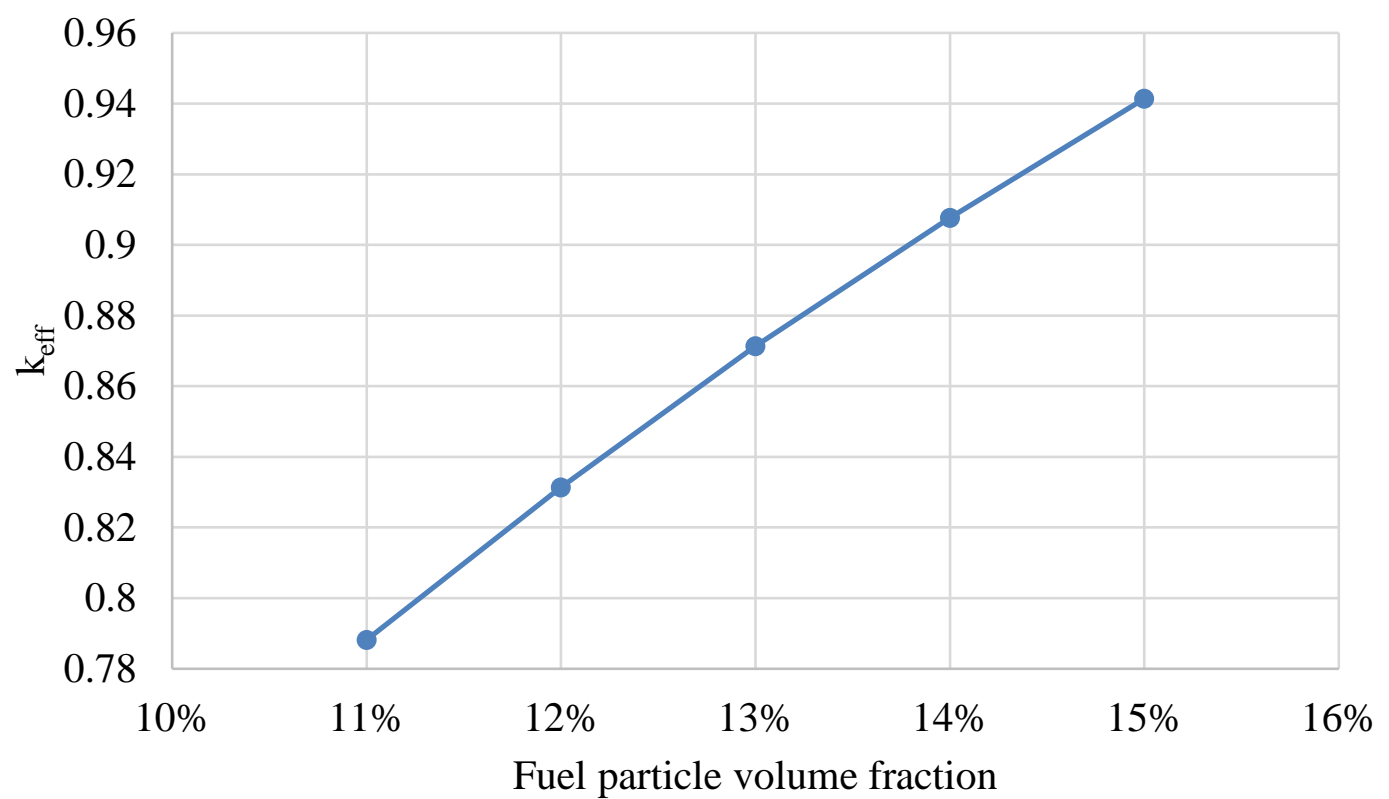

Figure 13. Fuel particle volume fraction selection for HALEU

The required reflector thickness was then evaluated for fuel particle volume fractions of $12.5 \%$, $13 \%, 14 \%$, and $15 \%$, according to the process described in Section 3.2.3 where the target $\mathrm{k}_{\mathrm{eff}}$ value of the reflected core is 1.053. Figure 14 shows $k_{\text {eff }}$ as the reflector thickness is varied for each of the evaluated cases with "FVF" in the legend referring to the fuel particle volume fraction. As the fuel particle volume fraction increases, Figure 13 shows that the unreflected $\mathrm{k}_{\text {eff }}$ increases, and Figure 14 shows that the required reflector thickness therefore decreases. Table 4 lists the required reflector thickness to produce $\mathrm{k}_{\mathrm{eff}}=1.053$ for each of the fuel particle volume fraction cases, the moderator thickness that maintains the selected $\mathrm{H}: \mathrm{U}$ ratio. At this stage, before the drums are introduced into the core model, the neutron leakage rate is $32-33 \%$ in the 12.5 , 13,14 , and $15 \%$ fuel particle volume fraction designs. 


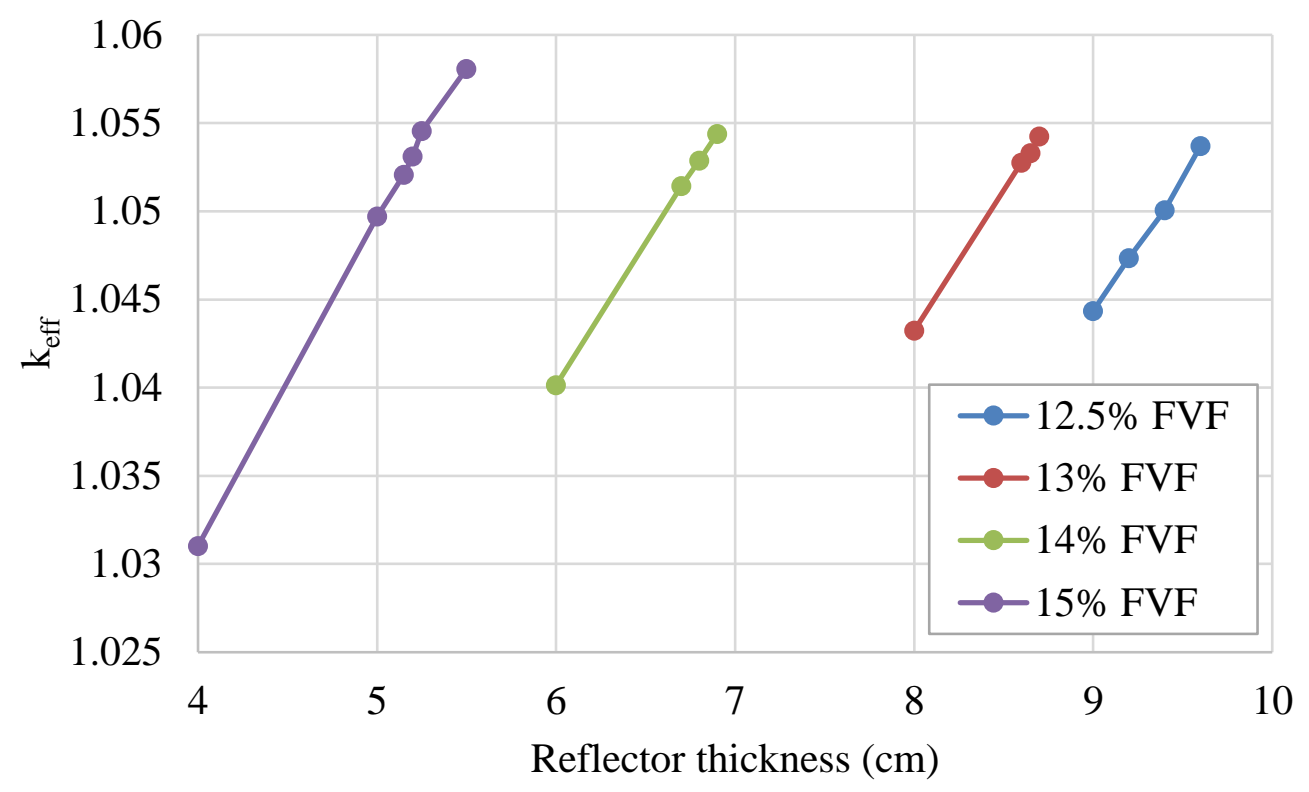

Figure 14. Reflector thickness evaluation for HALEU

Table 4. Candidate HALEU Fuel Designs

\begin{tabular}{|c|c|c|c|}
\hline $\begin{array}{c}\text { Fuel particle volume } \\
\text { fraction }\end{array}$ & $\begin{array}{c}\text { Moderator } \\
\text { thickness (cm) }\end{array}$ & $\begin{array}{c}\text { Reflector } \\
\text { thickness (cm) }\end{array}$ & $\begin{array}{c}\text { Core and Reflector } \\
\text { Mass (kg) }\end{array}$ \\
\hline $\mathbf{1 2 . 5 \%}$ & 0.083 & 9.60 & 2890 \\
\hline $\mathbf{1 3 \%}$ & 0.093 & 8.65 & 2926 \\
\hline $\mathbf{1 4 \%}$ & 0.113 & 6.80 & 2997 \\
\hline $\mathbf{1 5 \%}$ & 0.133 & 5.20 & 3069 \\
\hline
\end{tabular}

For the drum design, an initial sweep of control material $-\mathrm{B}_{4} \mathrm{C}$ and $\mathrm{Hf}-$ and the number of drums was performed, using a fixed control material span of 100 degrees and thickness of 2.5 $\mathrm{cm}$, for the $12.5,13,14$, and $15 \%$ fuel particle volume fraction designs with their corresponding reflector thicknesses. The results of this sweep showed that the desired drum worth and drumsout keff would most likely be achievable with the $13 \%$ fuel particle volume fraction design using natural $\mathrm{B}_{4} \mathrm{C}$ control material and a minimum of 15 drums. The $12.5 \%$ cases evaluated did not yield any options meeting the required excess reactivity and worth.

For the design with $13 \%$ fuel particle volume fraction and $8.65 \mathrm{~cm}$ reflector thickness, a more detailed sweep of drum design options was performed, varying the number of drums from 15 to 21 (in increments of 3 to maintain 1/3 symmetry), control material span from 80 to 180 degrees, and control material thickness from 1 to $3 \mathrm{~cm}$. While a total drum worth of more than 5,500 pcm is achievable for several combinations, the drums-out reactor keff always remains less than the target value of 1.048 .

With the fuel particle volume fraction fixed at $13 \%$, the reflector thickness was then slightly increased from $8.65 \mathrm{~cm}$ to $9.0 \mathrm{~cm}$ to increase the available control worth of the control drums by 
increasing the control surface area and reducing the reactivity penalty of the control material when rotated out. With this change, a drum design was found that produces the desired performance. With 21 beryllium drums each containing a 100-degree span and 1.5-cm thickness of $\mathrm{B}_{4} \mathrm{C}$, the control drum worth is $7,558 \mathrm{pcm}$, and the drums-out reactor $\mathrm{k}_{\mathrm{eff}}$ is 1.04997 . According to the Phase 4 process described in Section 3.2.4, the critical drum position was found to be 64.7 degrees, where 0 degrees is the position fully facing the core and 180 degrees is fully turned away. The core drum worth curve is shown in Figure 15.

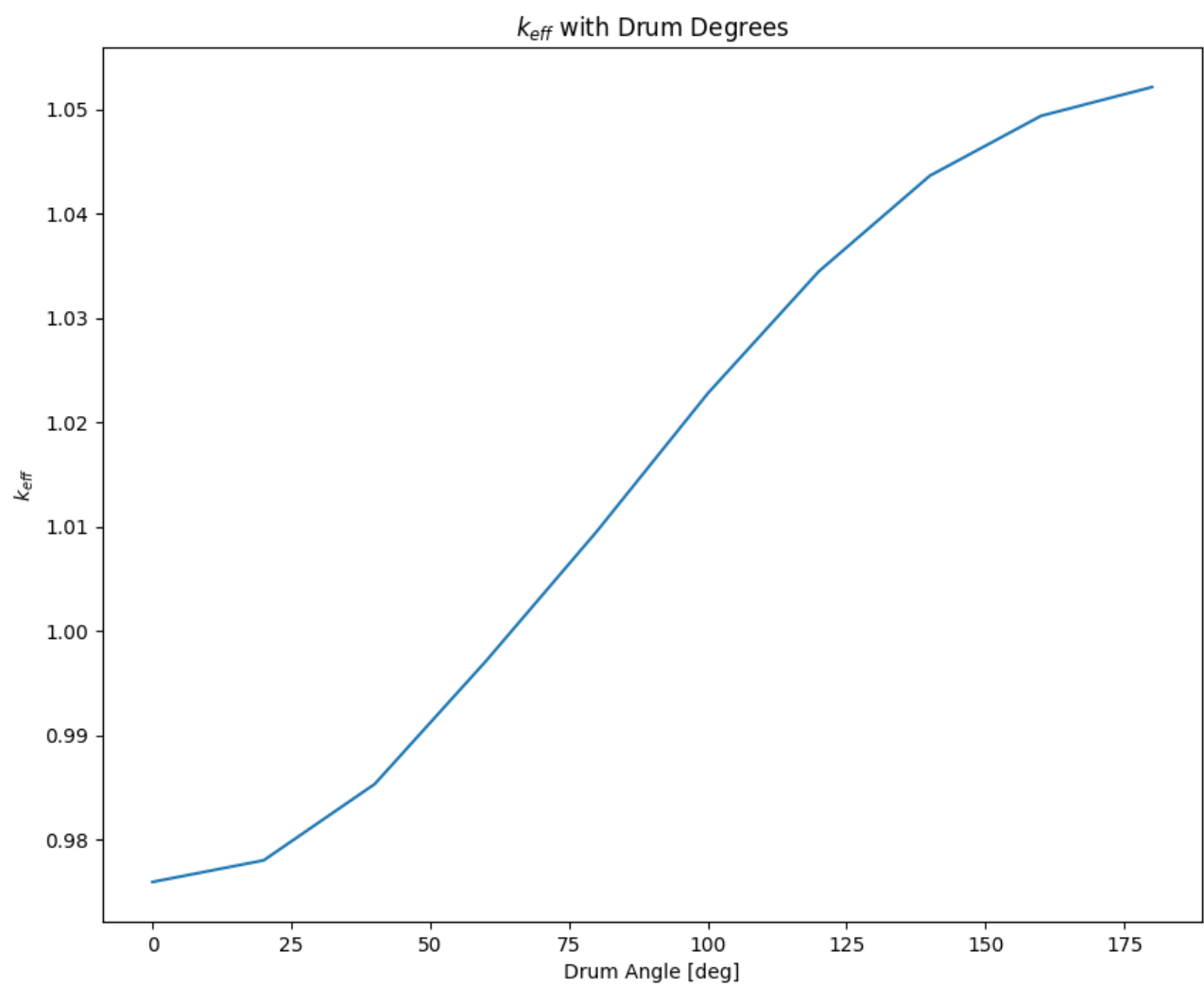

Figure 15. HALEU Core Drum Worth

The core power distribution was determined at the critical drum position. The resulting core radial and axial peaking profiles and hottest cell power were used to perform a final thermalhydraulics analysis, as described in Appendix C: Thermal-Hydraulic Analysis Model, for varying numbers of coolant holes in the fuel assembly. The smallest number of holes that the hottest assembly satisfies the $2800 \mathrm{~K}$ fuel temperature limit was selected as the final fuel design as this increases manufacturability and reduces the reactor core pressure drop. From this analysis, 127 coolant holes were selected, down from the 217-hole design identified in Phase 2 analysis. This reduction is driven by over-conservative assumptions made in the Phase 2 analysis. The Phase 4 analysis for HALEU confirmed that the initially assumed radial and axial power distributions were accurate, so a second iteration of these analyses was not needed. 


\subsection{Selected Design}

The final assembly layout, for this study, is shown in Figure 16, the radial core layout in Figure 17 , and the elevation view of the core (through a slice parallel to the $\mathrm{x}$-axis of Figure 17) in Figure 18. In Figure 16, the red material is the CERCER fuel, and the light blue are the coolant channels. Outside the outer coolant channel is the outer coolant gap (part of the second pass coolant), the low-density $\mathrm{ZrC}$ insulator, a second pass coolant channel gap, the $\mathrm{SiC} / \mathrm{SiC}$ insulator, a first pass coolant, and finally the moderator in yellow.

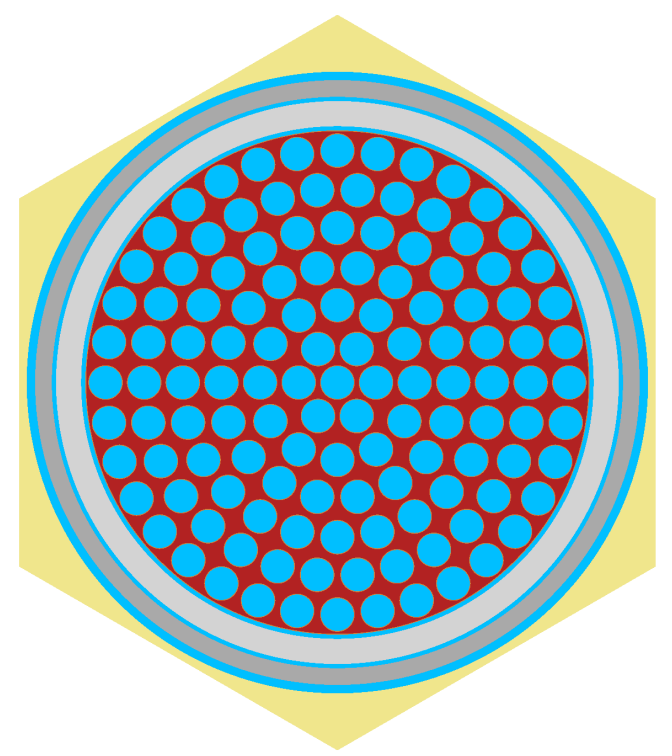

Figure 16. HALEU Assembly 


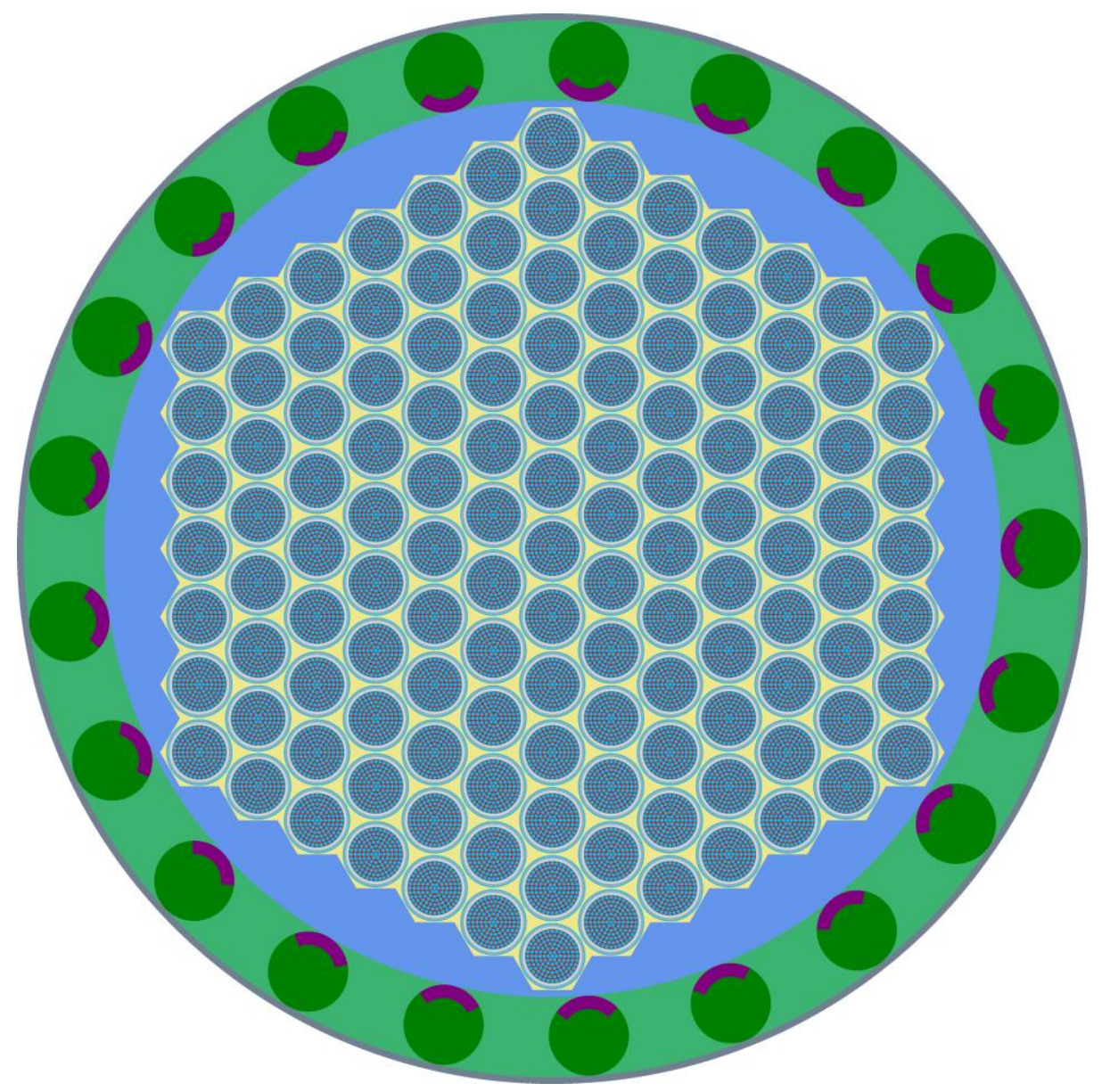

Figure 17. HALEU Full-Core Radial View 


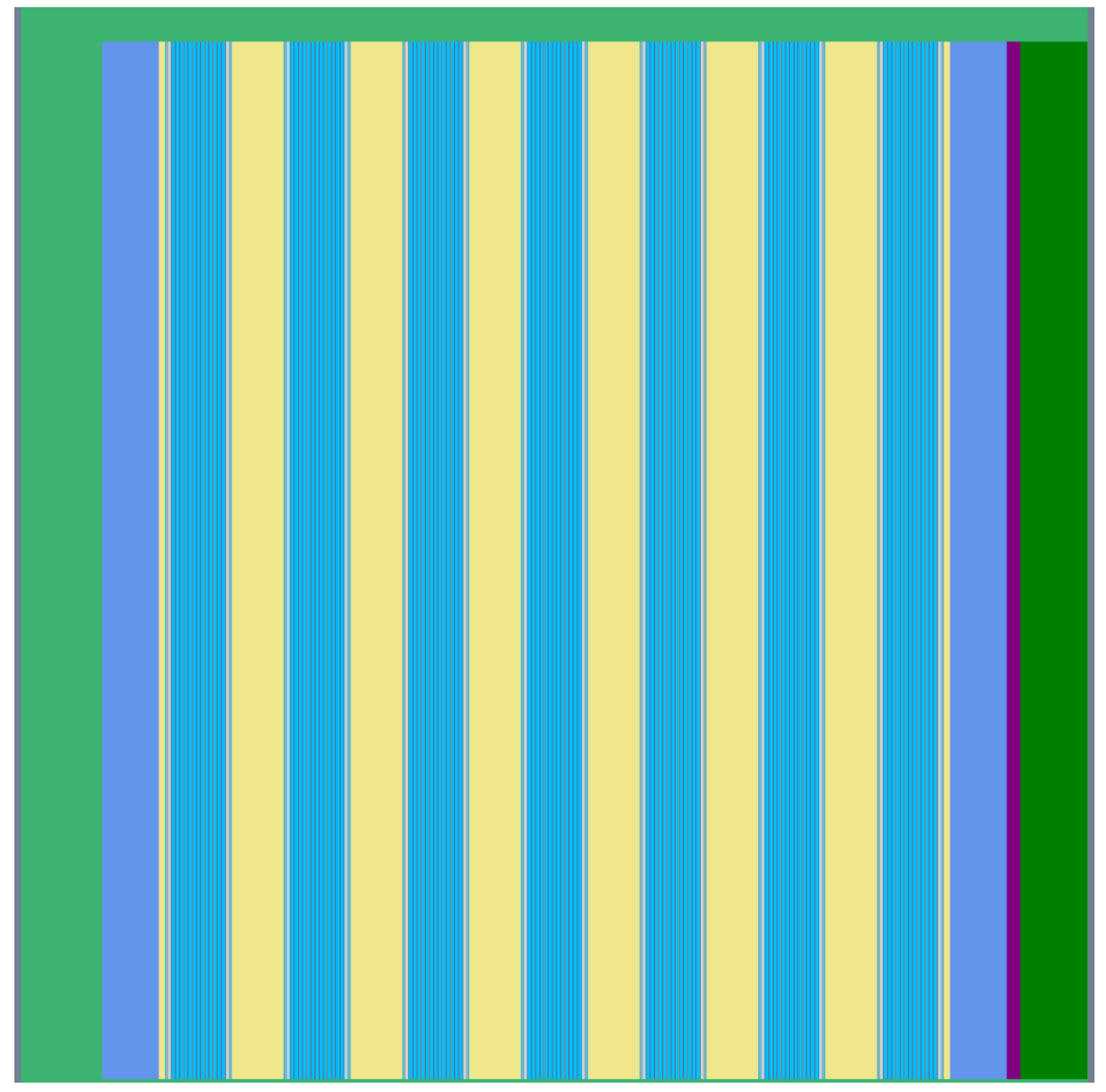

Figure 18. HALEU Full-Core Elevation View

The final HALEU core design characteristics are given in Table 5 and Table 6. 
Table 5. HALEU Final Core Characteristics, Part 1

\begin{tabular}{|l|c|c|}
\hline \multicolumn{1}{|c|}{ Parameter } & \multicolumn{1}{c|}{ Approach } & Value \\
\hline Fuel Radius & Fuel Assembly & $3.0 \mathrm{~cm}$ \\
\hline Coolant Channel Thickness & Fixed & $0.01 \mathrm{~cm}$ \\
\hline Fuel "clad" thickness & Fixed & $0.01 \mathrm{~cm}$ \\
\hline Fuel "clad" material & Fixed & ZrC \\
\hline Fuel Cylinder Coolant vol. frac. & Free variable & 0.6 \\
\hline Number of holes & Free variable & 127 \\
\hline CERCER particle vol. frac. & $\begin{array}{c}\text { Derived to obtain excess } \\
\text { reactivity }\end{array}$ & 0.13 \\
\hline Moderator web thickness & Moderator & $0.093 \mathrm{~cm}$ \\
\hline Insulator Materials & Free variable & SiC \\
\hline Insulator Dimensions & Fixed & Low-density ZrC and \\
\hline Insulator Gap Thicknesses & Fixed & $0.2 \mathrm{~cm} \mathrm{each}$ \\
\hline
\end{tabular}

Table 6. HALEU Final Core Characteristics, Part 2

\begin{tabular}{|c|c|c|}
\hline Parameter & Approach & Final Value \\
\hline \multicolumn{3}{|c|}{ Reflector } \\
\hline Axial reflector materials & Fixed & Be top, Inconel 718 bottom \\
\hline Axial reflector thicknesses & Fixed & $5 \mathrm{~cm}$ top, $1 \mathrm{~cm}$ bottom \\
\hline Axial reflector cooling fraction & Fixed & $30 \%$ \\
\hline Radial reflector material & Free variable & $\mathrm{Be}$ \\
\hline Radial reflector thickness & Derived for reactivity & $9.0 \mathrm{~cm}$ \\
\hline Radial reflector cooling fraction & Fixed & $15 \%$ \\
\hline \multicolumn{3}{|c|}{ Control } \\
\hline Control material & Free variable & $\mathrm{B}_{4} \mathrm{C}$ \\
\hline Control material thickness & Free variable & $1.5 \mathrm{~cm}$ \\
\hline Control material span & Free variable & 100 degrees \\
\hline Number of drums & Free variable & 21 \\
\hline \multicolumn{3}{|c|}{ Overall } \\
\hline Number of Rings & Free variable & 7 \\
\hline Core flow rate & Derived for outlet temp. & $13.6 \mathrm{~kg} / \mathrm{s}$ \\
\hline Fuel Height & Free variable & $150 \mathrm{~cm}$ \\
\hline Power & Fixed & $540 \mathrm{MW}$ \\
\hline Coolant Inlet Pressure & Fixed & $1 \mathrm{MPa}$ \\
\hline Coolant Inlet Temperature & Fixed & $300 \mathrm{~K}$ \\
\hline Target Outlet Temperature & Fixed & $2700 \mathrm{~K}$ \\
\hline Maximum Fuel Temperature & Fixed & $2800 \mathrm{~K}$ \\
\hline
\end{tabular}


The reactor and component masses are provided in Table 7. The largest mass component is the CERCER material (fuel and matrix) $(1,576.4 \mathrm{~kg}$ ); however, the uranium is only a minor component $(372.8 \mathrm{~kg}$ ) and therefore the remainder is the $\mathrm{ZrC}$ that is present simply to reduce the heat generation density. The total uranium loading is $372.8 \mathrm{~kg}$, with a ${ }^{235} \mathrm{U}$ mass of $73.6 \mathrm{~kg}$.

Table 7. HALEU Core Component Masses

\begin{tabular}{|l|r|r|}
\hline Material & Mass [kg] & Relative Mass [\%] \\
\hline Reflector & 792.9 & 19.2 \\
\hline Reactor Vessel & 358.7 & 8.7 \\
\hline ZrC Clad & 218.6 & 5.3 \\
\hline Low-Density ZrC & 243.2 & 5.9 \\
Insulator & 226.9 & \\
\hline SiC/SiC Insulator & 695.3 & 5.5 \\
\hline Moderator Block & $1,576.4$ & 16.8 \\
\hline CERCER & 4.9 & 38.1 \\
\hline Control Drum Material & 16.5 & 0.1 \\
\hline Drum Reflector & $4,133.3$ & 0.4 \\
\hline Total & & - \\
\hline
\end{tabular}

\subsection{Thermal and Power Profiles}

The intra-assembly radial power profile and axial power profile of the final design are shown in Figure 19 and Figure 20, respectively. This particular analysis was performed assuming fully reflective boundary conditions and thus will have a power distribution representative, but bounding, of the central assembly. In Figure 19, the color bar to the right shows the assignment of colors to an arbitrarily normalized power distribution. The temperature profile for the hottest coolant hole of the peak assembly is shown in Figure 21, and the pressure of the coolant in the channel is shown in Figure 22. In these axial figures, the axial distance shown is from within the fueled region. 
Power Distribution at Plane 1

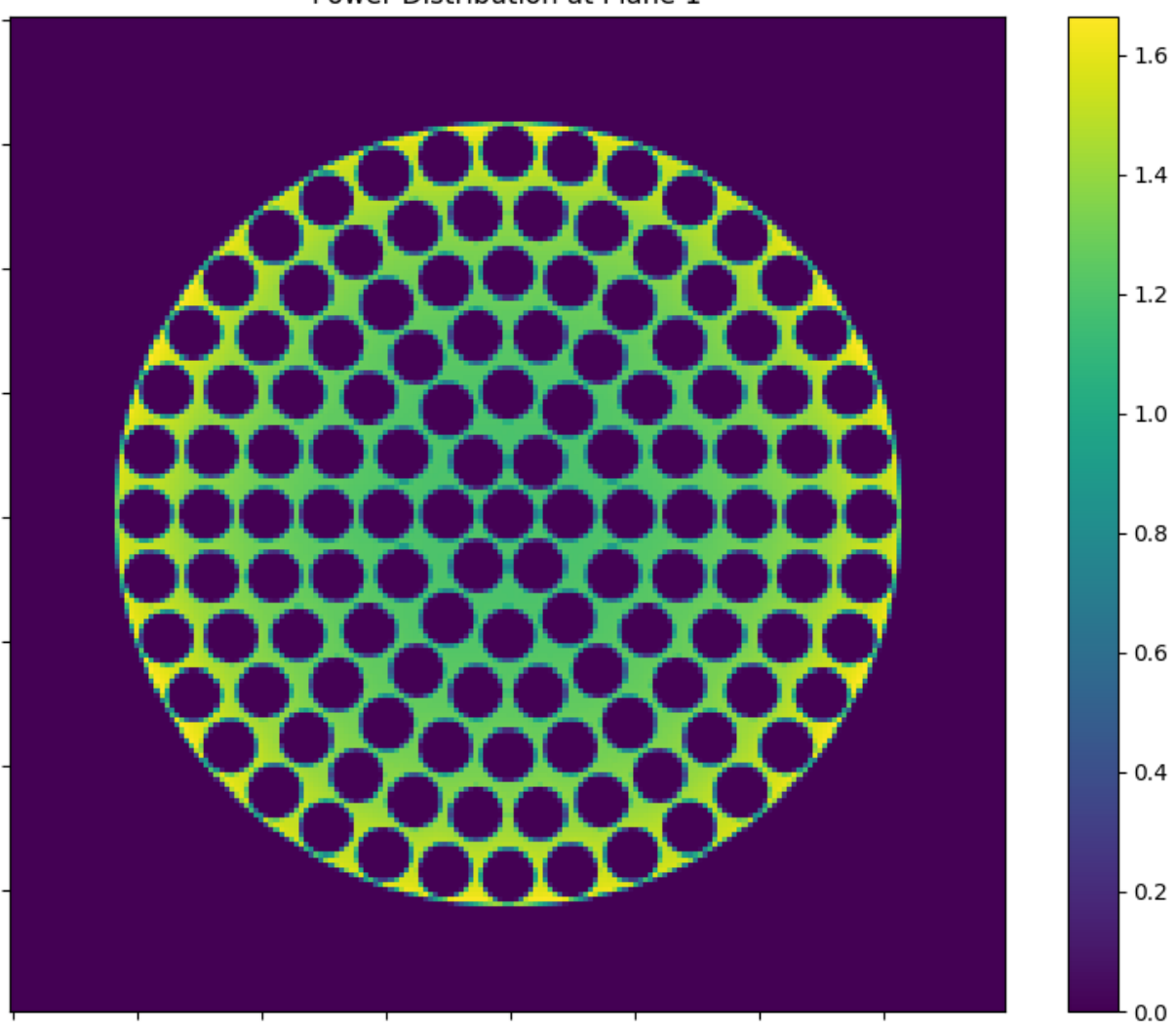

Figure 19. Normalized HALEU Intra-Assembly Power Distribution 


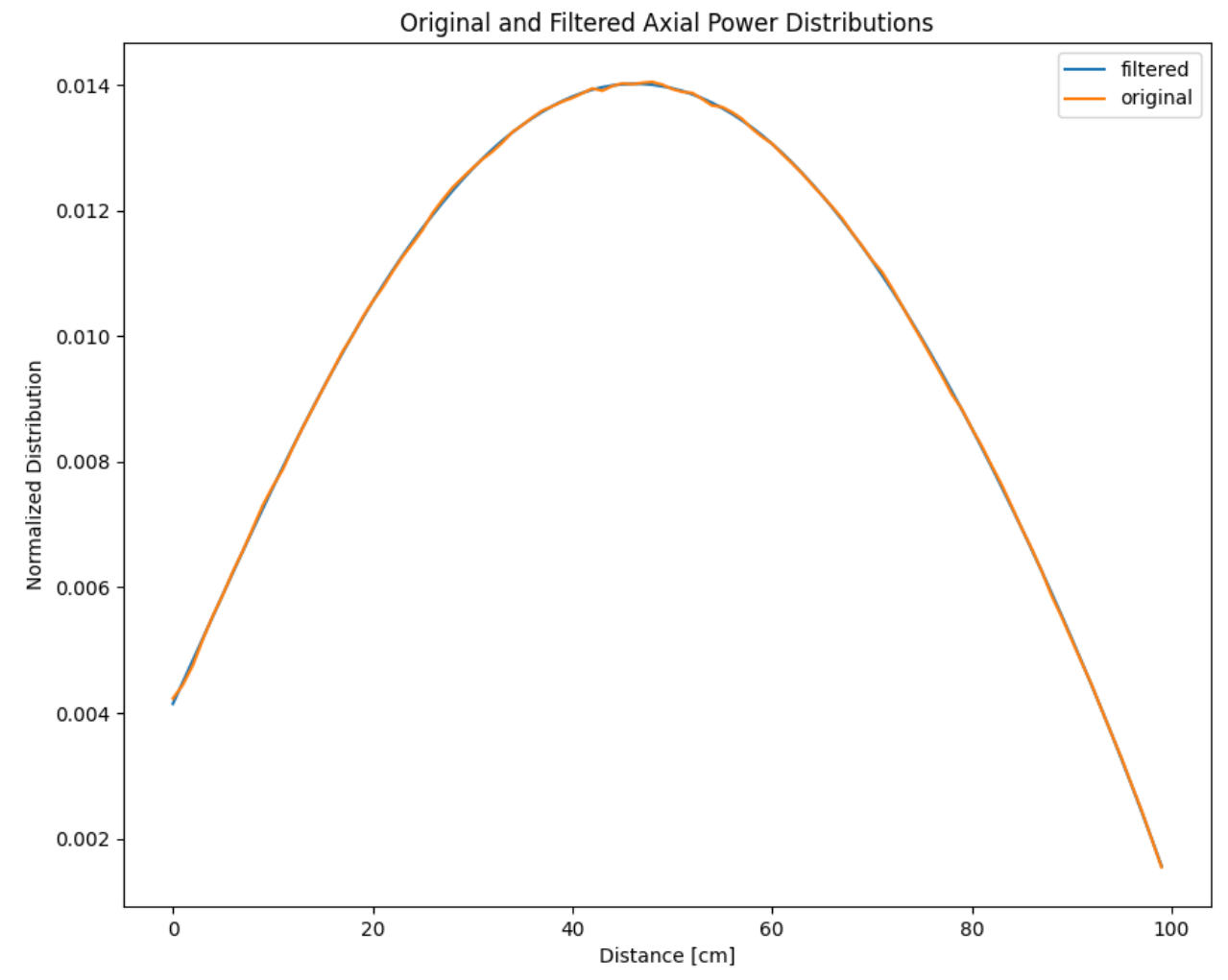

Figure 20. Axial Power Profile Used in Thermal Analysis for HALEU Core

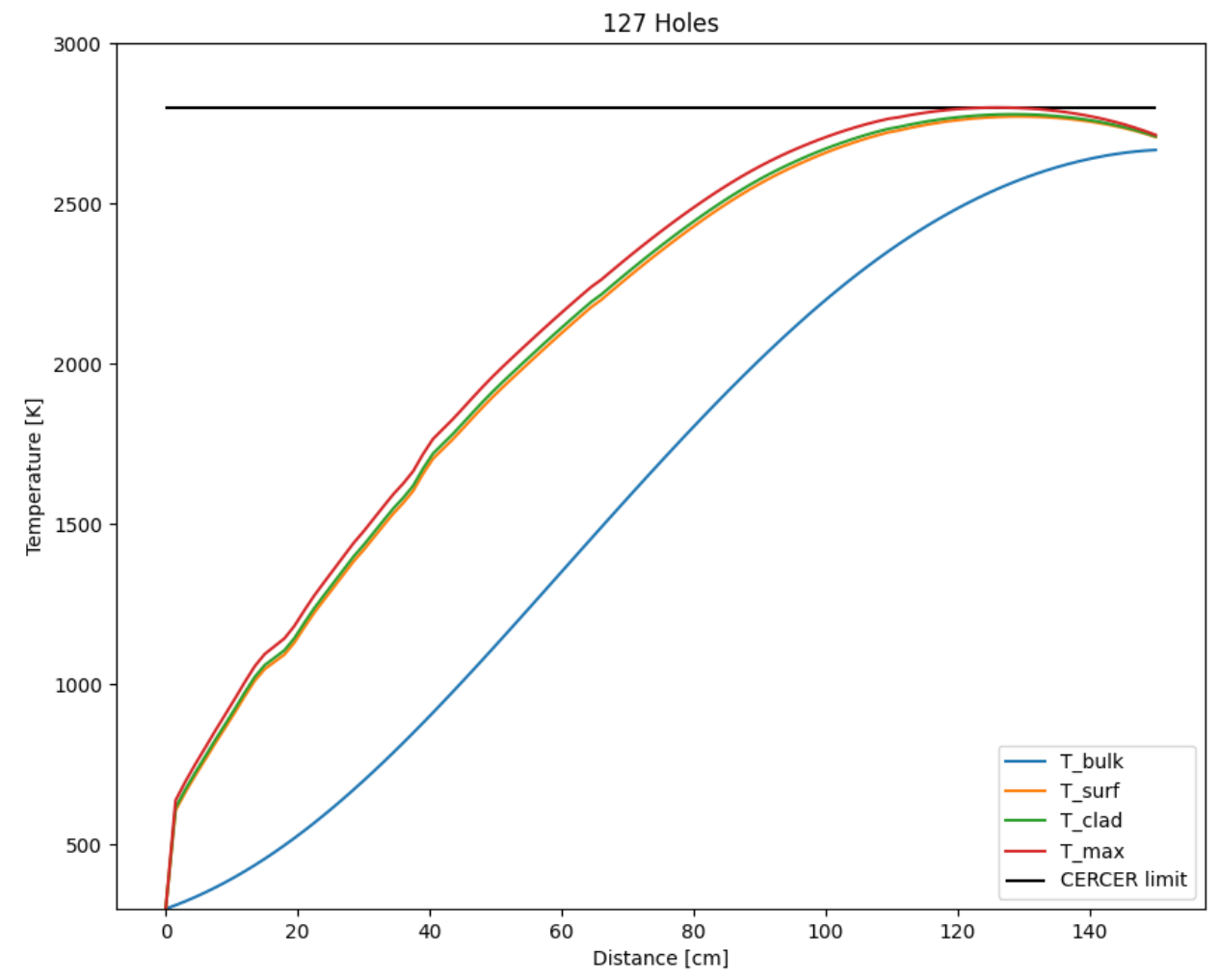

Figure 21. Peak Hole Temperature Axial Profile for HALEU Core 


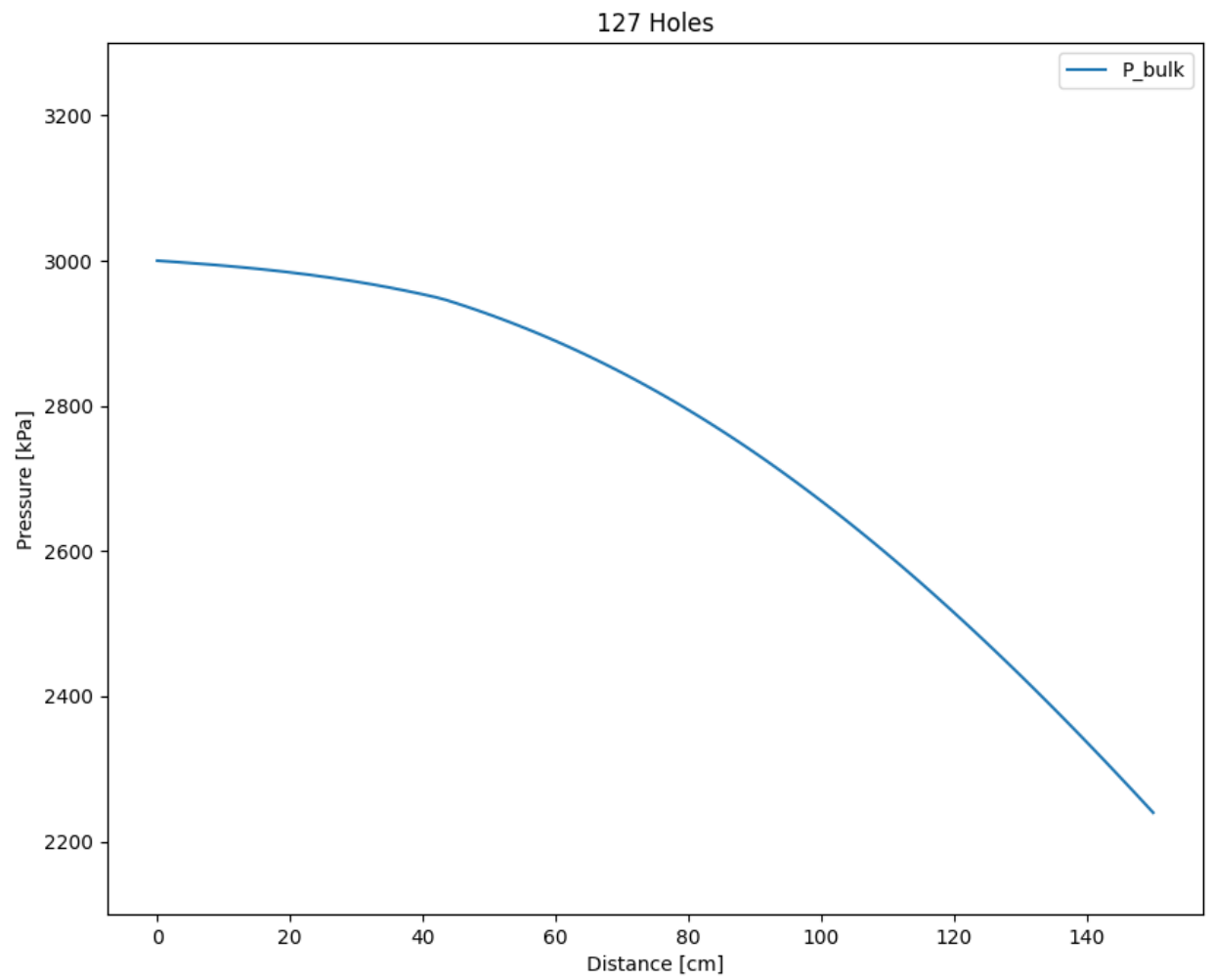

Figure 22. Peak Hole Pressure Axial Profile for HALEU Core

The neutron energy spectrum for the HALEU reactor for an assembly in each ring is provided in Figure 23. These spectra show that the reactor is thermal and that the variation in the spectrum is minimal among rings. 


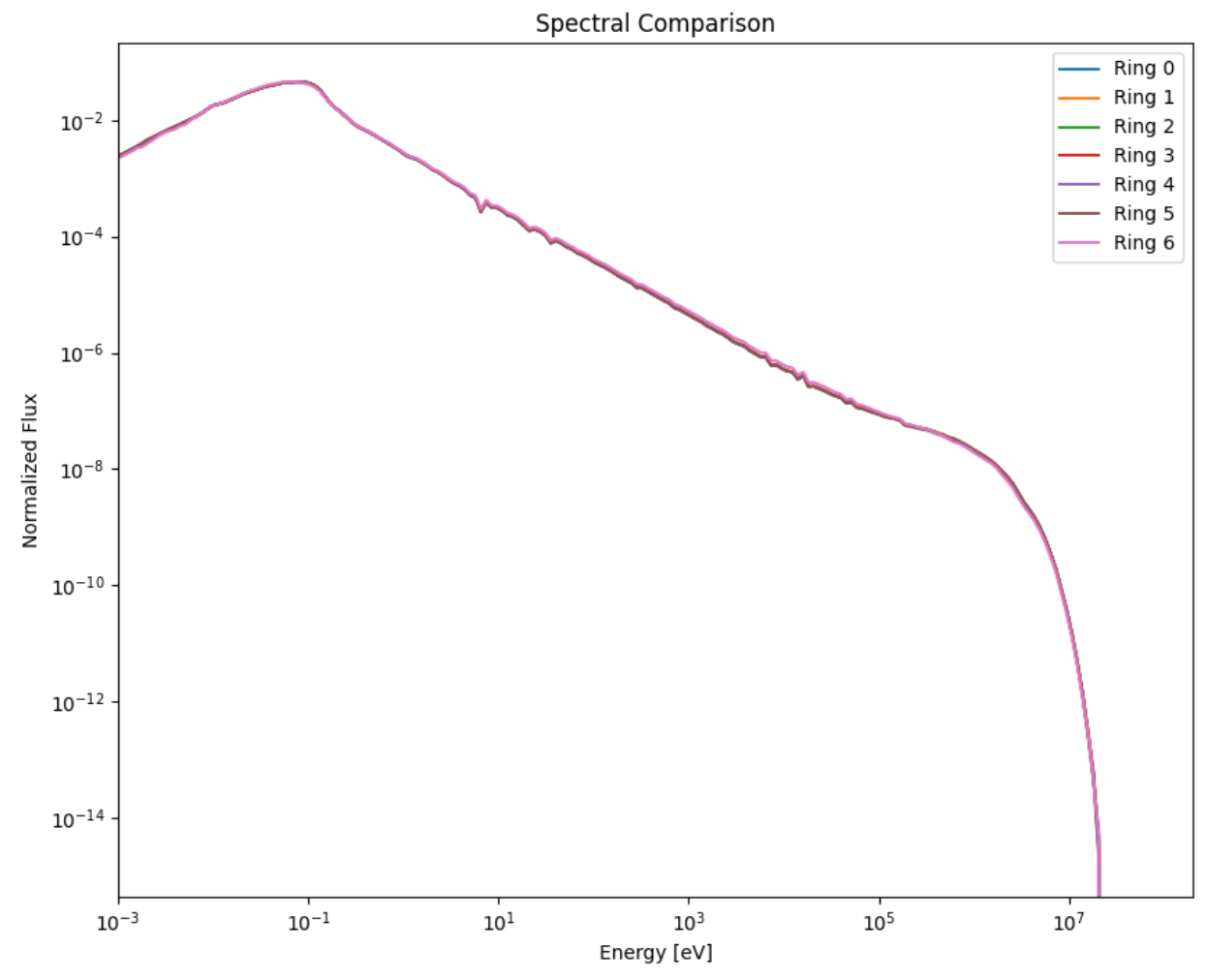

Figure 23. HALEU Neutron Energy Spectra

Next, the radial core power distribution is shown in Figure 24. The numerical values in this figure represent the cell power compared to an average cell. This figure shows that the power is as one would expect for a homogenous cylindrical-like reactor. 


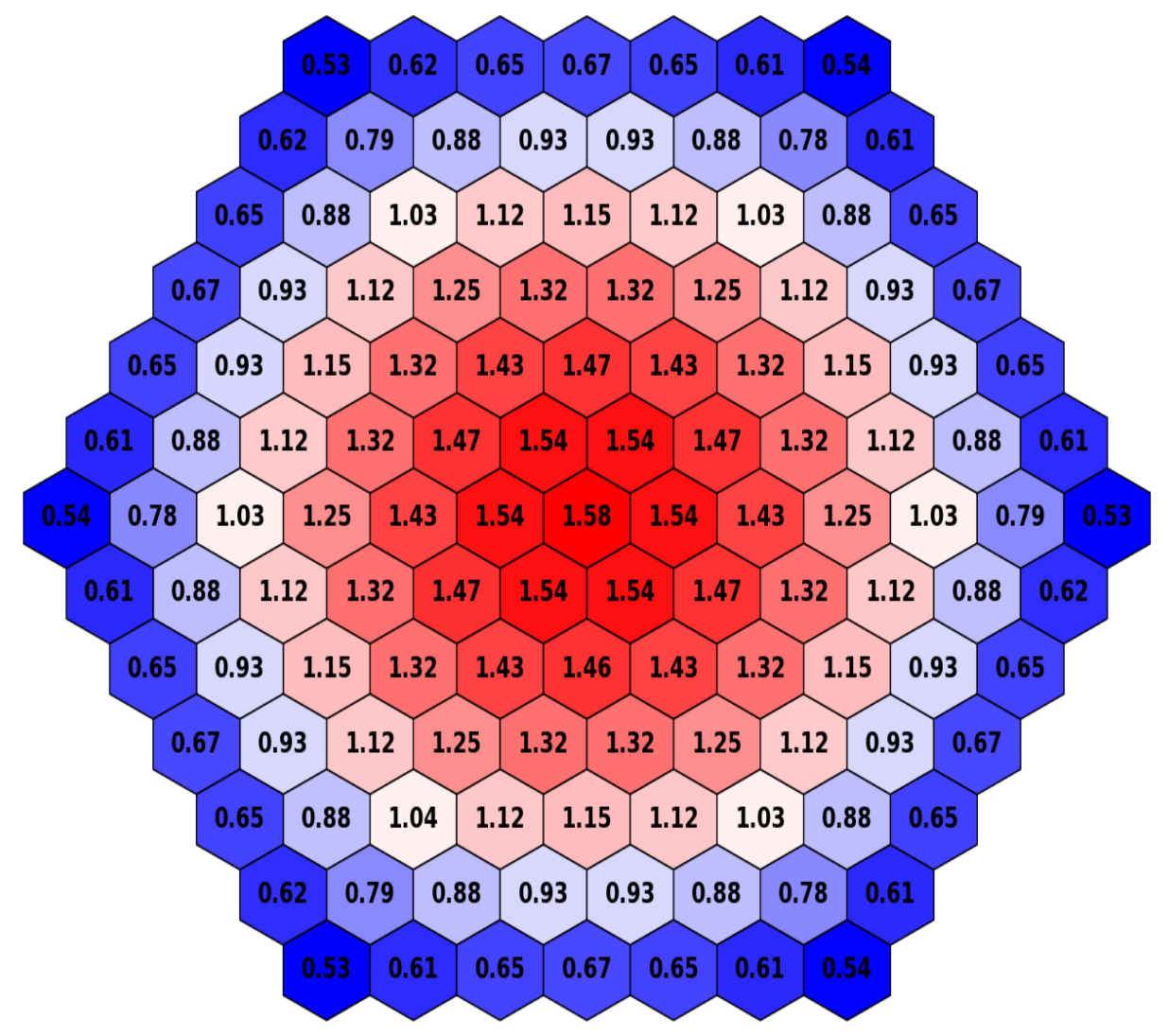

Figure 24. HALEU Assembly Power Distribution

\subsection{Depletion Reactivity}

The depletion reactivity and xenon override performance of the final HALEU core were evaluated according to the Phase 5 process described in Section 3.2.5. Figure 25 shows the trajectory of $k_{\text {eff }}$ over the simulated operation and shutdown cycle, where the reactor operates at full power for a total of 3 hours: from 0 to 2.5 hours, and 52.5 to 53 hours. Note that in this evaluation, the control drums are kept at their BOL critical position to highlight the change in reactivity from BOL. The significant result is that the reactivity difference between beginningof-life and the peak xenon reactivity condition, occurring at 63 hours, is 2,246 pcm. The HALEU core's 4,997 pcm excess reactivity is more than enough to overcome this peak xenon worth. 


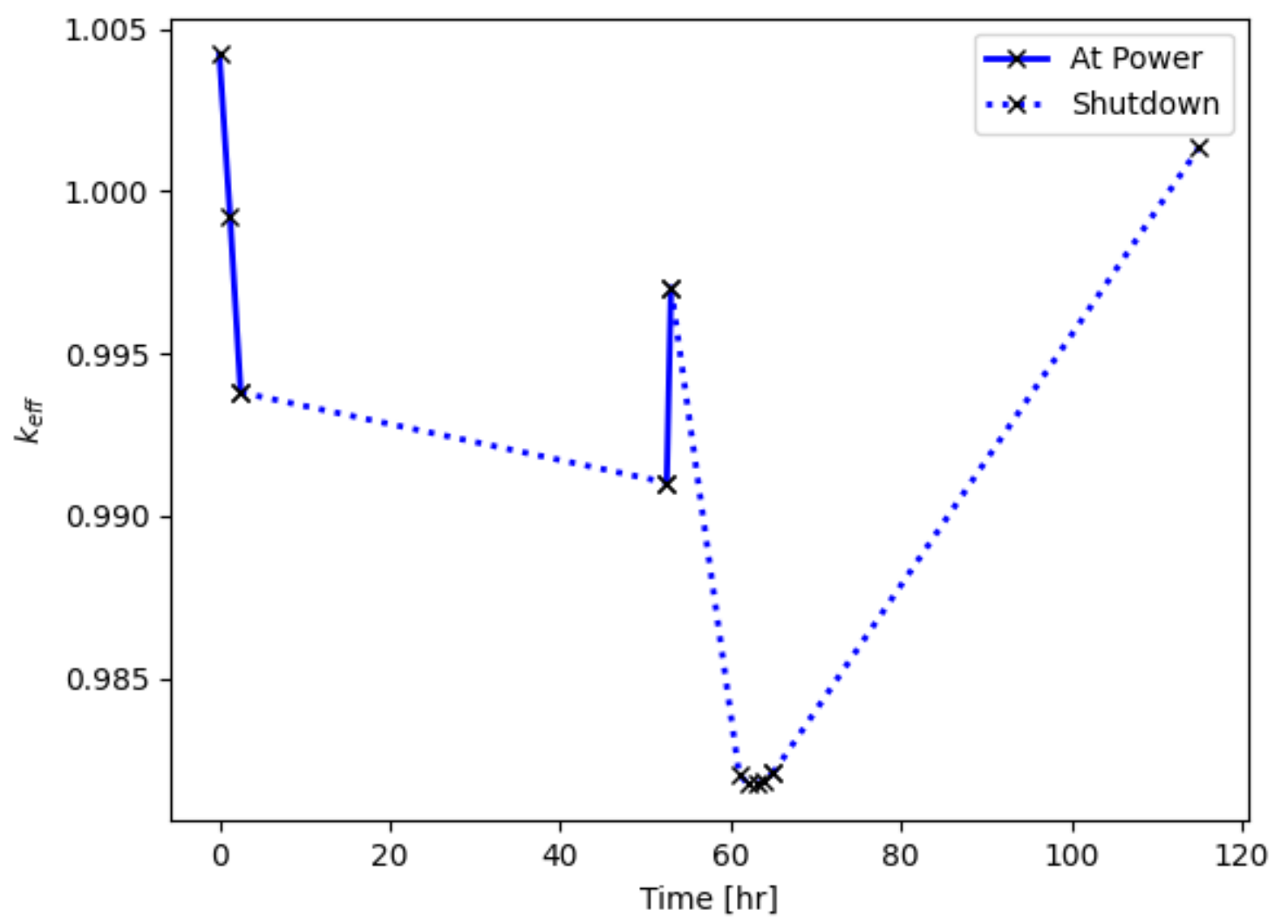

Figure 25. Uncontrolled Core Reactivity during HALEU reactor operation and shutdown

The detailed keff trajectory over the various stages of reactor operation and shutdown are briefly explained here, although these behaviors are of lesser importance at the current design stage and highly subject to the specific power history applied. Reactivity decreases during the first 2.5 hours of operation due to fuel burnup. During shutdown from 2.5 to 52.5 hours, a xenon concentration peak is reached, but since we were not interested in this peak for xenon override as this is not the limiting peak xenon reactivity, the evaluation of the peak was skipped in the calculations, which instead aimed to accurately determine the net reactivity at 2.5 and 52.5 hours. The decrease in $\mathrm{k}_{\text {eff }}$ between 2.5 and 52.5 hours indicates that the fission product ${ }^{149} \mathrm{Pm}$ was present in significant quantities at 2.5 hours and decayed with a 2.2 day half-life to its highlyabsorbing but stable decay product ${ }^{149} \mathrm{Sm}$ during this 50 hour interval. This change is not due to ${ }^{135} \mathrm{Xe}$ since the constituents in its' decay chain ${ }^{135} \mathrm{I}$ with a 6.57 hour half-life and ${ }^{135} \mathrm{Xe}$ with a 9.1 hour half-life) would have substantially decayed away during these 50 hours. During the following 30 minutes of operation, the sizeable spike in reactivity is explained by the burnup of the strong absorbers, ${ }^{149} \mathrm{Pm}$ and ${ }^{149} \mathrm{Sm}$. From 53 to 115 hours, reactivity initially decreases owing to xenon buildup, but as xenon decays away, reactivity eventually increases to a higher value than the final operational reactivity. It should be reiterated that this keff trajectory is specific to the assumed power history and the accumulation of fission products will depend on actual operating conditions. 


\subsection{Reactivity Coefficients}

Table 8 lists the $\mathrm{k}_{\text {eff }}$ values computed at CZP, HZP, and HFP (with the temperatures of each discussed in Section 3.2.5) to assess the Doppler reactivity feedback effect. These results have uncertainties of $3 \mathrm{pcm}$ to the 2-sigma level. From the uniform temperature difference between $\mathrm{CZP}$ and HZP, an overall Doppler reactivity coefficient of $-3.17 \mathrm{pcm} / \mathrm{K}$ is calculated. Note that this coefficient is stated as linear, however it will not vary linearly across the entire temperature range of interest; this should be evaluated further for any final design. The differences are less straightforward between HZP, where all materials are at $1000 \mathrm{~K}$, and HFP, with temperature distributions corresponding to $540 \mathrm{MW}$ operation. In HFP, the fuel temperature increases to nearly $2800 \mathrm{~K}$ at the outlet, while the moderator temperature ranges from $500 \mathrm{~K}$ at the inlet to $750 \mathrm{~K}$ at the outlet (see Appendix B). While the higher fuel temperature increases Doppler broadening of ${ }^{235} \mathrm{U}$ and ${ }^{238} \mathrm{U}$ resonances, the colder moderator temperature decreases Doppler broadening in zirconium capture resonances. The moderator effect seems to dominate the shift from HZP to HFP, so the overall core reactivity increases slightly. A second effect is that the increased Doppler broadening at HFP is greater towards the bottom of the core. This shifts power up in the HFP case relative to the HZP. As a result, more power is generated near the top axial reflector $(5 \mathrm{~cm} \mathrm{Be})$, which is more effective than the bottom reflector $(1 \mathrm{~cm}$ Inconel). This reduces the leakage in the HFP case, increasing reactivity.

Table 8. Doppler Reactivity Feedback in HALEU Core

\begin{tabular}{|l|c|c|}
\hline \multicolumn{2}{|c|}{ Condition } & keff \\
\hline CZP & $100 \mathrm{~K}$ & 1.00370 \\
\hline HZP & $1000 \mathrm{~K}$ & 0.97575 \\
\hline HFP & $540 \mathrm{MW}$ & 0.99664 \\
\hline
\end{tabular}

Table 9 lists the keff values computed to assess the coolant pressure reactivity feedback effect. For both HZP and CZP, the reactivity decreases as pressure decreases, due to the small moderating effect of the coolant. The difference between the $1 \mathrm{MPa}$ and $0.01 \mathrm{MPa}$ is greater at $\mathrm{CZP}$ compared to HZP, owing to the nearly ten times greater coolant density at CZP.

\section{Table 9. Pressure Reactivity Feedback in HALEU Core}

\begin{tabular}{|l|c|}
\hline \multicolumn{1}{|c|}{ Condition } & \multicolumn{1}{c|}{ keff } \\
\hline HZP 1MPa & 0.97167 \\
\hline HZP 0.01 MPa & 0.96957 \\
\hline HZP void & 0.96932 \\
\hline CZP 1MPa & 1.02125 \\
\hline CZP 0.01 MPa & 0.9996 \\
\hline CZP void & 0.99711 \\
\hline
\end{tabular}

The Doppler and pressure reactivity feedback determinations show that the control drum worth is sufficient to control the reactor for the range of reactivity levels expected due to Doppler and pressure variations. These combined effects can lead to an inherently safe reactor. 


\subsection{Design Summary}

The key performance parameters of the selected HALEU design, evaluated in Phase 4 and Phase 5 analysis, are summarized in Table 10.

Table 10. Summary of HALEU Performance Parameters

\begin{tabular}{|c|c|}
\hline Parameter & Value \\
\hline \multicolumn{2}{|c|}{ Total Reactor Mass } \\
\hline Fuel Loading & $4,133.3 \mathrm{~kg}$ \\
\hline Total Reactor Mass & $372.8 \mathrm{~kg}$ \\
\hline \multicolumn{2}{|l|}{ Thermal-hydraulic } \\
\hline Core radial peaking & 1.58 \\
\hline Core axial peaking & 1.40 \\
\hline Intra-assembly radial peaking & 1.25 \\
\hline Hottest cell power & $6.71 \mathrm{MW}$ \\
\hline \multicolumn{2}{|l|}{ Control drums } \\
\hline Total control drum worth & $7,558 \mathrm{pcm}$ \\
\hline Drums-out excess reactivity & $4,997 \mathrm{pcm}$ \\
\hline Critical drum position & 64.7 degrees \\
\hline \multicolumn{2}{|l|}{ Reactivity Data } \\
\hline BOL-to-Peak Xe Defect & $2,246 \mathrm{pcm}$ \\
\hline Doppler reactivity coefficient & $-3.17 \mathrm{pcm} / \mathrm{K}$ \\
\hline
\end{tabular}




\section{HEU Core Design Description}

The HEU core design was performed according to the process described in Section 3.2 and demonstrated for the HALEU core in Section 4. As the process and findings for the HALEU apply to the HEU core, many of these details are not repeated. Instead, this section focuses on key starting points and decisions for the actual HEU design.

Similar to the HALEU core, the Phase 3 analyses for the HEU core revealed that the number of assembly rings could be reduced from 8 - estimated by the thermal-hydraulic scoping of Phase 2 - to 7. This was due to the use of over-conservative power peaking factors in the Phase 2 analyses as compared to the explicitly analyzed 7-ring core.

\subsection{Design Process}

The first step in the Phase 3 design process was to identify the moderator thickness that results in the desired $\mathrm{H}: \mathrm{U}$ ratio at the initial fuel particle volume fraction of $40 \%$. Figure 26 provides $\mathrm{k}_{\mathrm{inf}}$ as a function of moderator thickness from the Phase 1 scoping calculations described in Section 3.2.1. This is computed for the selected fuel radius $(3.0 \mathrm{~cm})$ and coolant volume fraction $(60 \%)$.

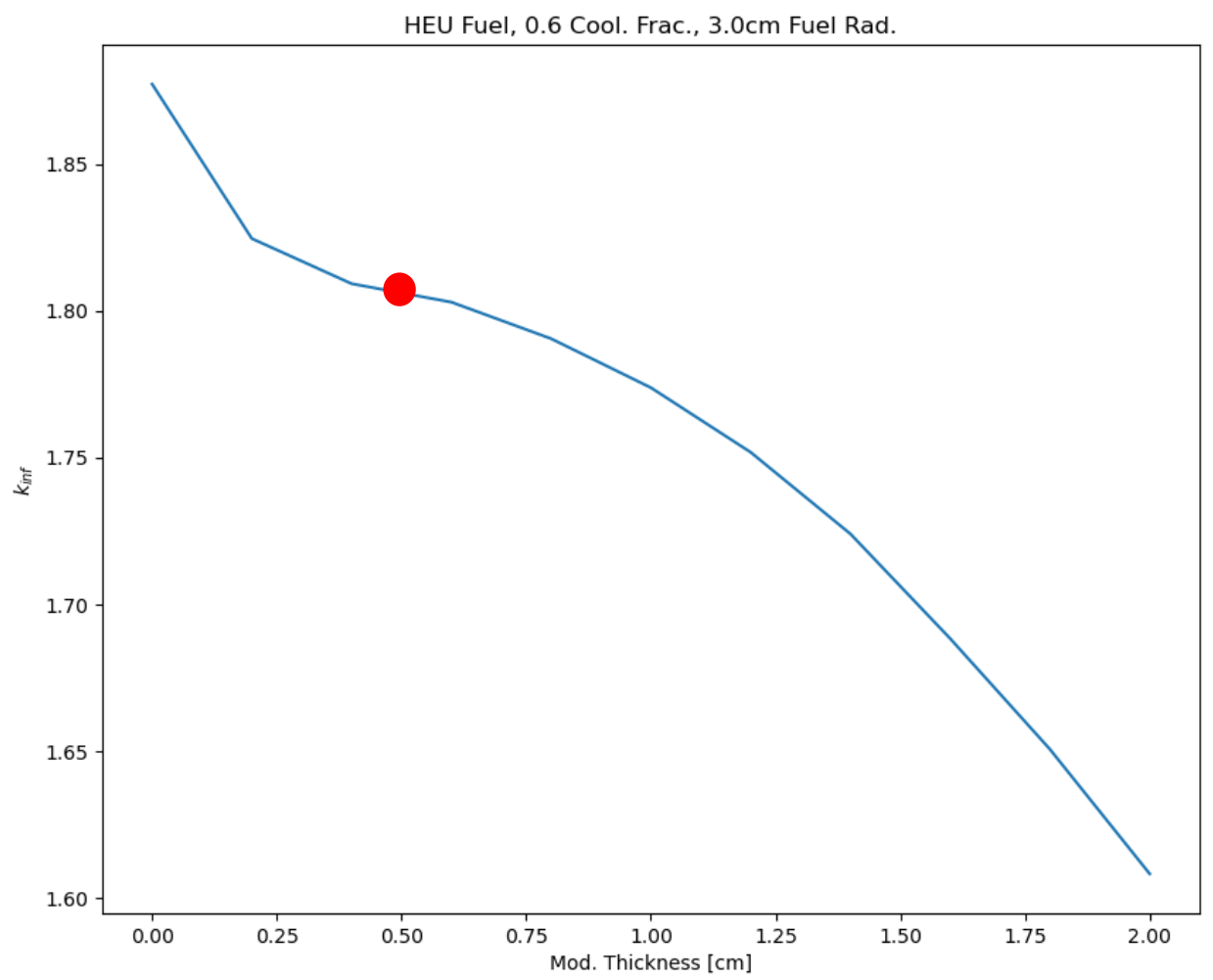

Figure 26. kinf with Moderator Thickness for HEU

This figure shows that the HEU-fueled reactor with the fuel inventory corresponding to the selected fuel assembly radius is sufficient for use in a fast reactor because the $\mathrm{k}_{\text {inf }}$ is maximized when no moderator is present. As the moderator thickness becomes larger than approximately 
$0.3 \mathrm{~cm}$, the typical thermal reactor moderated behavior is observed. As this work is focused on a thermal reactor, the moderator thickness was initially chosen to be $0.5 \mathrm{~cm}$, as shown with the red dot in Figure 26 to yield an $\mathrm{H}: \mathrm{U}$ ratio of around 8 . This value is only slightly under-moderated but is sufficient to make the reactor thermal. The feasibility of a fast reactor is discussed in Section 7.

As described in Section 3.2.3, although the moderator thickness corresponds to a fuel particle volume fraction of $40 \%$, the moderator thickness and fuel particle volume fraction will be reduced along a line of constant $\mathrm{H}: \mathrm{U}$ ratio to produce an unreflected core $\mathrm{k}_{\text {eff }}$ of approximately 0.85. The result of this process was selection of a fuel particle volume fraction of $6 \%$ and a moderator web thickness that is essentially not present; this lattice is shown in Figure 28. Note that this moderator thickness is the minimum feasible with the hexagonal lattice arrangement as discussed in Section 3.2.3. This minimum thickness was reached before the $\mathrm{k}_{\text {eff }}$ was at its target level. After this point, only the fuel particle volume fraction was reduced. This resulted in an increase of the initial $\mathrm{H}: \mathrm{U}$ ratio from 8 to 14 .

This would result in an over-moderated core per the Figure 26 trend; however, two features alleviate this concern:

- The trend in Figure 26 was computed for an infinite core. As leakage is accounted for, the multiplication factor at low moderator thicknesses will decrease and the H:U ratio at which the core becomes over-moderated will increase. Therefore, this core may in fact be under-moderated. This is observed in the calculation of reactivity coefficients, presented later in this section.

- In a realistic application, some of the moderator material will be replaced with structural material. This will further reduce the moderator inventory and further decrease the $\mathrm{H}: \mathrm{U}$ ratio.

With fuel particle volume fraction and moderator thickness determined, the next step was to identify the reflector thickness according to a process similar to that used for the HALEU core. In this case, the final reflector thickness was chosen to be $9 \mathrm{~cm}$, which produced a reflected $\mathrm{k}_{\text {eff }}$ of 1.06670. Although greater than the desired $\mathrm{k}_{\mathrm{eff}}$ of 1.05300 , the extra reactivity was found necessary to accommodate the reactivity reduction caused by the presence of the drums when rotated all out.

The control drum design was performed in the same way as for the HALEU core. In the end, a configuration of 21 drums was selected with each drum containing a $2.5 \mathrm{~cm}$-thick $\mathrm{B}_{4} \mathrm{C}$ absorber layer spanning 100 degrees of the drum. This resulted in an all-drums-out $\mathrm{k}_{\text {eff }}$ of 1.05050 and a total control drum worth of $8,530 \mathrm{pcm}$ when rotated all the way out vs all the way in.

The control drum reactivity worth versus drum angle is shown in Figure 27. This analysis shows that the critical drum position is 69.3 degrees rotated out. 


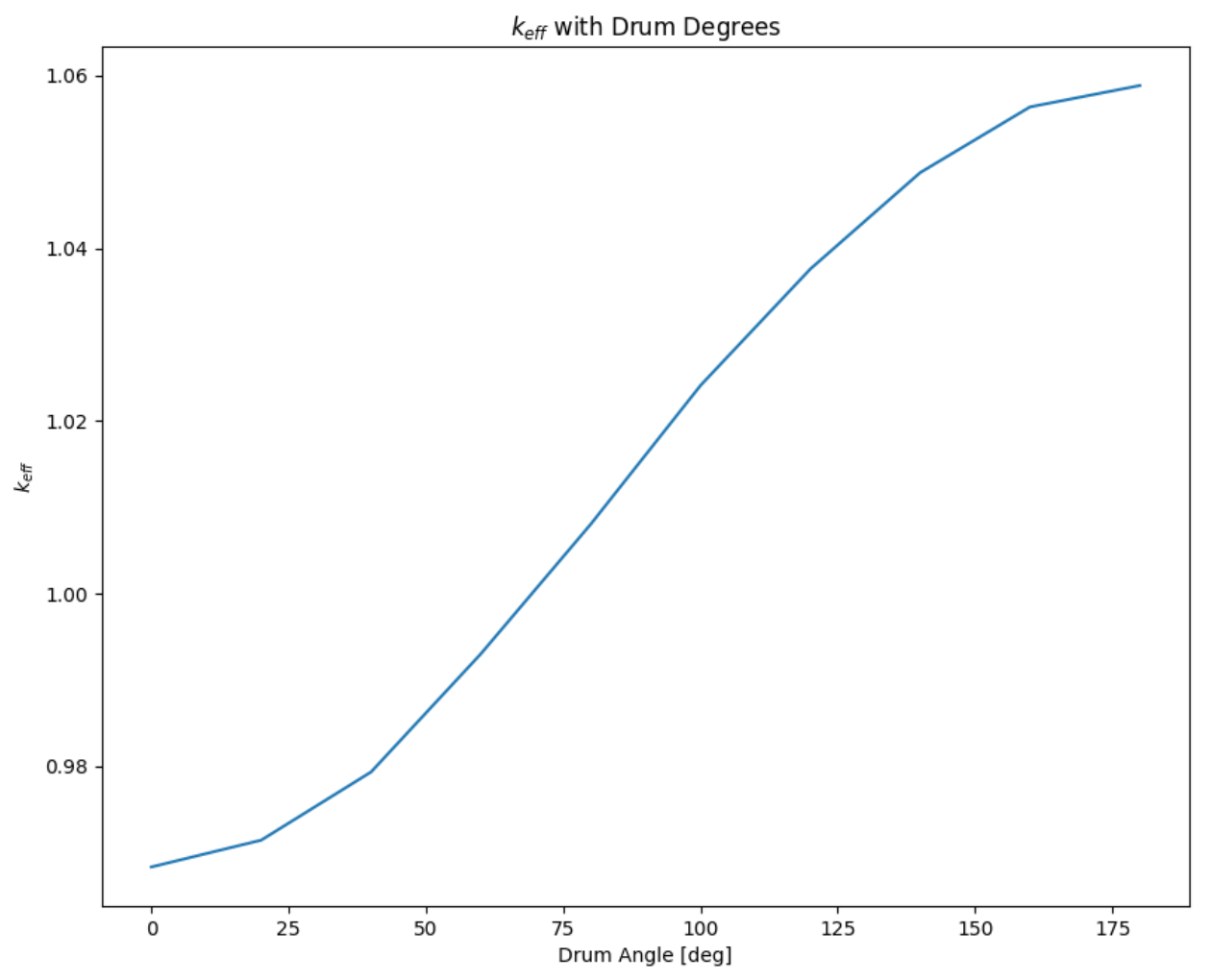

Figure 27. HEU Core Drum Worth

The final parameters to establish are the Phase 4 thermal-hydraulic parameters, as described in Section 3.2.4. The critical drum position was used to compute the core power distribution and the resulting radial and axial peaking profiles and hottest cell power used to perform a thermalhydraulic analysis. As for the HALEU core, this analysis showed that 127 coolant holes are required to satisfy the $2800 \mathrm{~K}$ fuel temperature limit for the hottest assembly.

\subsection{Selected Design}

The final assembly layout is shown in Figure 28, the radial core layout in Figure 29, and the elevation view of the core (through a slice parallel to the x-axis of Figure 29) in Figure 30. In Figure 28, the red material is the CERCER fuel, and the light blue is the coolant channels. Outside the outer coolant channel is the outer coolant gap (part of the second pass coolant), the low-density $\mathrm{ZrC}$ insulator, a second pass coolant channel gap, the $\mathrm{SiC} / \mathrm{SiC}$ insulator, a first pass coolant, and finally the moderator in yellow. 


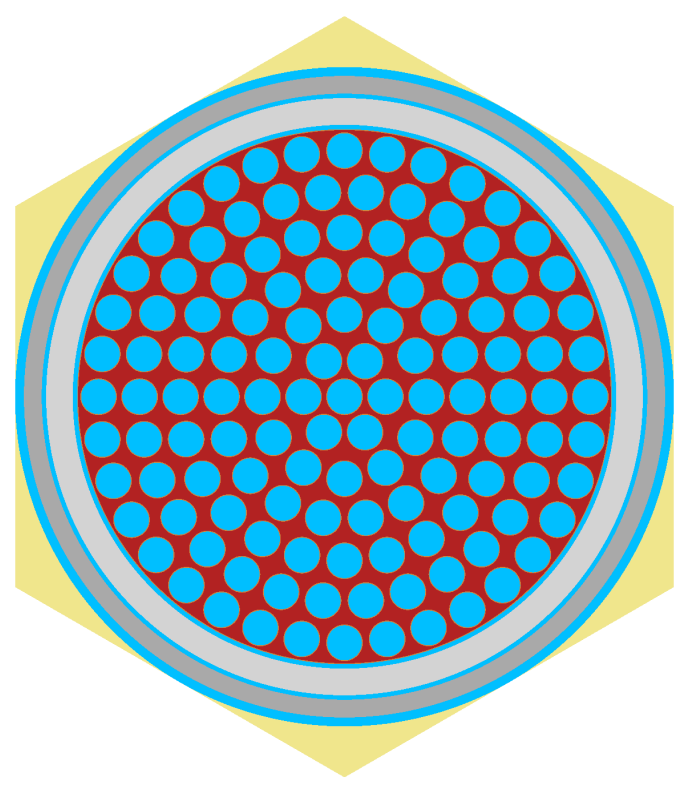

Figure 28. HEU Assembly 


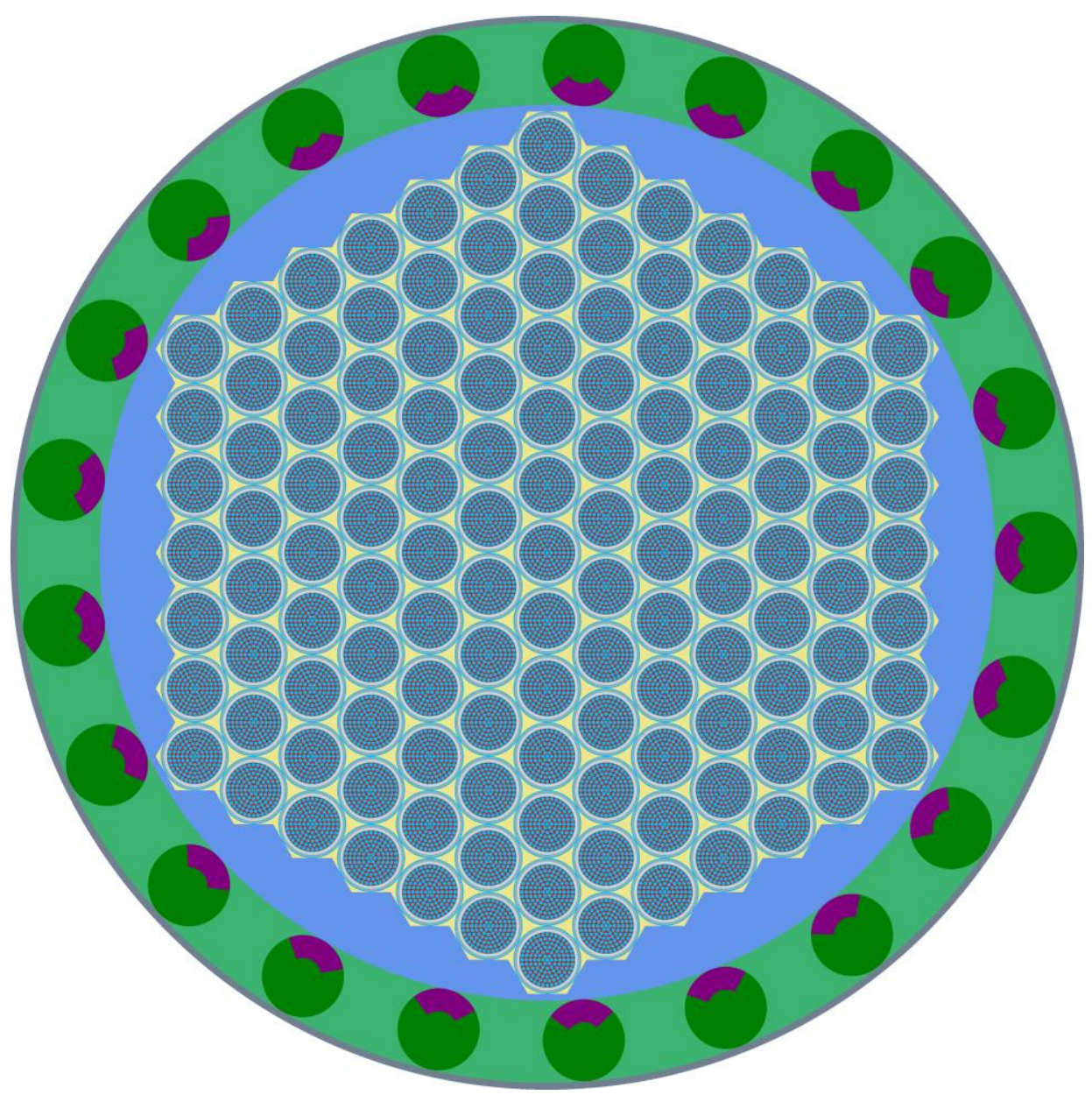

Figure 29. HEU Full-Core Radial View 


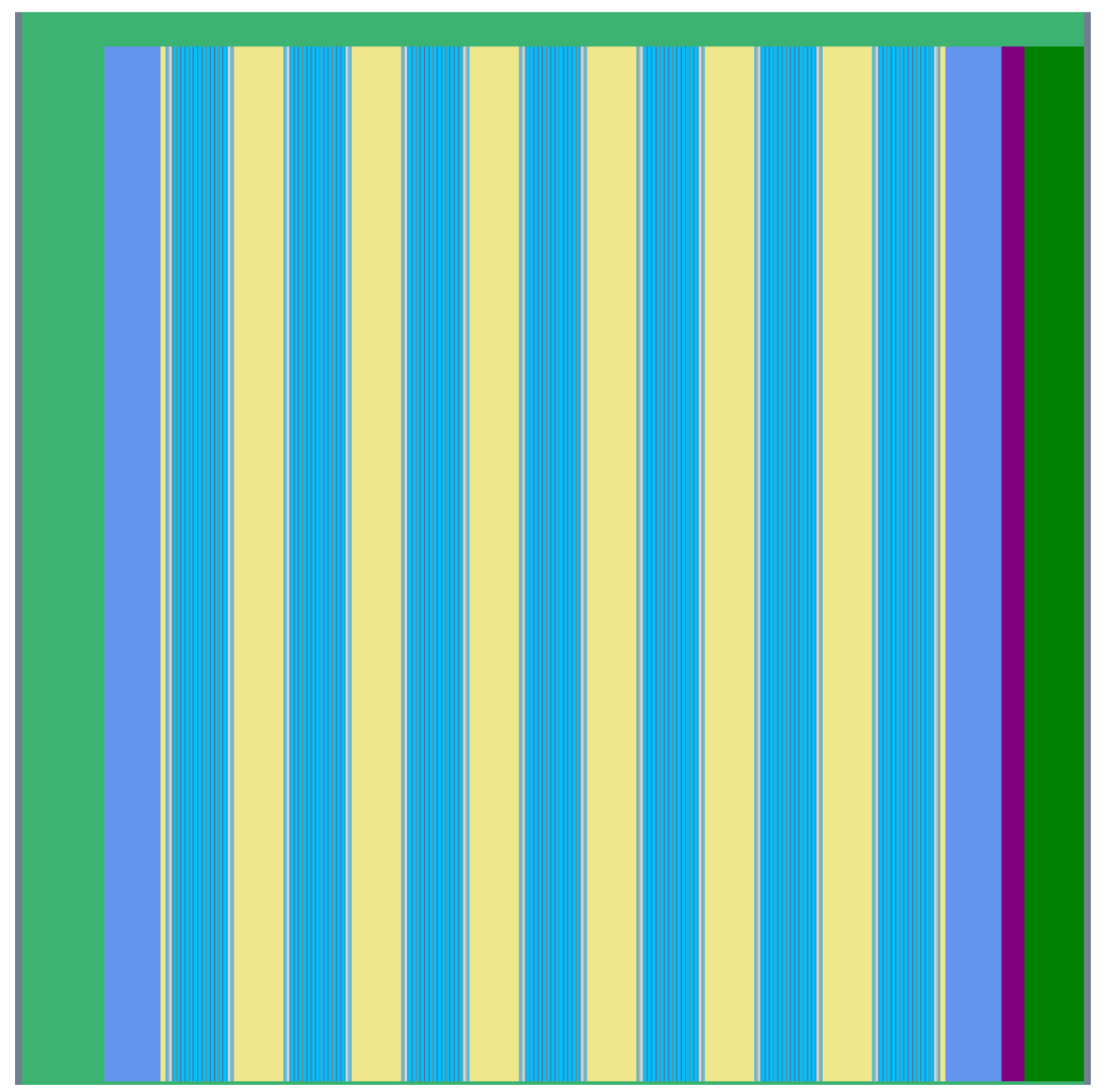

Figure 30. HEU Full-Core Elevation View

The final HEU core design parameters are given in Table 11 and Table 12. 
Table 11. HEU Final Core Characteristics, Part 1

\begin{tabular}{|c|c|c|}
\hline Parameter & Approach & Final Value \\
\hline \multicolumn{3}{|c|}{ Fuel Assembly } \\
\hline Fuel Radius & Free variable & $3.0 \mathrm{~cm}$ \\
\hline Coolant Channel Thickness & Fixed & $0.01 \mathrm{~cm}$ \\
\hline Fuel "clad" thickness & Fixed & $0.01 \mathrm{~cm}$ \\
\hline Fuel "clad" material & Fixed & $\mathrm{ZrC}$ \\
\hline Fuel Cylinder Coolant vol frac & Free variable & 0.6 \\
\hline Number of holes & Free variable & 127 \\
\hline CERCER particle vol frac & $\begin{array}{l}\text { Derived to obtain excess } \\
\text { reactivity }\end{array}$ & 0.06 \\
\hline \multicolumn{3}{|c|}{ Moderator } \\
\hline Moderator web thickness & Free variable & $10^{-4} \mathrm{~cm}$ \\
\hline Insulator Materials & Fixed & $\begin{array}{c}\text { Low-density } \mathrm{ZrC} \text { and } \\
\mathrm{SiC}\end{array}$ \\
\hline Insulator Dimensions & Fixed & $0.2 \mathrm{~cm}$ each \\
\hline Insulator Gap Thicknesses & Fixed & $0.02 \mathrm{~cm}$ each \\
\hline
\end{tabular}

Table 12. HEU Final Core Characteristics, Part 2

\begin{tabular}{|l|c|c|}
\hline \multicolumn{1}{|c|}{ Parameter } & Approach & \multicolumn{1}{c|}{ Final Value } \\
\hline Axial reflector materials & Fixed & Be top, Inconel 718 bottom \\
\hline Axial reflector thicknesses & Fixed & $5 \mathrm{~cm}$ top, $1 \mathrm{~cm}$ bottom \\
\hline Axial reflector cooling fraction & Fixed & $30 \%$ \\
\hline Radial reflector material & Free variable & Be \\
\hline Radial reflector thickness & Derived for reactivity & $9.0 \mathrm{~cm}$ \\
\hline Radial reflector cooling fraction & Fixed & $15 \%$ \\
\hline & Control & \\
\hline Control material & Free variable & B $\mathrm{C}$ \\
\hline Control material thickness & Free variable & $2.5 \mathrm{~cm}$ \\
\hline Control material span & Free variable & $100 \mathrm{degrees}$ \\
\hline Number of drums & Free variable & 21 \\
\hline & Overall & 7 \\
\hline Number of Rings & Free variable & $13.6 \mathrm{~kg} / \mathrm{s}$ \\
\hline Core flow rate & Derived for outlet temp. & $150 \mathrm{~cm}$ \\
\hline Fuel Height & Free variable & $540 \mathrm{MW}$ \\
\hline Power & Fixed & $1 \mathrm{MPa}$ \\
\hline Coolant Inlet Pressure & Fixed & $300 \mathrm{~K}$ \\
\hline Coolant Inlet Temperature & Fixed & $2700 \mathrm{~K}$ \\
\hline Target Outlet Temperature & Fixed & $2800 \mathrm{~K}$ \\
\hline Maximum Fuel Temperature & Fixed & \\
\hline & & \\
\hline
\end{tabular}


The reactor and component masses are provided in Table 13. The total uranium loading is 174.0 $\mathrm{kg}$, with a ${ }^{235} \mathrm{U}$ mass of $161.8 \mathrm{~kg}$. The largest mass component is the fuel material $(1,469.5 \mathrm{~kg})$, however, the uranium is only a minor component $(174.0 \mathrm{~kg})$ and therefore the remainder is the $\mathrm{ZrC}$ that is present simply to reduce the heat generation density.

Table 13. HEU Core Component Masses

\begin{tabular}{|l|r|r|}
\hline Material & Mass [kg] & Relative Mass [\%] \\
\hline Reflector & 772.5 & 20.6 \\
\hline Reactor Vessel & 351.3 & 9.4 \\
\hline ZrC Clad & 218.6 & 5.8 \\
\hline Low-Density ZrC Insulator & 243.2 & 6.5 \\
\hline SiC/SiC Insulator & 226.9 & 6.0 \\
\hline Moderator Block & 450.1 & 12.0 \\
\hline CERCER & $1,469.5$ & 39.1 \\
\hline Control Drum Material & 7.0 & 0.2 \\
\hline Drum Reflector & 15.2 & 0.4 \\
\hline Total & $3,754.2$ & - \\
\hline
\end{tabular}

\subsection{Thermal and Power Profiles}

The intra-assembly radial power profile and axial power profile of the final design are shown in Figure 31 and Figure 32, respectively. This particular analysis was performed assuming fully reflective boundary conditions and thus will have a power distribution representative, but bounding, of the central assembly. In this figure, the color bar to the right shows the assignment of colors to an arbitrarily normalized power distribution. Note that the mesh used in Figure 31 is of higher resolution than in the HALEU equivalent of this figure (Figure 19) and so the color scale cannot be used to directly compare the results for these two enrichments.

The temperature profile for the hottest coolant hole of the peak assembly is shown in Figure 33, and the pressure of the coolant in the channel is shown in Figure 34. In both cases the axial distance shown is from within the fueled region. This axial power profile includes the tally directly from OpenMC and the smoothed power profile that was actually used in the thermal analyses. Note that in these cases it is assumed that flow is metered for these holes such that the flowrate yields an outlet temperature of $2700 \mathrm{~K}$. This is an unrealistic assumption, however it was made for simplicity as it has no bearing on the comparison of performance with enrichment. Future improvement to this design will clearly require additional development here. Finally, the temperature profile shown in Figure 33 includes points where the slope is not smooth; this is driven by points when the entrance-length treatment of the friction factor and Nusselt correlation are turned on and off as described in Appendix C. 
Power Distribution at Plane 1

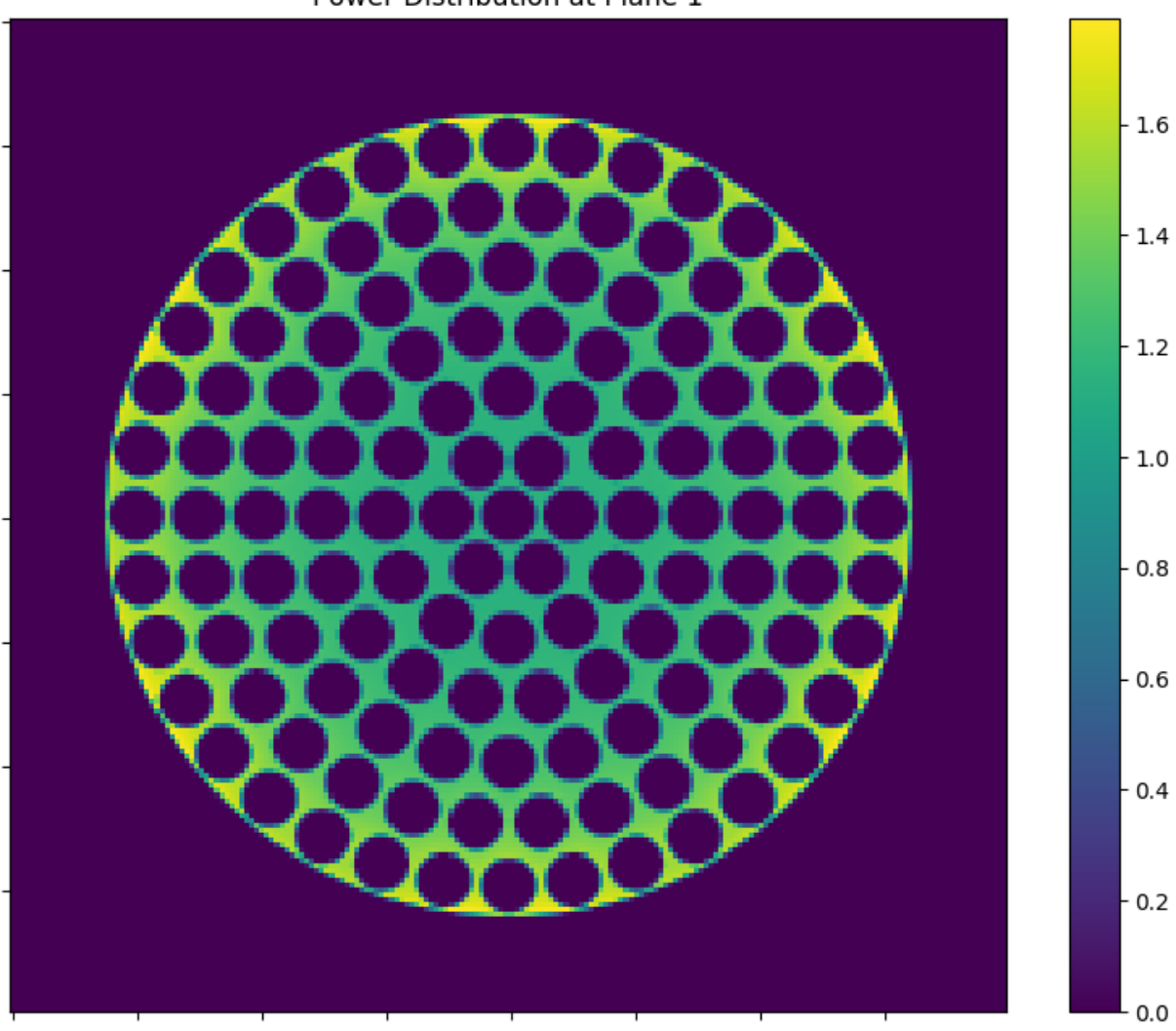

Figure 31. Normalized HEU Intra-Assembly Power Distribution 


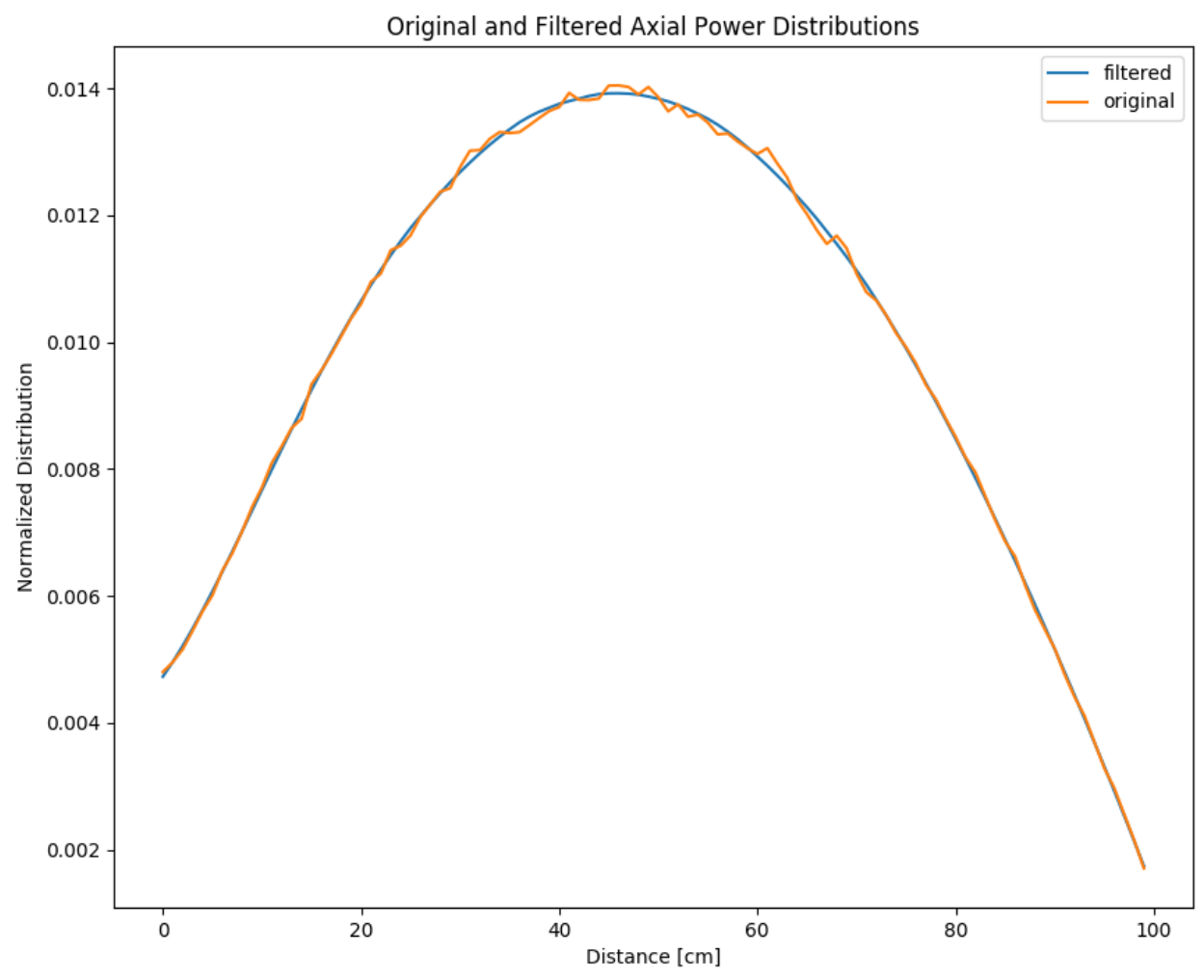

Figure 32. Axial Power Profile Used in Thermal Analysis for HEU Core

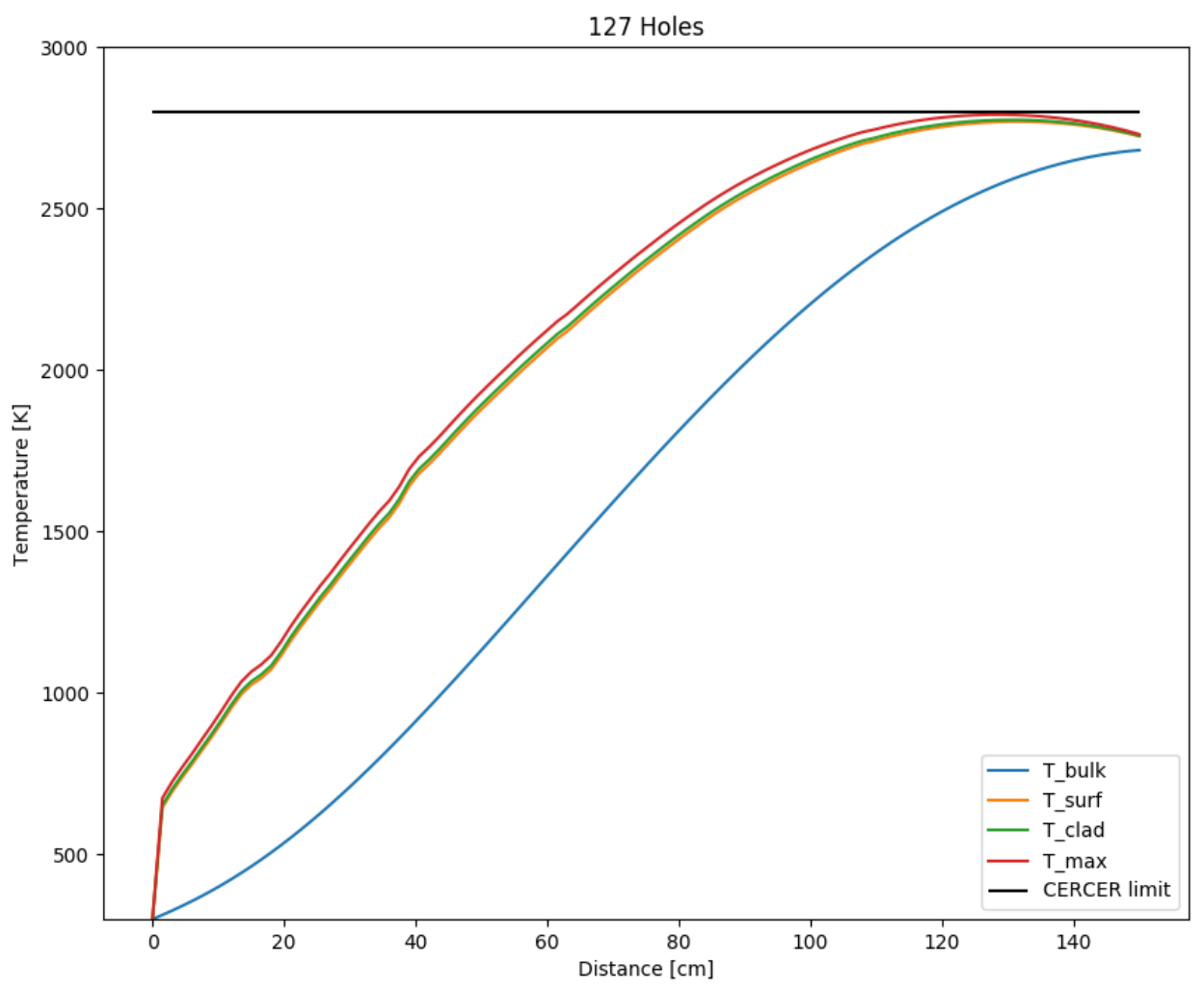

Figure 33. Peak Hole Temperature Axial Profile for HEU Core 


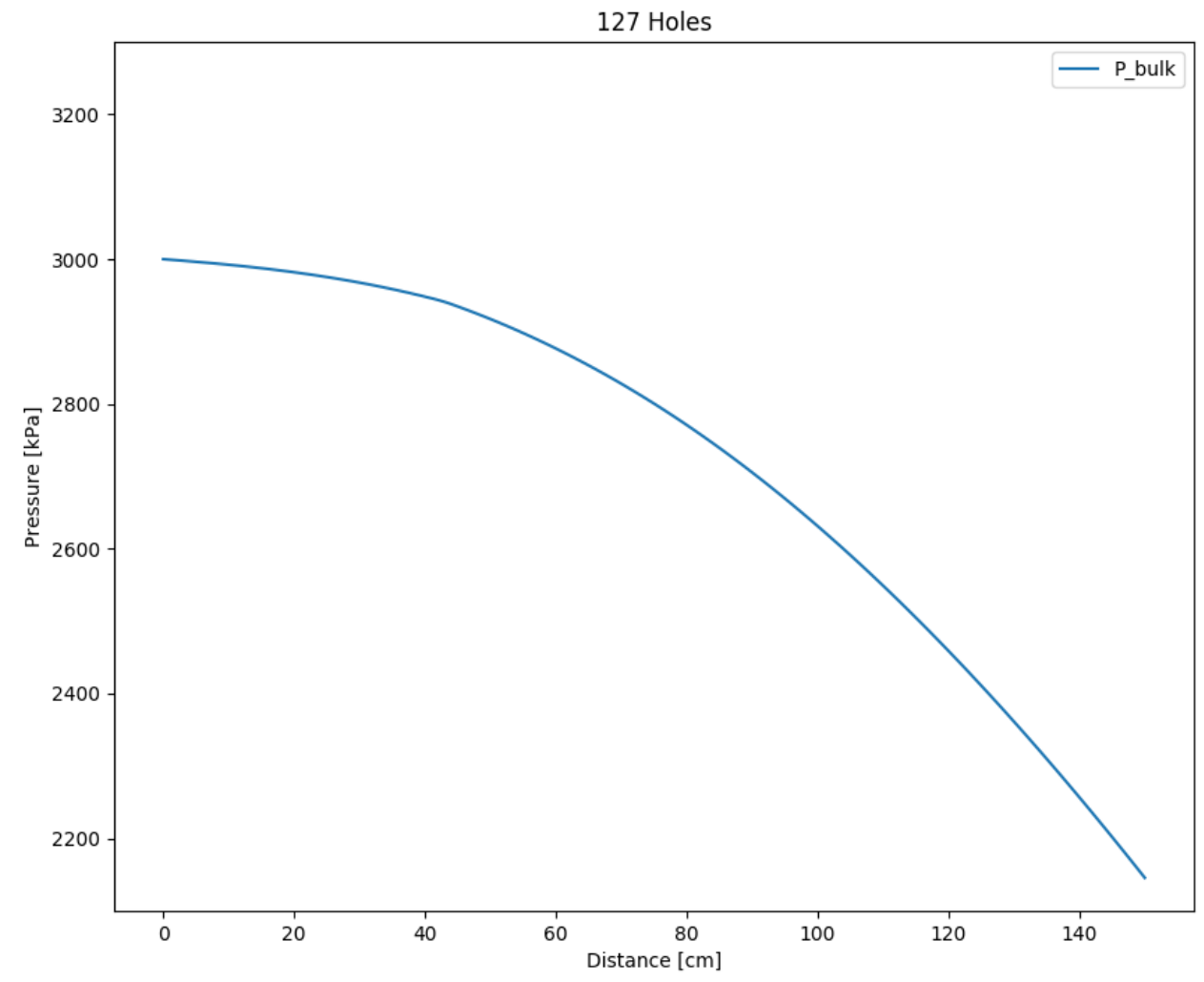

Figure 34. Peak Hole Pressure Axial Profile for HEU Core

The neutron energy spectrum for this HEU reactor for an assembly in each ring is provided in Figure 35. These spectra show that the reactor is indeed thermal and that the variation in the spectra is minimal among rings.

The radial core power distribution is shown in Figure 36. The numerical values in this figure represent the cell power compared to an average cell. This figure shows that the power is as one would expect for a homogenous cylindrical-like reactor. 


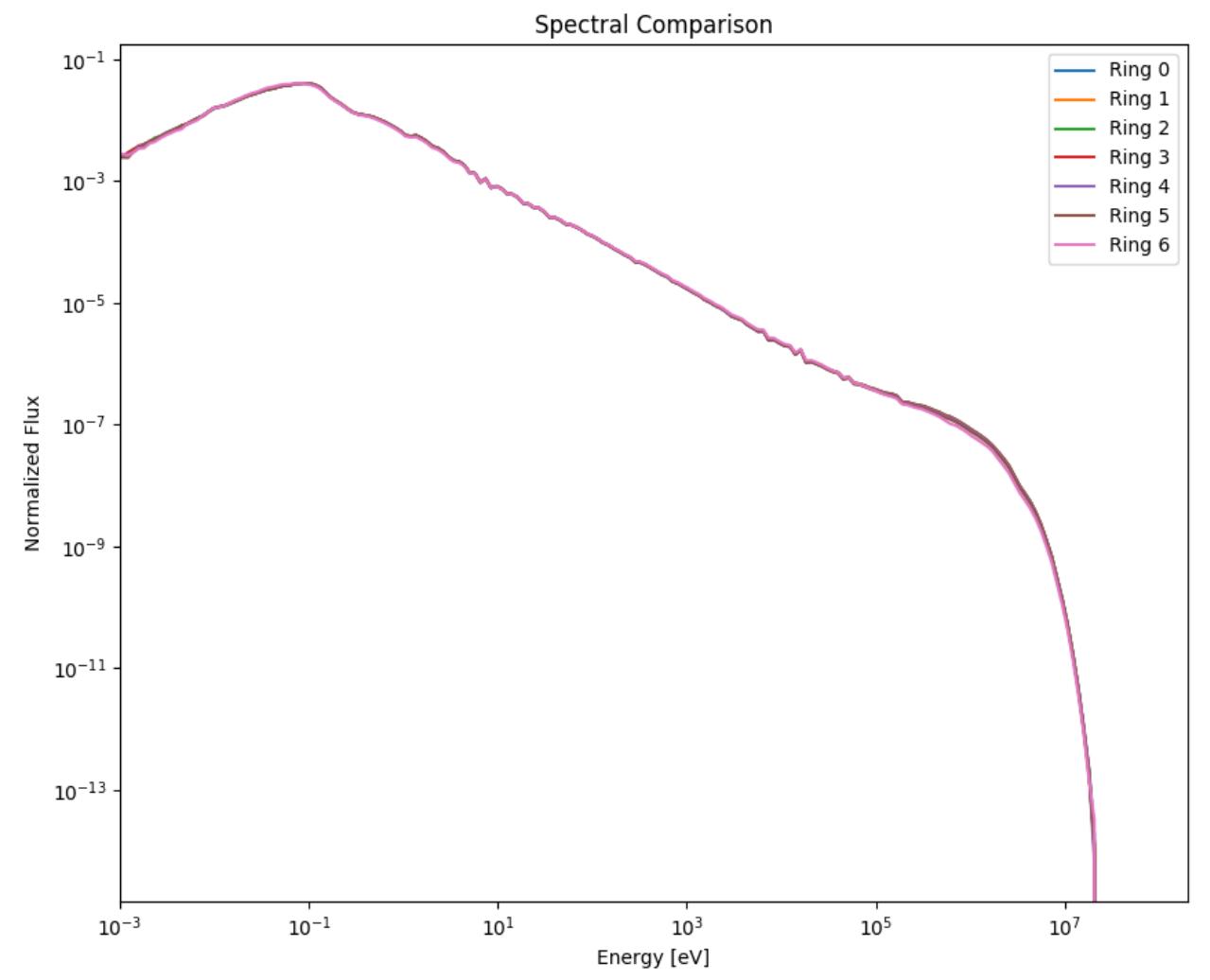

Figure 35. HEU Neutron Energy Spectra 


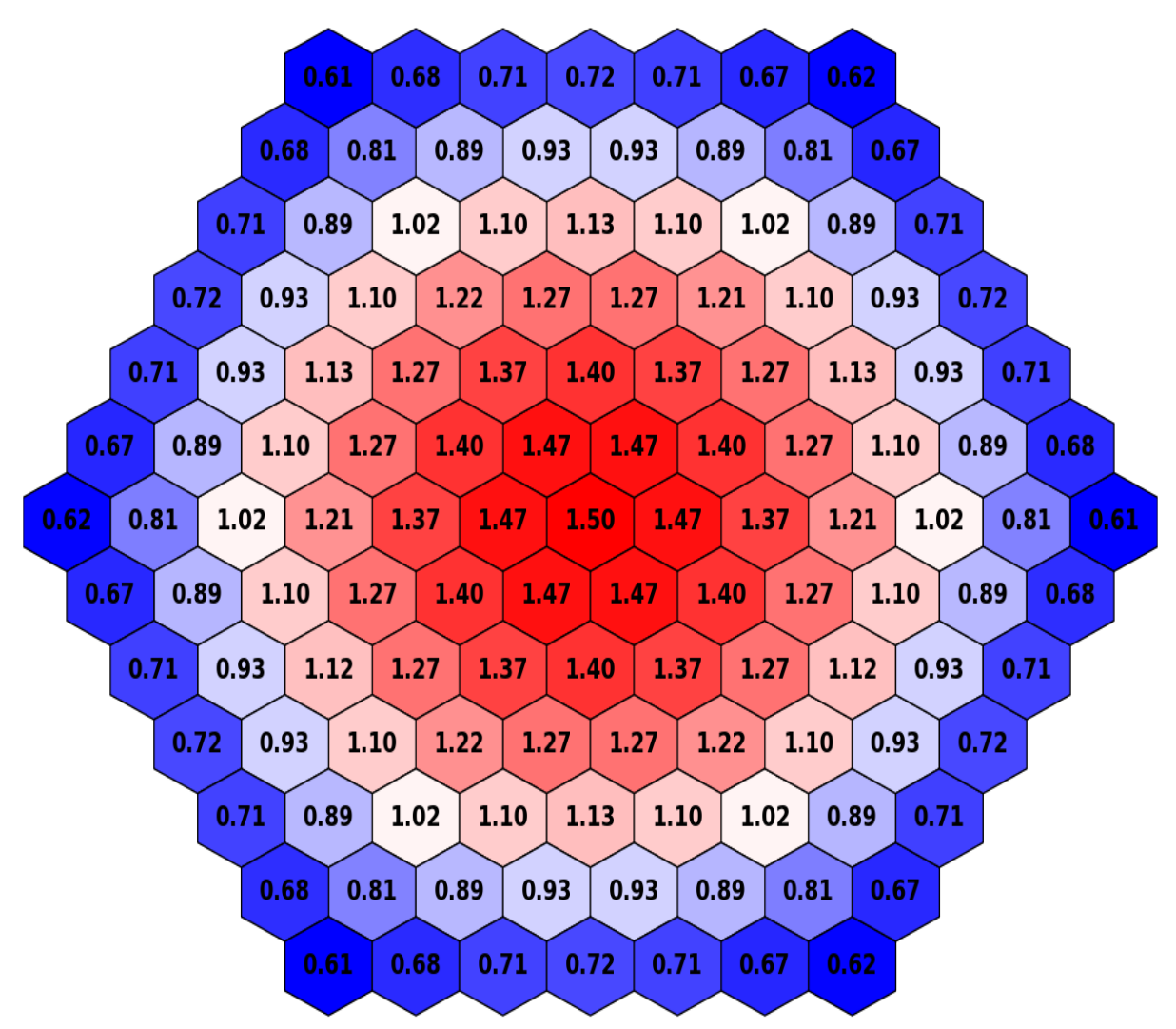

Figure 36. HEU Assembly Power Distribution

\subsection{Depletion Reactivity}

The depletion reactivity and xenon override performance of the final HEU core were evaluated according to the Phase 5 process described in Section 3.2.5. Figure 37 shows the trajectory of $\mathrm{k}_{\text {eff }}$ over the simulated operation and shutdown cycle, where the reactor operates at full power for only 3 hours: from 0 to 2.5 hours, and 52.5 to 53 hours. Note that in this evaluation, the control drums are kept at their BOL critical position to highlight the change in reactivity from BOL. The significant result is that the reactivity difference between BOL and the peak xenon reactivity condition, occurring at 63 hours, is $632 \mathrm{pcm}$. The HEU core's 5,050 pcm excess reactivity is more than enough to overcome this peak xenon worth. This indicates that the Phase 1 excess reactivity estimation, performed on a smaller core, was an over-estimate, likely caused by neutron leakage increasing the sensitivity to burnup in the center of the reactor. 


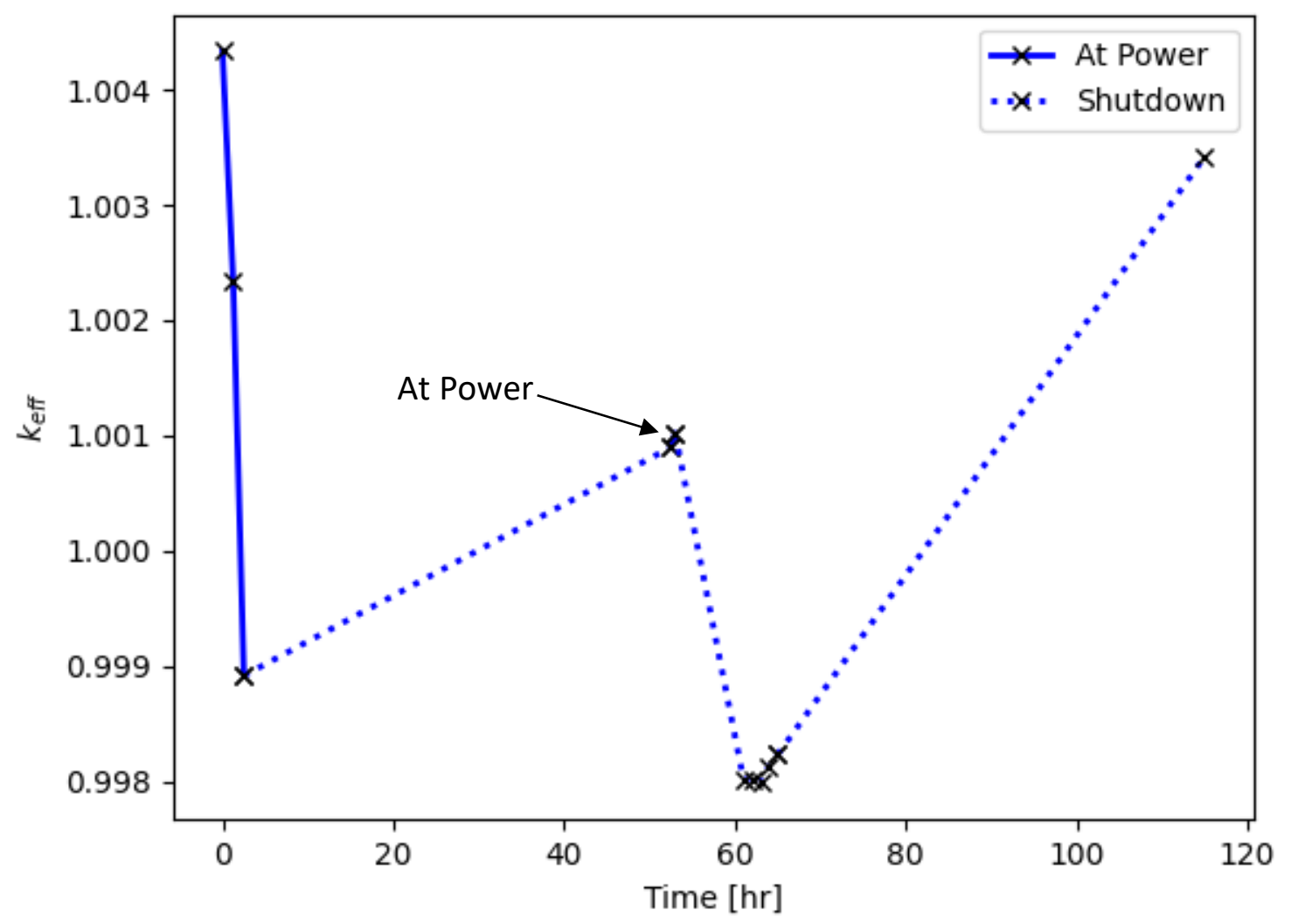

Figure 37. Uncontrolled Core Reactivity during HEU reactor operation and shutdown

The detailed reactivity trajectory over the various stages of reactor operation and shutdown is discussed here, although, like for the HALEU core, these behaviors are of lesser importance at the current design stage and highly subject to the specific power history applied. Reactivity decreases during the first 2.5 hours of operation due to fuel burnup. During the shutdown from 2.5 to 52.5 hours, a xenon peak is expected, but since we were not interested in this known overconservative peak for xenon override as discussed in Section 3.2.5, the evaluation of the peak was skipped in the calculations to significantly reduce the computational expense. The net reactivity at 2.5 and 52.5 hours was determined accurately. The increase in $k_{\text {eff }}$ at 52.5 hours indicates that the HEU core was more sensitive to the ${ }^{135} \mathrm{~J} /{ }^{135} \mathrm{Xe}$ chain than the HALEU core; due to differences in spectrum between the HEU and HALEU cores, ${ }^{149} \mathrm{Pm}$ is accumulating at a slower rate. During the final 30 minutes of operation, the reactivity increases slightly as the minimal ${ }^{149} \mathrm{Pm}$ and ${ }^{149} \mathrm{Sm}$ present in the core are burnt out. In the period from 53 to 115 hours, reactivity initially decreases due to xenon buildup, but as xenon decays away, reactivity eventually increases to a higher value than the final operational reactivity. Note that no core reactivity evaluations were performed between the peak reactivity just after 60 hours and the final data point at 115 hours, the behavior in this region will roughly follow the radioactive decay of the ${ }^{135} \mathrm{Xe}$. This reactivity trajectory is specific to the assumed power history, and the accumulation of fission products will depend on actual operating conditions. 


\subsection{Reactivity Coefficients}

Table 14 lists the $\mathrm{k}_{\text {eff }}$ values computed at CZP, HZP, and HFP (with the temperatures of each discussed in Section 3.2.5) to assess the Doppler reactivity feedback effect. These results have uncertainties of $3 \mathrm{pcm}$ to the 2-sigma level. From the uniform temperature difference between $\mathrm{CZP}$ and HZP, an overall Doppler reactivity coefficient of $-1.20 \mathrm{pcm} / \mathrm{K}$ is calculated. Note that this coefficient is stated as linear, however it will not vary linearly across the entire temperature range of interest; this should be evaluated further for any final design. Between HZP and HFP, the differences are driven by the same phenomena discussed for the HALEU core: zirconium resonance absorption differences and a shift in the axial power distribution, which affects leakage.

Table 14. Doppler Reactivity Feedback in HEU Core

\begin{tabular}{|l|c|c|}
\hline \multicolumn{2}{|c|}{ Condition } & keff \\
\hline CZP & $100 \mathrm{~K}$ & 1.00158 \\
\hline HZP & $1000 \mathrm{~K}$ & 0.99083 \\
\hline HFP & $540 \mathrm{MW}$ & 0.99763 \\
\hline
\end{tabular}

Table 15 lists the $\mathrm{k}_{\text {eff }}$ values computed to assess the coolant pressure reactivity feedback effect. For both HZP and CZP, $\mathrm{k}_{\text {eff }}$ decreases as pressure decreases, due to the small moderating effect of the coolant. The difference between the $1 \mathrm{MPa}$ and $0.1 \mathrm{MPa}$ is greater at CZP compared to $\mathrm{HZP}$, owing to the nearly ten times greater coolant density at CZP.

Table 15. Pressure Reactivity Feedback in HEU Core

\begin{tabular}{|l|l|}
\multicolumn{1}{|c|}{ Condition } & \multicolumn{1}{c|}{ keff } \\
\hline HZP 1MPa & 0.98509 \\
\hline HZP 0.1MPa & 0.98207 \\
\hline HZP void & 0.98169 \\
\hline CZP 1MPa & 1.02596 \\
\hline CZP 0.1MPa & 0.99582 \\
\hline CZP void & 0.99230 \\
\hline
\end{tabular}

The Doppler and pressure reactivity feedback calculations show that the control drum worth is sufficient to control the reactor for the range of reactivities expected due to Doppler and pressure variations. These combined effects can lead to an inherently safe reactor. 


\subsection{Design Summary}

The key performance parameters of the final HEU design, evaluated in Phase 4 and Phase 5 analysis, are summarized in Table 16.

Table 16. Summary of HEU Performance Parameters

\begin{tabular}{|l|c|}
\hline \multicolumn{1}{|c|}{ Marameter } & Value \\
\hline \multicolumn{2}{|c|}{ Thermal-hydraulic } \\
Total Reactor Mass & $3,754.2 \mathrm{~kg}$ \\
\hline Fuel Loading & $174.0 \mathrm{~kg}$ \\
\hline \multicolumn{2}{|c|}{ Control drums } \\
\hline Core radial peaking & 1.50 \\
\hline Core axial peaking & 1.38 \\
\hline Intra-assembly radial peaking & $6.38 \mathrm{MW}$ \\
\hline Hottest cell power & $8,530 \mathrm{pcm}$ \\
\hline \multicolumn{2}{|c|}{ Reactivity Data } \\
\hline Total control drum worth \\
\hline Drums-out excess reactivity & $5,050 \mathrm{pcm}$ \\
\hline Critical drum position & $69.3 \mathrm{degrees}$ \\
\hline \multicolumn{2}{|c|}{$632 \mathrm{pcm}$} \\
\hline BOL-to-Peak Xe Defect & $-1.20 \mathrm{pcm} / \mathrm{K}$ \\
\hline Doppler reactivity coefficient
\end{tabular}




\section{Effects of HEU to HALEU Change}

The HALEU and HEU designs presented in Sections 4 and 5, respectively, approached feasibility but were not fully optimized. The impetus for this work is to identify the tradeoffs to the core design when the fuel enrichment is increased from HALEU to HEU. This section will compare the core designs discussed previously to identify these tradeoffs.

As stated in Section 2 the most important tradeoffs, based on first principles alone, are expected to relate to the total mass and the Doppler feedback reactivity coefficient. The mass difference between the HALEU and HEU cores was expected to be significantly less than it might be in other reactor applications as the NTP reactor is very power dense. The Doppler reactivity coefficient was expected to be less for the HEU core than the HALEU core due to the presence of additional ${ }^{238} \mathrm{U}$ in the HALEU core and its important resonances that can be Doppler broadened. These expectations are confirmed when comparing the cores as designed in this work. Table 17 and Table 18 provide a comparison of core masses and general reactor parameters, respectively. The remainder of this section will discuss the important differences observed in these tables, their sources, and implications.

In Table 17, the most important difference in the mass is that the HALEU core is approximately $9 \%$ heavier $(379.1 \mathrm{~kg})$ than the HEU core. This is driven primarily by the differences in the moderator block mass $(245.1 \mathrm{~kg}$ difference) and the fuel loading $(198.8 \mathrm{~kg}$ ). The moderator block is lighter for the HEU core because significantly less moderator is necessary to yield a maximized $k_{\text {eff. }}$ In fact, Section 5.1 hints at how the HEU core could potentially be designed with no moderator. This is discussed further in Section 7.2.

Table 17. HALEU vs HEU Mass Comparison

\begin{tabular}{|l|c|c|c|}
\hline \multicolumn{1}{|c|}{ Material } & HALEU [kg] & HEU [kg] & HALEU - HEU [kg] \\
\hline Reflector & 792.9 & 772.5 & 20.4 \\
\hline Reactor Vessel & 358.7 & 351.3 & 7.4 \\
\hline ZrC Clad & 218.6 & 218.6 & 0.0 \\
\hline Low-Density ZrC Insulator & 243.2 & 243.2 & 0.0 \\
\hline SiC/SiC Insulator & 226.9 & 226.9 & 0.0 \\
\hline Moderator Block & 695.3 & 450.1 & 245.1 \\
\hline CERCER & $1,576.4$ & $1,469.5$ & 107.0 \\
\hline Control Drum Material & 4.9 & 7.0 & -2.2 \\
\hline Drum Reflector & 16.5 & 15.2 & 1.3 \\
\hline Total & $4,133.3$ & $3,754.2$ & 379.1 \\
\hline Uranium Loading & 372.8 & 174.0 & 198.8 \\
\hline 235U Loading & 73.6 & 161.8 & -89.1 \\
\hline
\end{tabular}

The CERCER mass difference is driven by the change in uranium loading. The total uranium loading is provided in the table where it is clear that the change in uranium loading between HALEU and HEU cases is only approximately $2.1 \mathrm{x}$. This is driven by significant fast fissions in these reactors because of the highly heterogenous fuel and moderator configuration and a slight offset due to the change in absorptions in zirconium in the CERCER's ZrC. 
These findings also show that the ${ }^{235} \mathrm{U}$ loading is lower in the HALEU core than the HEU core. This result is also driven by the significant fast fission rates in these cores. Specifically, $8 \%$ of the neutron losses in the HALEU core lead to ${ }^{238} \mathrm{U}$ fission where as that value for the HEU core is only $1 \%$. The HALEU core's high ${ }^{238} \mathrm{U}$ fission rate therefore reduces the amount of ${ }^{235} \mathrm{U}$ required to achieve the desired reactivity.

Table 18 shows that the thermal-hydraulically driven parameters-including the fuel radius, coolant volume fraction, coolant holes, fuel height, number of rings, and the peaking parameters - are nearly equivalent for both the HALEU and HEU cores. This is because the reactor power peaking values are similar, and therefore the total fuel and coolant volumes are consistent as the core size needed for adequate heat generation and heat transfer is the same.

While the power peaking values are similar enough to warrant the same fuel-volume-based parameters, the HEU core peak assembly power is 5\% lower than that of the HALEU core. This is driven primarily by the smaller uranium fuel particle volume fraction of the HEU core, which in turn results in a lower optical thickness. This lower optical thickness allows for more leakage. Counterintuitivaly, this actually reduces the power peaking because the beryllium reflector is so effective that an increase in leakage leads to a reduction in power peaking; more neutrons can be utilized at the core periphery, flattening the radial power distribution.

Table 18. HALEU vs HEU Reactor Parameter Comparison

\begin{tabular}{|l|c|c|}
\hline & HALEU & HEU \\
\hline Fuel radius (cm) & 3.0 & 3.0 \\
\hline Coolant volume fraction & $60 \%$ & $60 \%$ \\
\hline Fuel particle volume fraction & $13 \%$ & $6 \%$ \\
\hline Coolant Holes per Assembly & 127 & 127 \\
\hline Fuel height (cm) & 150 & 150 \\
\hline Moderator thickness (cm) & 0.093 & $10^{-4}$ \\
\hline Number of rings & 7 & 7 \\
\hline Reflector thickness (cm) & 9 & 9 \\
\hline Number of drums & 21 & 21 \\
\hline Control material & $\mathrm{B} 4 \mathrm{C}$ & $\mathrm{B} 4 \mathrm{C}$ \\
\hline Control material span (degrees) & 100 & 100 \\
\hline Control material thickness (cm) & 1.5 & 2.5 \\
\hline Control drum worth (pcm) & 7,558 & 8,530 \\
\hline Drums-out keff & 1.04997 & 1.05050 \\
\hline Critical drum position (degrees) & 64.7 & 69.3 \\
\hline Core radial peaking & 1.579 & 1.500 \\
\hline Core axial peaking & 1.397 & 1.384 \\
\hline Intra-assembly radial peaking & 1.25 & 1.20 \\
\hline Hottest cell power (MW) & 6.71 & 6.38 \\
\hline BOL-to-Peak Xe Defect (pcm) & 2,246 & 632 \\
\hline Doppler react. coeff. (pcm/K) & -3.17 & -1.20 \\
\hline
\end{tabular}

The reflector and control drum parameters are similar, though the control material thickness is different between the two core designs. These differences are driven by the slight differences in 
the leakage between the designs. The neutron mean free path is larger in the HEU core due to the reduced moderator inentory and because the total uranium loading is smaller. This larger mean free path results in a higher leakage rate than in the HALEU core. Further, the neutron energy spectra of neutrons entering the reflector region from the core will also be different between designs. These factors lead to slight differences in control drum designs.

The drums-out $\mathrm{k}_{\text {eff }}$ is the same between the two cores. This is by design, as the fuel particle volume fraction, reflector thickness, and drum parameters were chosen specifically to obtain a drums-out $\mathrm{k}_{\mathrm{eff}}$ of approximately that value.

As noted in Sections 4.4 and 5.4, the BOL-to-peak xenon reactivity defect will be highly dependent on the power history of interest. However, the difference in depletion reactivity is large, with the HEU core depleting less than the HALEU core which is consistent with the HEU core's higher ${ }^{235} \mathrm{U}$ loading. It is possible that differences in the neutron energy spectrum impact the spatial self-shielding effect in the outer edge of the fuel cylinder. Further investigation is required to fully understand this difference-additional design iterations based on this result further reduce the mass of the HEU core (on the order of tens of kilograms).

Finally, the Doppler reactivity coefficient for the HEU core is approximately $38 \%$ less negative than for the HALEU core. This number primarily reflects the differences in the amount of ${ }^{238} \mathrm{U}$ in the cores.

A key advantage of the more negative Doppler coefficient in the HALEU core is a rapidly responding negative reactivity feedback effect that can be used to: simplify the reactor startup procedure, reduce the reliance on instrumentation and control systems, and/or to provide additional reactor safety during operational transients. Therefore, the HALEU reactor can be expected to be safer and more self-regulating than the HEU core due to this larger negative feedback. The sufficiency of the Doppler feedback coefficient for the HEU core will need to be analyzed further by representative transient analyses.

However, a disadvantage of a more negative Doppler coefficient is the possible additional control drum worth required to ensure the reactor is shutdown at cold conditions. This would result in a final reactor design with more control drums and/or a larger radial reflector thickness. Therefore, the smaller Doppler coefficient of the HEU core could be used in subsequent analyses to reduce the radial reflector thickness and reduce mass. This was not taken advantage of in this work as this is generally the focus of later design phases.

The advantages and disadvantages of this increased Doppler feedback will need to be evaluated further, however, generally speaking the HALEU core's enhanced rapidly responding reactivity feedback is a desirable feature of a reactor. 


\section{Anticipated Design Opportunities}

The HALEU and HEU-fueled reactors described in the previous sections are the result of a rapid design process with a baseline CERCER-fueled and $\mathrm{ZrH}$-moderated concept. This section will summarize potential improvements that can be made to the designs as presented (Section 7.1) and discuss other design concepts, which may provide some benefit in terms of a more refined design or an increased chance of overall program success (Section 7.2).

The subsections that follow do not explicitly discuss how these changes may affect conclusions regarding the impact of enrichment on reactor mass and performance. For these effects, the discussion of Section 2 is considered applicable: as the heat generation volume approaches the volume required for reactivity, the differences due to enrichment choice increase.

\subsection{Improvements to the Moderated CERCER Design}

This section discusses improvements that can be made to the moderated CERCER-fueled design, either by refining the design or with slight perturbations to the design baseline.

\subsubsection{Power Shaping}

The design process detailed in Section 3.2 is consistent with that employed for other preconceptual reactor designs. As such, there are conservatisms present that will produce a working, but over-sized, reactor design. The primary source of conservatism is the lack of any power shaping. This subsection introduces the concepts of local and regional power shaping and describes how they might be leveraged to improve the reactor design.

At a high level, power shaping is useful for reducing the peak fuel temperature for the same overall core power. In the case of NTP this would be used to either increase the core power and thus the rocket performance, or the reactor size could be made smaller, improving the thrust-toweight ratio. Power shaping is also useful for reducing differences in the coolant outlet temperature which allows for a simpler and potentially lighter manifold or orifice.

Local power shaping is a design technique that modifies the power distribution within an assembly to reduce intra-assembly power peaking, providing additional thermal margin. For example, the left side of Figure 38 shows the intra-assembly power peaking from the HEU core. The right side of Figure 38 shows the thermal-to-total flux ratio. These plots show that power is peaked towards the outer edges of the fuel cylinder as this is closer to the thermal neutron source (the moderator). As an aside, Appendix B states that the power peaking in the homogenously mixed fuel considered in this work is expected to be under-predicted relative to a model that includes the fuel particles explicitly, which would feature increased self-shielding. This effect has not been evaluated further. 

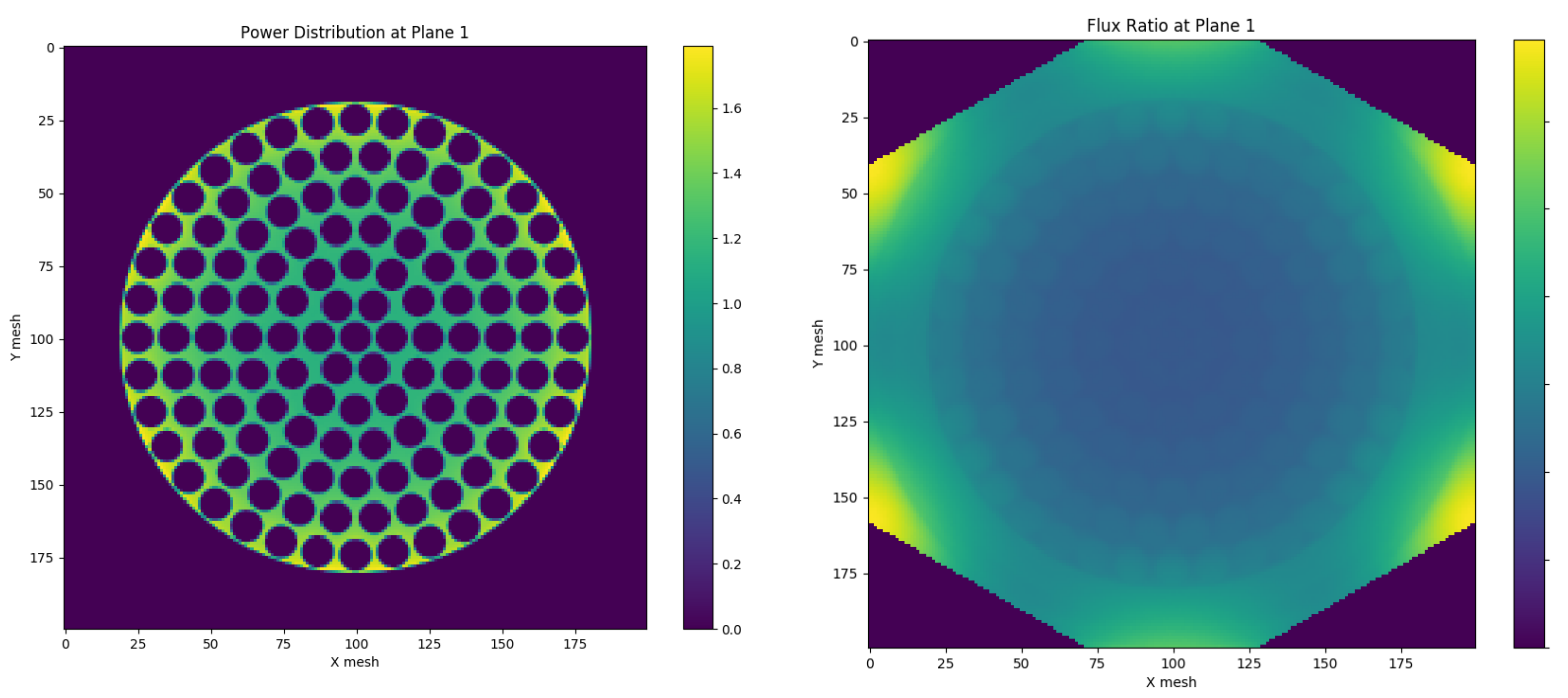

\section{Figure 38. Example Intra-Assembly Power Peaking (Left) and Thermal-to-Total Flux Ratio (Right)}

Power peaking reductions can be used to reduce the number of coolant channels, which will improve manufacturability. Additionally, it may be possible to reduce the fuel cylinder radius and/or height, which also improves manufacturability and reduces core volume and mass. Some improvements that can be investigated to improve this local peaking are:

- Application of Fuel Loading Gradients: Since the fuel concept in this core involves UN fuel particles within a $\mathrm{ZrC}$ matrix, it may be possible to manufacture the cylindrical CERCER block with a reduced fuel particle density near the cylinder edge. This strategy will increase the thermal neutron mean-free-path, allowing the neutrons to travel further into the fuel cylinder to spread power production. This approach would incur significant changes to any fuel manufacturing techniques developed and qualified to date. Therefore, adopting this change would require additional fuel manufacturing development and pilot production runs for qualification. This will be a costly endeavor and the benefit of a loading gradient should be investigated before any changes to the fuel production are pursued.

- Optimization of Coolant Channel Dimensions and Positioning: The power distribution shown in the left side of Figure 38 is skewed to the outer edges of the assembly. This implies that the coolant hole placement and their sizes can be optimized. This should be the future of any further work in such a design concept to better locate the cooling near the heat.

- Investigation of Non-Cylindrical Geometries: A geometry exists that optimizes both the local coolant, moderator, and fuel surface areas and volumes to maximize the reactivity while minimizing reactor mass or volume. Given the self-shielding that leads to the power distribution of the left side of Figure 38 is non-optimal, it is likely that the cylindrical geometry under consideration here is not that optimum. One challenge for such designs is that the moderator melting temperature is significantly lower than the fuel melting temperature. Pursuing this approach would require an increase in insulator mass 
and additional cooling by first-pass coolant. Further investigation may be warranted to evaluate the benefits and drawbacks of such alternative geometries.

Whereas local power shaping affects the power within an assembly, regional power shaping aims to shift the power distribution on a core-wide basis using fuel and/or poison to gain thermal margin. An example radial power peaking from the HEU core is shown below in Figure 39. As discussed in Sections 4 and 5, no regional power shaping was pursued for this work but should be investigated in a more mature reactor design. The benefit is a reduction in the peak assembly powers and linear heat generation rates to allow for a smaller core design as discussed earlier.

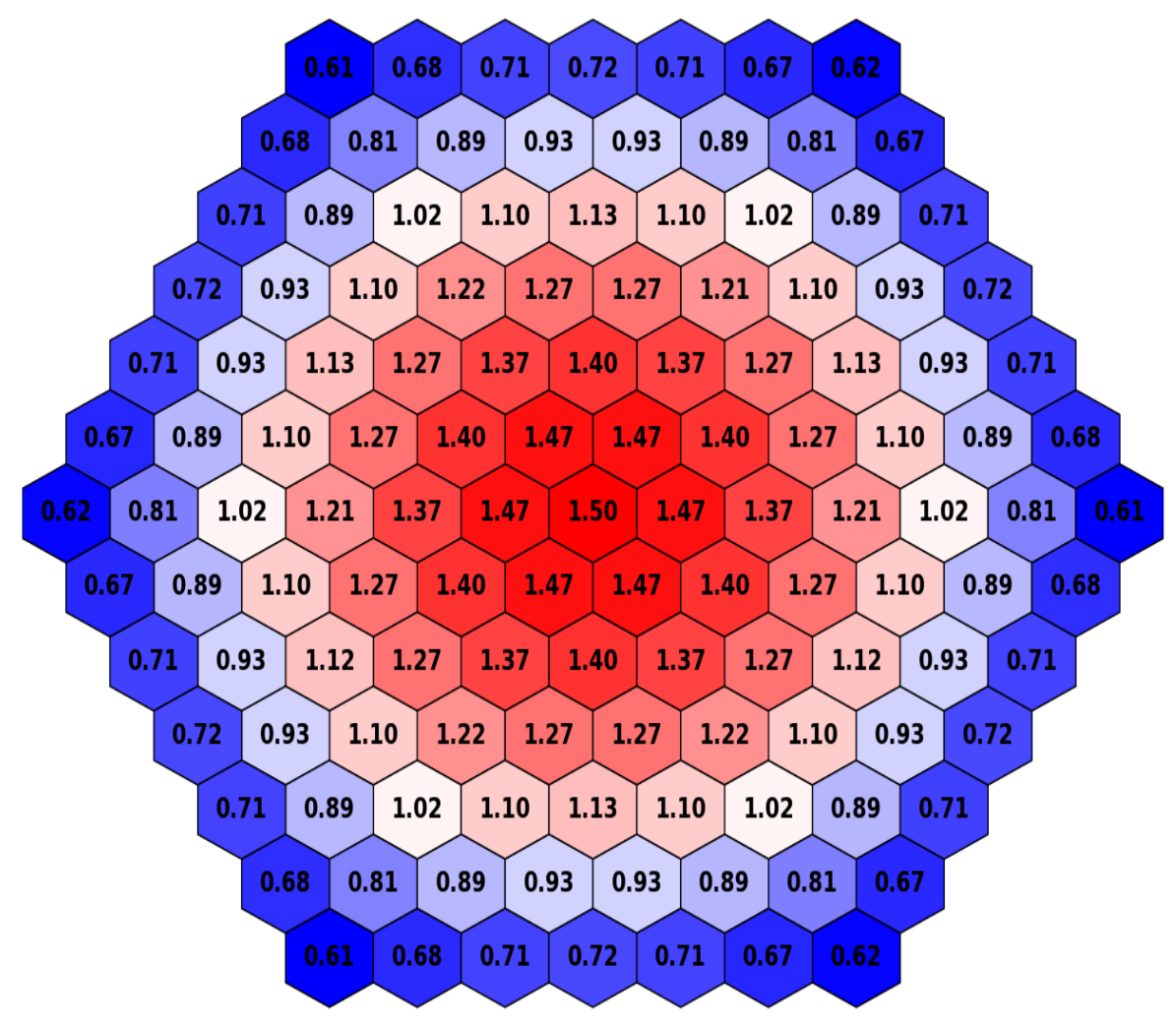

Figure 39. Example Radial Power Distribution

Axial power shaping is another area that should be pursued. Specifically, since the outlet coolant temperature of $2700 \mathrm{~K}$ is only $100 \mathrm{~K}$ lower than the fuel temperature limit of $2800 \mathrm{~K}$, even a small local power excursion at the bottom of the core can exceed thermal limits. Therefore, shifting power to higher in the core can increase the thermal margin.

Some regional radial and axial power shaping improvements that could be investigated are:

- Distributed Poison: Regional reactivity can be reduced by introducing a neutron poison into the fuel either as a particle or in the fuel matrix material. One potential option for either form could be HfC. Hafnium is a commonly used poison material in thermal reactors. It is desirable because it is non-growing (i.e., unlike ${ }^{10} \mathrm{~B}$, its capture reaction 
does not emit a gas), and long-lasting (as natural hafnium contains multiple isotopes with significant neutron absorption resonances in the epithermal energy range). Chemically, hafnium is typically compatible with zirconium and so it is likely also compatible with the $\mathrm{ZrC}$ matrix material. The introduction of hafnium will require additional materials and irradiations testing, manufacturing qualification, etc., all of which can increase the duration, cost, and risk of the project.

- Fuel Enrichment or Fuel Loading Gradients: The regional power density can be modified by varying ${ }^{235} \mathrm{U}$ enrichment in each assembly while keeping loading constant, varying the total uranium loading on an assembly basis or in axial zones, or by varying coolant channel, fuel cylinder radius or moderator thicknesses axially. Fuel loading gradients are preferred as a zoning tool over enrichment gradients because fuel loading differences are more easily observable during non-destructive quality assurance tests during the core manufacturing process than are fuel enrichment changes. Like all the other options that change the fuel material, this approach may require additional materials and irradiations testing, manufacturing qualifications, etc.

\subsubsection{Moderator Material}

The maximum allowable temperature of the $\mathrm{ZrH}_{1.85}$ moderator is significantly lower ( 900 K) than the desired outlet coolant temperature $(2700 \mathrm{~K})$ and the operating fuel temperature $(2800 \mathrm{~K})$ due to hydrogen dissociation taking place at high temperatures. This requires the core to rely heavily on the use of insulators and first-pass coolant channels.

This work did not evaluate the peak moderator temperature or determine the optimal cooling strategy for the moderator. Excess reactivity margin was included in the analysis because the moderator will likely be structurally weak and will be somewhat displaced by non-moderating neutron-absorbing high-temperature structural material.

Additionally, this evaluation did not investigate nor recommend alternative moderating materials. However, NASA should consider whether alternative moderators, such as the various forms of yttrium-hydride, have sufficient technology readiness levels to warrant leveraging their potential for higher temperature limits [8].

\subsubsection{Possibility of Further Reduced Enrichment}

The CERCER fuel of the HALEU concept is loaded with a fuel volume fraction of $13 \%$. This low loading fraction means that it is possible to reduce enrichment further. The ability to reduce enrichment will be valuable should down-blending not be an available option. However, the amount that the uranium enrichment can be reduced depends on the UN particle volume fraction limit in the $\mathrm{ZrC}$; this must be determined by manufacturing qualification and irradiations testing.

To determine the extent that the enrichment can be reduced, a sensitivity study was performed to evaluate the enrichment that provides the same excess reactivity as the HALEU reactor of this report. This was performed at particle volume fraction limits of $40 \%, 64 \%$, and $74 \%$. The first is judged to be a realistic loading limit, the second is the loading limit achieved with random packing of similar sized spheres, and the latter is the maximum theoretical packing fraction of 
spheres. These analyses found that enrichments of approximately $8.0 \mathrm{wt} \%, 5.6 \mathrm{wt} . \%$, and 5.0 wt. $\%$ were required for the $40 \%, 64 \%$, and $74 \%$ loading fractions, respectively.

These results indicate that reducing the enrichment to commercial PWR levels of less than 5 wt. $\%$ would require an increase in core size as the $64 \%$ and $74 \%$ loading fractions may not be achievable.

\subsection{Alternative Design Concepts}

This section discusses concepts that deviate from the baseline CERCER-fueled and $\mathrm{ZrH}-$ moderated concept. Specifically, it covers: (1) the feasibility of a fast reactor design; (2) the benefits of a porous fuel/particle bed design; (3) a CERMET fuel as opposed to CERCER fuel; and (4) liquid-fueled designs. Of these, only the fast reactor design has been scoped by the authors with calculations.

\subsubsection{Fast Reactor Design}

As stated in Section 7.1.2, the moderator temperature limit is significantly lower than the fuel termperature limit, requiring design accomodations such as insulators and a multi-pass coolant scheme. By contrast, a fast reactor does not require moderator and therefore would at least alleviate this limitation. A side-study was performed to evaluate the feasibility of this approach and to quantify the mass reduction offered by removing the insulator and moderator block masses.

To that end, the HALEU and HEU concepts discussed in Sections 4 and 5, respectively, were modified to remove the moderator block and insulators and the fuel lattice pitch reduced accordingly. The remaining inter-assembly volume was filled with first-pass coolant at $300 \mathrm{~K}$ and $1 \mathrm{MPa}$. The CERCER fuel material and its $\mathrm{ZrC}$ cladding was left unchanged. The core height, fuel cylinder radius, and coolant volume fraction were left at their thermal-hydraulically dictated levels, as determined by the Phase 2 analysis.

A reduced-scope Phase 3 analysis was then performed for these HEU and HALEU fast reactor concepts. Since the power requirements are the same as for the thermal core, the same thermalhydraulics-driven parameters were used ( 7 assembly rings, a height of $150 \mathrm{~cm}$, a fuel cylinder radius of $3 \mathrm{~cm}$, and a coolant channel volume fraction of $60 \%$ ). To allow for a simple feasibility study, the reflector and control drums were taken from the final thermal HEU core design of Section 5 for both the HALEU and HEU fast reactor cases.

This analysis was performed by varying the fuel particle volume fraction to find the fuel loading required to achieve the same excess reactivity targeted in the thermal reactor Phase 3 analysis (i.e., a $\mathrm{k}_{\mathrm{eff}}$ of around 1.05). Note that this would not correspond to exactly the same physical core reactivity as in the Phase 3 analysis, since the neutronics analysis of the thermal reactor does not account for the additional reactivity effect of particle self-shielding, while the fast reactor does not have this effect at all.

Based on this evaluation, the 7-ring HEU core could be designed with sufficient reactivity using a fuel particle volume fraction of $26.1 \%$. The authors concluded that an HEU fast reactor with 
these materials is practically achievable. By contrast, the 7-ring HALEU core was significantly subcritical with the fuel particle volume fraction at the $40 \%$ limit. In fact, the HALEU core would require an untenable 31 rings at a fuel particle volume fraction of $40 \%$ to achieve the desired reactivity; the resulting core mass would be 59 metric tons. Increasing the HALEU fuel particle volume fraction to the theoretical packing fraction limit of $74 \%$ still requires greater than 20 rings. The authors concluded that a HALEU fast reactor with these materials is not practical.

Table 19 compares the mass of the HEU-fueled fast reactor with the HEU-fueled thermal reactor of Section 5. These results show that in addition to avoiding the thermal design constraint of the moderator material, the additional fuel required by the fast reactor is more than offset by the mass reductions from removing moderator and insulator. Removing the moderator also produces a smaller core radius, allowing for lighter reflector and reactor vessel.

Table 19. Fast vs Thermal HEU Core Mass Comparison

\begin{tabular}{|l|c|c|c|}
\hline \multicolumn{1}{|c|}{ Material } & Fast [kg] & Thermal [kg] & Thermal - Fast [kg] \\
\hline Reflector & 632.5 & 772.5 & 140.0 \\
\hline Reactor Vessel & 299.6 & 351.3 & 51.7 \\
\hline ZrC Clad & 218.6 & 218.6 & 0.0 \\
\hline Low-Density ZrC Insulator & - & 243.2 & 243.2 \\
\hline SiC/SiC Insulator & - & 226.9 & 226.9 \\
\hline Moderator Block & - & 450.1 & 450.1 \\
\hline CERCER Fuel & $1,776.67$ & $1,469.5$ & -307.2 \\
\hline Control Drum Material & 7.0 & 7.0 & 0.0 \\
\hline Drum Reflector & 15.2 & 15.2 & 0.0 \\
\hline Total & $2,949.5$ & $3,754.2$ & 804.7 \\
\hline Uranium Loading & 757.0 & 174.0 & -583.0 \\
\hline
\end{tabular}

In addition to the reduced mass and complexity, the fast reactor had a smaller radial peaking factor than the thermal HEU core (1.12 versus 1.50) and slightly lower axial peaking (1.36 versus 1.38) as a result of the larger mean free path of the fast neutrons. The intra-assembly peaking was not evaluated but is likely also lower than in the thermal core for the same reason. This indicates that it may be possible to reduce the number of rings in the fast core from 7 to 6 , further reducing mass. This was not evaluated by the authors as it was considered outside the scope of this project, though it should be evaluated further in future work.

It should be noted that the fuel and reflector materials used in these evaluations are not optimized for a fast reactor; therefore, additional mass reductions and performance may be achievable with different material selections.

Aside from the potentially lower mass, a fast reactor design also features more stable excess reactivity behavior that can result in a smaller excess reactivity requirement for lifetime and xenon override concerns as ${ }^{135} \mathrm{Xe}$ and other fission products are not significant fast neutron absorbers. A fast reactor is also more likely to have a lower $k_{\text {eff }}$ than a thermal reactor in a water submersion accident. 
Design challenges will persist with a fast-spectrum NTP concept. For example, significant additional shielding mass may be required, reducing the potential mass benefits of a fast reactor. This is because fast reactors typically have higher ex-core neutron fluxes than thermal reactors due to the increased neutron mean free path, and in this particular reactor design the lack of a moderator block can result in significant neutron and photon streaming paths from the core. This additional ex-core neutron and photon flux will require the shield to be thicker to reduce the dose rates to the same levels as the thermal core. For example, assuming the operational photon dose is limiting and that the fast reactor requires four additional half-value thicknesses of shield, an additional $500 \mathrm{~kg}$ of lead shielding would be required for the fast reactor.

Fast reactors also introduce other sources of risk, should such a variant be pursued. For example, control drum design might be more difficult, as fast reactor control typically requires significant volume for absorption which will displace reflector material. Also, NTP fuel irradiation research that has focused on thermal reactors may not be extendible to a fast reactor variant. Additionally, the Doppler reactivity coefficient is likely smaller for a fast reactor than a thermal reactor, as the higher energy resonances are less broadened than the lower energy resonances.

Finally, removal of the moderator block in a fast reactor-based design removes a convenient heat extraction mechanism and flowpath from the reactor plant. This heat extraction mechanism in the thermal reactor design is useful for providing energy to the balance-of-plant during startup and at full power. This coolant flowpath is also useful for providing heat to systems such as the high efficiency orbital maneuvering system during low power operations. The loss of this flowpath will likely require alternative approaches which will also reduce the mass and complexitiy benefit offered by the above analysis that was only focused on the neutronics performance of the core.

\subsubsection{Porous Media Fuel Design}

In a porous fuel design, the hydrogen coolant flows through, rather than around, the fuel. These flows can be both axial or radial. An example of such a design is the particle bed reactor design investigated with the Space Nuclear Thermal Propulsion project (SNTP) [9].

The performance benefit of this approach is that the fuel-to-coolant heat transfer area is significantly increased and so the surface-to-bulk fluid temperature gradient is decreased. This will have a large effect on the reactor volume because the majority of the temperature rise for the CERCER solid fuel concept is in the surface-to-bulk fluid temperature gradient (for example, see Figure 21 or Figure 33).

The primary performance downside of the porous media approach is the increase in pressure drop. Additionally, the complexity of the flowpath and the resultant flow resistance network would require larger uncertainties to conservatively capture the highly-variable as-built conditions, as well as the "unknown unknowns" of flow through such a system.

The porous media approach may also provide an opportunity to reduce manufacturing risks. Specifically, the CERCER concept that is the subject of this report requires the successful manufacture of tall ceramic fuel cylinders with many coolant holes. These are challenging to manufacture due to the required uniformity of properties across the height as well as the need to 
drill, and clad, the small coolant channel holes. With a porous media, these manufacturing challenges are significantly lessened and replaced with the challenge of manufacturing larger fuel particles for the porous media to reduce the likely large coolant pressure drop due to frictional losses. Since this latter challenge is also faced by the U.S. DOD and DOE in TRISO particle applications, the risk is distributed and may have a higher chance of success.

\subsubsection{CERMET Fueled Design}

CERMET fuels are useful for power-dense reactor designs because they provide both the high uranium density of a ceramic and the high thermal conductivity of a metal matrix. The increased thermal conductivity reduces the temperature gradient of the fuel and can allow for a higher power density.

Another benefit when using a refractory metal matrix (such as rhenium or enriched tungsten) is that the metal matrix melting temperature can be quite high. This is ideal for NTP applications because the maximum coolant outlet temperature depends on the temperature limits of the fuel. However, these refractory metals are either very expensive or have high neutron absorption cross sections.

It is expected that utilizing a CERMET fuel in the NTP application will incur either significant cost penalty or increased uranium loading to counteract increased parasitic neutron absorption. Increased uranium loading may drive NTP designers to increase the fuel particle volume fraction and use HEU fuel. Alternatively, it may be possible to increase the core size to reduce leakage and increase reactivity; however, doing so significantly increases the total reactor mass.

\subsubsection{Liquid-Uranium-Fueled Designs}

A liquid-uranium design allows the hottest component of the reactor - the fuel-to exist in a liquid form. The thermal limit on the fuel is then no longer dictated by the melting temperature, allowing for higher coolant temperatures. Since the liquid fuel needs to be contained, other solid material is necessary and its temperature will likely be the new constraining thermal limit. Liquid-uranium-fueled approaches can be categorized into three general groups. These are presented in the order of increased benefit to the rocket performance and decreased technology readiness level.

In the first group, the fuel particle of a CERCER or CERMET fuel is simply allowed to begin the phase change. This increases thermal margin somewhat at the expense of fuel structural integrity and thermal fatigue damage to the components, which remain solid. This translates to a slight increase in the coolant outlet temperature.

In the second, the fuel elements are allowed to melt but they are kept stationary in some type of high-temperature cladding. The coolant travels outside the cladding and receives heat by conduction. This approach should allow for significantly more thermal margin than in the first approach, resulting in significantly hotter coolant outlet temperatures, but it includes significant challenges. First, either the fuel must be kept as a liquid with the installation of heaters and an electricity source for the heaters (at least until decay heat is available), or the fuel must be allowed to melt during the reactor startup phase. If the fuel is melted by fission heat, then either 
the reactor startup duration will be long (affecting the mission and possibly the coolant supply), or significant operational transients must be accomodated. Second, reactor power transients may be introduced due to convection within the fuel. These may be controlled with the usage of axial partitions in the fuel to minimize the maximum density gradient that may develop. Alternatively, high levels of friction on the internal wall would reduce the rate of liquid fuel convection.

The third approach is a combination of this liquid uranium fueled design and a porous media fuel design. This would provide both the high thermal limit of the liquid uranium and the high heat tranfer of the porous media approach. These can be used together to significantly increase the coolant outlet temperature and reduce the volume of the reactor core. One interesting concept is to spin the liquid fuel in centrifuge-like assemblies into which hydrogen coolant is injected. The rotational force pulls the heavy uranium to the walls of the centrifuge and the light gaseous coolant collects in an open channel in the center. The coolant can then exit the fuel assembly with minimal entrained uranium. The centrifugal motion also provides an additional design benefit by forcing the denser (and cooler) liquid uranium to the external surface of the centrifuge so that the "cladding" material thermal limits are better respected. Alternatively, a thin "shell" layer of solid fuel can be allowed to form on the cladding wall by external cooling, protecting the cladding from the hotter liquid fuel.

This approach shares the challenges of the second design group and adds the following. First, the centrifugal motion of the assembly and the hydrogen gas flow requirements introduce additional complexity and risk to the design and quality assurance process. Second, designs of this type have no fission product barrier: the fuel is direcly exposed to the coolant and thus directly to the environment. Regardless of the operator's regulatory stance in space, earth-bound design assurance experiments will be difficult and expensive to develop and perform to the satisfaction of the relevant regulatory authority. 


\section{Conclusion}

This study assessed the impact of changing enrichment from HEU to HALEU on NTP reactor core design goals. Based on the same conceptual NTP system, two reactor core designs were created in parallel using a multi-stage design process. These reactors - one fueled with HALEU, the other with HEU - were used to assess opportunities and challenges posed by each enrichment option relative to each other. This study was focused on the reactor core performance from a neutronics and thermal-hydraulics perspective.

Both cores were found to be extremely power-dense, meaning that their size is largely dictated by the extent that power can be removed effectively. This leads to the core sizes being roughly equivalent and minimal differences in reactor masses. The difference in mass between the HALEU and HEU cores was found to be smaller than what might be predicted based on fissile mass alone: the HALEU core is approximately $9 \%$ more massive $(379.1 \mathrm{~kg})$ than the HEU core, driven by mass differences in the moderator block and fuel loading.

The two cores also exhibited some neutronic differences, the benefits of which were split between them. On one hand, it was found that the HEU core experiences a significantly smaller depletion reactivity decrement, potentially offering more operational flexibility. On the other hand, the Doppler reactivity coefficient for the HALEU core is approximately $38 \%$ more negative than for the HEU core, offering a stronger safety feedback. These outcomes may have impacts on operations and safety posture.

Future work may consider further development of these core designs. Although the comparisons made in this report will stand, applying design techniques such as power shaping may result in more refined cores with better resolved differences caused by fuel enrichment. Additionally, analysis indicated that a fast-spectrum HEU-fueled NTP reactor core is feasible and may offer some advantages. Because the fast reactor needs no moderator nor insulator to shield the moderator from high temperatures, the difference in mass between the fast and thermal HEU cores is greater than that between the HEU and HALEU thermal cores. Future work should explore this opportunity further to assess its benefits and challenges relating to improving the reactor core design as well as assessing the impact of spectrum selection to the reactor plant and shielding. 


\section{References}

[1] Nuclear Energy Institute, "Addressing the Challenges with Establishing the Infrastructure for the front-end of the Fuel Cycle for Advanced Reactors," NEI White Paper, January 2018. https://www.nrc.gov/docs/ML1810/ML18103A250.pdf.

[2] J. Balcomb, "Nuclear Rocket Reference Data Summary," Los Alamos National Laboratory, LA-5057-MS, Los Alamos, NM, USA (1972).

[3] J. T. Thomas, "Nuclear safety guide. TID-7016, Revision 2," United States, (1978). DOI:10.2172/6231577. https://www.osti.gov/servlets/purl/6231577.

[4] H. Knox, et al., "Nuclides and Isotopes: Chart of the Nuclides," KAPL, Schenectady, NY (2010).

[5] P. K. Romano, N. E. Horelik, B. R. Herman, A. G. Nelson, B. Forget, and K. Smith, "OpenMC: A state-of-the-art Monte Carlo code for research and development," Ann. Nucl. Energy, vol. 82 (2015).

[6] M. B. Chadwick et al., "ENDF/B-VII.1 Nuclear Data for Science and Technology: Cross Sections, Covariances, Fission Product Yields and Decay Data," Nuclear Data Sheets, vol. 112, no. 12, pp. 2887-2996, (2011). DOI: 10.1016/j.nds.2011.11.002.

[7] P. Ferroni, “An Inverted Hydride-Fueled Pressurized Water Reactor Concept," PhD Thesis, Massachusetts Institute of Technology (2010).

[8] J. L. Anderson, W. Mayo, E. Lantz, "Reactivity Control of Fast-Spectrum Reactors by Reversible Hydriding of Yttrium Zones," NASA TN D-4615 (1968). https://ntrs.nasa.gov/citations/19680015087.

[9] R. A. Haslett, “Space Nuclear Thermal Propulsion Program Final Report," PL-TR-95-1064, Phillips Laboratory (1995). 


\section{Appendix A: Material Properties}

Table A-1 summarizes the material property data utilized throughout this analysis. Data for two gases, hydrogen $\left(\mathrm{H}_{2}\right)$ and nitrogen $\left(\mathrm{N}_{2}\right)$ were tabulated over the temperature and pressure ranges obtained data obtained by the references listed. The properties were evaluated by 2D interpolation over the given ranges. The sources of density and thermal conductivity for solid materials are also listed in the table. Densities are given for all materials and are used in the neutronics calculations. Because only fuel, clad, and coolant temperatures were evaluated, thermal conductivities are only provided for those materials.

The HEU uranium composition is treated for this work as $1 \mathrm{wt} \%{ }^{234} \mathrm{U}, 93 \mathrm{wt} \%{ }^{235} \mathrm{U}$, and $6 \mathrm{wt} \%$

${ }^{238} \mathrm{U}$. The HALEU composition is treated as downblended HEU with a diluent of natural uranium to yield the HALEU composition below the limit of $20 \mathrm{wt} \%{ }^{235} \mathrm{U}$. The resultant HALEU composition is $0.21 \mathrm{wt} \%{ }^{234} \mathrm{U}, 19.50 \mathrm{wt} \%{ }^{235} \mathrm{U}$, and $80.29 \mathrm{wt} \%{ }^{238} \mathrm{U}$.

The volume fraction of UN particles in the $\mathrm{ZrC}$ matrix is assumed to be limited to $40 \%$. Note that this is lower than the random-sphere packing limit of $64 \%$. This $40 \%$ limit was chosen to reflect that the random-sphere packing limit is unlikely to be achievable. Further, even if it were achievable, a lower limit is likely to assure a high enough loading of non-fuel material that can retain some strength under irradiation.

The fuel and moderator melting temperatures are provided in Table A-2. The fuel limit for the CERCER fuel is taken as around $90 \%$ of the minimum melting temperature of its two constituent materials: UN and ZrC. Since the UN's melting temperature is limiting, $90 \%$ of its magnitude is $2808 \mathrm{~K}$. This work will therefore use a fuel temperature limit of $2800 \mathrm{~K}$. The moderator temperature limit is not established in this report as the moderator temperature was not analyzed as part of this work.

For all solid materials involved in temperature calculations, a thermal conductivity penalty factor was applied to represent the effect of burnup. First, the range of atom-percent fissions was found to be as much as 4 at.\%. The largest values were obtained for the smallest cores, which were neutronically infeasible. For more realistic cores, the burnup was around 0.2 at.\%. Given that (1) thermal conductivity generally follows swelling and (2) the fuel thermal conductivity will be the most impacted by the burnup due to lattice changes and cracking, this analysis aimed to determine the degradation in fuel thermal conductivity with burnup and applied that value to all other materials. Previous works [1] assumed $0.7 \%$ volumetric swelling per at.\% burnup (based on [2]). With 4 at.\% burnup this results in a $2.8 \%$ increase in volume, which we assume is inversely proportional to thermal conductivity. To add a conservative buffer, this analysis assumed a $5 \%$ thermal conductivity penalty in order to overestimate temperatures.

The densities of the materials considered in the neutronics analysis were adjusted to reflect increases in porosity at high temperature. These factors were obtained by analysis and engineering judgement and are reported in the Notes column of Table A-1. In some cases, where coefficients of thermal expansion (CTE) were available, these were used to project the decrease in density from cold to hot condition. 
Table A-1. Material property references and assumptions utilized in the reported analysis

\begin{tabular}{|c|c|c|c|}
\hline Name & Property & Ref. & Notes \\
\hline \multirow[t]{5}{*}{$\mathrm{H}_{2}$} & Density & \multirow{5}{*}{$\begin{array}{c}{[3]} \\
(\operatorname{tab} .8)\end{array}$} & \multirow{5}{*}{$\begin{array}{l}\text { T: } 32-3000 \mathrm{~K} \\
\mathrm{P}: 1000-3500 \mathrm{kPa}\end{array}$} \\
\hline & Specific heat $(\mathrm{Cp}, \mathrm{Cv})$ & & \\
\hline & Thermal conductivity & & \\
\hline & Viscosity & & \\
\hline & Prandtl number & & \\
\hline \multirow[t]{4}{*}{$\mathrm{N}_{2}$} & Density & \multirow[t]{4}{*}{ [4] } & \multirow{4}{*}{$\begin{array}{l}\mathrm{T}: 280-420 \mathrm{~K} \\
\mathrm{P}: 68.95-344.75 \mathrm{kPa}\end{array}$} \\
\hline & Specific heat $(\mathrm{Cp}, \mathrm{Cv})$ & & \\
\hline & Thermal conductivity & & \\
\hline & Viscosity & & \\
\hline \multirow[t]{2}{*}{ UN } & Density & {$[5]$} & $\begin{array}{l}\text { Constant cold }(300 \mathrm{~K}) \text { and hot }(2000 \mathrm{~K}) \text { values } \\
\text { Assume porosity reduction factor of } 0.99\end{array}$ \\
\hline & Thermal conductivity & [6] & $\begin{array}{l}\text { Effect of porosity included in equation; assumed value of } \\
0.05 \text {. }\end{array}$ \\
\hline \multirow[t]{2}{*}{$\mathrm{ZrC}$} & Density & {$[7,8]$} & (a) \\
\hline & Thermal conductivity & [9] & $\begin{array}{l}\text { T: } 100-2600 ; \text { scaled by porosity factor of } \\
(1-\varepsilon) /(1+\varepsilon) \text {, with porosity }(\varepsilon)=0.05 \text {. }\end{array}$ \\
\hline $\mathrm{ZrH}_{1.85}$ & Density & [10] & Assume $95 \%$ reported density \\
\hline $\mathrm{SiC}$ & Density & [11] & Taken as $2.7 \mathrm{~g} / \mathrm{cc}$, middle of the reported range \\
\hline $\mathrm{CBe}_{2}$ & Density & [12] & Assume $95 \%$ reported density \\
\hline $\mathrm{BeO}$ & Density & [13] & Assume $95 \%$ reported density \\
\hline $\mathrm{Be}$ & Density & [14] & $\begin{array}{l}\text { Constant cold }(293.15 \mathrm{~K}) \text { and hot }(1000 \mathrm{~K}) \text { values (hot } \\
\text { calculated with reported CTE }) \text {; assume } 95 \% \text { reported } \\
\text { density. }\end{array}$ \\
\hline Hf & Density & [14] & $\begin{array}{l}\text { Constant cold }(293.15 \mathrm{~K}) \text { and hot }(1000 \mathrm{~K}) \text { values (hot } \\
\text { calculated with reported CTE); assume } 95 \% \text { reported } \\
\text { density. }\end{array}$ \\
\hline $\mathrm{HfC}$ & Density & [13] & $\begin{array}{l}\text { Constant (includes 5\% porosity); assume 95\% reported } \\
\text { density. }\end{array}$ \\
\hline $\mathrm{HfB}_{2}$ & Density & {$[12]$} & Constant; assume 95\% reported room temperature value \\
\hline $\mathrm{B}_{4} \mathrm{C}$ & Density & {$[15]$} & Constant; assume $95 \%$ reported room temperature value \\
\hline IN718 & Density & [16] & $\begin{array}{l}\text { Composition obtained using mid-range values with } \\
\text { balance Fe; constant cold }(293.15 \mathrm{~K}) \text { and hot }(1000 \mathrm{~K}) \\
\text { values (hot calculated with reported CTE) and assume } \\
95 \% \text { reported density. }\end{array}$ \\
\hline
\end{tabular}

(a) Calculated as a function of carbon stoichiometry as shown below [7], with $\mathrm{C}=0.98$ ( $\mathrm{T}=298.15)$ :

$$
\rho=\left\{\begin{array}{cl}
6.05+0.24 C+0.32 C^{2} & 0.6 \leq C \leq 1 \\
2.0-\frac{2.0}{C}+\frac{6.61}{C} & C>1
\end{array}\right.
$$

Porosity reduces the density; a default value of $3 \%$ porosity for hot-pressed $\mathrm{ZrC}$ is assumed [7]. If "low density" $\mathrm{ZrC}$, the porosity may be as high as $68 \%$ [8]. In this case, the density is adjusted by a factor of $1-0.68=$ 0.32 .

Table A-2. Material Melting Temperatures

\begin{tabular}{|l|l|l|}
\hline & Melting T (K) & Ref. \\
\hline $\mathrm{ZrC}$ & 3700 & {$[17]$} \\
\hline $\mathrm{UN}$ & $3120+/-35$ & {$[18]$} \\
\hline $\mathrm{ZrH} 1.85$ & $\sim 900$ & {$[19]$} \\
\hline
\end{tabular}




\section{References}

[1] B. Feng, A.Karahan, M. Kazimi. "Steady-state fuel behavior modeling of nitride fuels in FRAPCON-EP”. Journal of Nuclear Materials v. 427 no. 1-3, pp 30-38 (2012). DOI: 10.1016/j.jnucmat.2012.04.011.

[2] I. I. Konovalov, Y.S. Stetsky, "Development status of metallic, dispersion and nonoxide advanced and alternative fuels for power and research reactors," IAEA-TECDOC1374, International Atomic Agency, Vienna (Austria), 2003.

[3] R. D. McCarty, J. Hord, H. M. Roder. "Selected Properties of Hydrogen (Engineering Design Data)". National Bureau of Standards Monograph 168 (1981). https://nvlpubs.nist.gov/nistpubs/Legacy/MONO/nbsmonograph168.pdf.

[4] E. W. Lemmon, M. O. McLinden and D. G. Friend, "Thermophysical Properties of Fluid Systems" in NIST Chemistry WebBook, NIST Standard Reference Database Number 69, Eds. P.J. Linstrom and W.G. Mallard, National Institute of Standards and Technology, Gaithersburg MD, 20899, https://doi.org/10.18434/T4D303, (retrieved September 14, 2020).

[5] S. L. Hayes, J. K. Thomas, K. L. Peddicord. "Material property correlations for uranium mononitride: I. Physical properties". Journal of Nuclear Materials v. 171 no. 2-3, pp. 262-270 (1990). DOI: 10.1016/0022-3115(90)90374-V.

[6] J. A. Webb, I. Charit. "Analytical determination of thermal conductivity of W-UO2 and W-UN CERMET nuclear fuels”. Journal of Nuclear Materials v. 427 no 1-3, pp 87-94 (2012). DOI: $10.1016 /$ j.jnucmat.2012.04.020.

[7] Yutai Katoh, Gokul Vasudevamurthy, Takashi Nozawa, Lance Snead. "Properties of zirconium carbide for nuclear fuel applications." Journal of Nuclear Materials v. 441 13, pp 718-742 (2013). DOI: 10.1016/j.jnucmat.2013.05.037.

[8] H. Chen, H. Xiang, F. Z. Dai, J. Liu, Y. Zhou. "Low thermal conductivity and high porosity $\mathrm{ZrC}$ and $\mathrm{HfC}$ ceramics prepared by in-situ reduction reaction/partial sintering method for ultrahigh temperature applications." Journal of Materials Science \& Technology, v35 12, pp 2778-2784 (2019). DOI: 10.1016/j.jmst.2019.05.044.

[9] B. H. Morrison, L. L. Sturgess. "Thermal diffusivity and conductivity of zirconium carbide and niobium carbide from 100 to $2500 \mathrm{~K}$ ". Rev. Int. Hautes Temp. Refract. 7: No 4, pp 351-358 (1970).

[10] M. T. Simnad. "The U-ZrHx alloy: Its properties and use in TRIGA fuel". Nuclear Engineering and Design v. 64 no. 3 pp. 403-422 (1981). DOI: $\underline{10.1016 / 0029-}$ 5493(81)90135-7.

[11] T. Koyanagi, Y. Katoh, G. Singh, M. Snead. "SiC/SiC Cladding Materials Properties Handbook". ORNL/TM-2017/385 (2017). URL: https://info.ornl.gov/sites/publications/ Files/Pub100714.pdf.

[12] D. R. Lide, ed. "CRC Handbook of Chemistry and Physics, 79 th Edition". CRC Press, Boca Raton, FL (1998). (Accessed via http://www.matweb.com on September 14, 2020).

[13] M. Bauccio, ed. “ASM Engineered Materials Reference Book, 2 ${ }^{\text {nd }}$ Edition”. ASM International, Materials Park, OH (1994). (Accessed via http://www.matweb.com on September 14, 2020). 
[14] R. C. Weast, ed. "CRC Handbook of Chemistry and Physics, 62 ${ }^{\text {nd }}$ Edition”. CRC Press, Boca Raton, FL, (1981). (Accessed via http://www.matweb.com on September 14, 2020).

[15] CoorsTek Cercom PAD B4C Pressure Assisted Densification Boron Carbide. http://www.matweb.com/search/DataSheet.aspx?MatGUID=079ec590726d48d6bdd71 52c55a756ed (Accessed September 14, 2020).

[16] Special Metals Inconel Alloy 718. http://www.matweb.com/search/datasheet.aspx? matguid=94950a2d209040a09b89952d45086134\&ckck=1 (Accessed September 14, 2020).

[17] A.F. Guillermet, "Analysis of thermochemical properties and phase stability in the zirconium-carbon system". Journal of Alloys and Compounds v. 217 pp. 69-89 (1995).

[18] U. C. Nunez, D. Prieur, R. Bohler, and D. Manara, "Melting point determination of uranium nitride and uranium plutonium nitride: A laser heating study". Journal of Nuclear Materials v. 449 pp. 1-8 (2014).

[19] D. Olander, E. Greenspan, H. D. Garkisch, B. Petrovic, "Uranium-zirconium hydride fuel properties”. Nuclear Engineering and Design v. 239 pp. 1406-1424 (2009). 


\section{Appendix B: Neutronics Analysis Methodology}

The neutronics evaluations performed in this work used the OpenMC [1] Monte Carlo neutron and photon transport simulation code. In this work, the OpenMC software was used to determine the $\mathrm{k}$-eigenvalue ( $\mathrm{k}_{\text {eff }}$ and $\mathrm{k}_{\text {inf }}$ ) and associated flux/reaction rate distributions as needed.

The continuous-energy Monte Carlo method was used for this work, as opposed to a determnistic transport or diffusion method, to limit the aount of engineer time associated with building a model that can be trusted to yield reasonably accurate results. This concern is primarily driven by the need to generate, and correct multigroup cross sections to cover the range of designs, temperatures, and conditions encountered in this work. There are other more mature Monte Carlo codes which could have been used, however, OpenMC was chosen for this project because it has an interface most suited towards batch processing, is one of the faster Monte Carlo solvers available for reactor analysis, and an expert user and developer of the software is a member of the ANL team enabling rapid model development.

The remainder of this section will generally describe the OpenMC models. Specific deviations from what is presented herin will be discussed in the corresponding main body of this work when relevant.

\section{B.1: OpenMC Version}

Early analyses of this work use a pre-release version of OpenMC v0.12. The Phase 4 and 5 analyses (i.e., the final designs) were performed with the formally released version of OpenMC, version 0.12 .

\section{B.2: Nuclear Data}

The nuclear data used with this effort was the ENDF/B-VII.1 data obtained from the National Nuclear Data Center [2]. This data was then processed, using a modified version of the generate_endf71.py script from the openmc-dev/data repository to produce continuous-energy neutron-nucleus cross sections at: 0, 250, 293.6, 600, 900, 1200, 1500, 2000, 2100, 2200, 2300, 2400, 2500, 2600, 2700, 2800, 2900, 3000, 3100, and 3200 degrees Kelvin. This script uses NJOY (in this case NJOY2016) to process the ENDF data, convert to ACE, and eventually, produce OpenMC HDF5 data libraries. Note that this process does not evaluate execute the LEAPR module for thermal scattering temperatures different than are provided in the ENDF evaluation. For $\mathrm{Zr}-\mathrm{H}$, Be-metal, and $\mathrm{Be}$ in $\mathrm{BeO}$, this produces $\mathrm{S}(\mathrm{a}, \mathrm{b})$ libraries at $296 \mathrm{~K}, 400 \mathrm{~K}$, $500 \mathrm{~K}, 600 \mathrm{~K}, 700 \mathrm{~K}, 800 \mathrm{~K}, 1000 \mathrm{~K}$, and $1200 \mathrm{~K}$. For ${ }^{56} \mathrm{Fe}$, the available temperatures are $20 \mathrm{~K}$, $80 \mathrm{~K}, 294 \mathrm{~K}, 400 \mathrm{~K}, 600 \mathrm{~K}$, and $800 \mathrm{~K}$.

The depletion chain, recoverable energy per fission, and branching ratio information is the simplified depletion chain produced by the Consortium for Advanced Simulation of Light Water Reactors (CASL) for LWR applications [3]. This chain reduces the total number of isotopes in the system from nearly 4,000 to 255 while preserving $k_{\text {eff }}$ with depletion for a variety of hydrogen-moderated systems. While the usage of a simplified depletion chain in analysis is common, the usage of an LWR chain in a non-LWR application is an approximation that will introduce some error. However, since the important isotopes present in the NTP designs of 
interest here are similar to those in LWRs, no significant deviations are expected to be encountered.

There may be some additional error in HEU cases using this chain compared to an HALEU case as the chain was developed for low-enriched uranium applications and so the build-up of ${ }^{236} U$ and its subsequent neutron absorption chain may be misrepresented. However, this error should be small due to the low burnups of the NTP reactors in question.

\section{B.3: Simulation Settings}

Each simulation in OpenMC was run with enough histories that the keff uncertainty was significantly smaller than the trends trying to observe. This generally resulted in an absolute uncertainty on $\mathrm{k}_{\text {eff }}$ of 0.00030 .

The initial source in each was a point source in the geometric center of the core with a typical ${ }^{235} \mathrm{U}$ Watt spectrum.

Resonance scattering was enabled using the "rvs" method and a maximum energy of $500 \mathrm{eV}$. This option enables the resonance up-scattering effect to be treated on-the-fly at any arbitrary temperature so long as $0 \mathrm{~K}$ data is present. $0 \mathrm{~K}$ data is present for all nuclides in our case.

Finally, Doppler broadening of resonances was not performed on the fly, and instead the nearest temperature available to the temperature of interest was used. This will result in some small error, but given that the temperature data is provided at $100 \mathrm{~K}$ intervals at the fuel temperatures (where the strongest resonances are present), this error should be minimal.

Depletion calculations were run using a predictor-corrector methodology. This produces more accurate results than traditional predictor at double the computational time. This extra accuracy is likely not needed, but until a thorough study of the finely stepped depletion behavior can be done it was chosen in lieu of the predictor method.

\section{B.4: Material Modelling}

The materials implemented in the model have densities and isotopic inventories consistent with those discussed in Appendix A: Material Properties. The $\mathrm{ZrH}_{1.85}$, Inconel, $\mathrm{Be}$, and $\mathrm{BeO}$ (used in reflector studies) have the ENDF/B-VII.1 thermal scattering data applied. Specifically, $\mathrm{ZrH}_{1.85}$ has both the $\mathrm{H}$ in $\mathrm{ZrH}$ and $\mathrm{Zr}$ in $\mathrm{ZrH}$ tables assigned, Inconel has the ${ }^{56} \mathrm{Fe}$ table assigned, Be has the corresponding beryllium metal table assigned, and the $\mathrm{BeO}$ has the $\mathrm{Be}$ in $\mathrm{BeO}$ table assigned. Scattering at thermal energies for all other isotopes and materials are treated with free-gas kinematics for non-resonant reactions per standard practice for neutron energies up to $400 * \mathrm{kT}$ $(10 \mathrm{eV}$ at room temperature, $100 \mathrm{eV}$ at $3000 \mathrm{~K})$. Resonant reactions are treated with the previously discussed "rvs" method for resonant scattering at energies up to $500 \mathrm{eV}$ regardless of temperature.

Rather than explicitly modeling the heterogeneity of UN particles in the CERCER fuel, the fuel block was modeled as a homogeneous mixture with the respective volume fractions of fuel, coating, and moderator materials. The UN particle diameter is $800 \mu \mathrm{m}$, and the particle volume 
fraction in the fuel element is $13 \%$ in the HALEU core and $6 \%$ in the HEU core. Time constraints prevented quantifying the effect of the homogeneous modeling approach on reactivity and intraassembly power peaking, but qualitative generalizations have been drawn from the literature.

It has been shown that reactivity can increase significantly with particle heterogeneity due to improved resonance self-shielding, and that the extent of the effect depends on particle size, loading fraction, and uranium enrichment [4]. As particle diameter increases, the particle's surface area-to-volume ratio increases, and more efficient self-shielding increases reactivity. Higher fuel particle loading fractions also increase reactivity. The closer packing of particles causes them to "shadow" each other, creating a similar effect to the larger particle size. The heterogeneity effect is driven by resonance absorption in ${ }^{238} \mathrm{U}$, so it decreases as uranium enrichment increases, and there will be a smaller modeling bias between the homogeneous and explicit heterogeneous models.

The heterogeneity effect was quantified for a system with TRISO fuel particles using $17 \%$ uranium enrichment, $910 \mu \mathrm{m}$ particle diameter, and $61 \%$ packing fraction [5]. In this system, decreasing the modeling fidelity from fully explicit modeling of the particles and each $\mathrm{SiC}$ coating layer, to homogenizing the components of each particle but maintaining the heterogeneity of particles and matrix material resulting in over $1 \%$ decrease in reactivity of a unit cell model. Between the fully explicit model and the fully homogenized model, a $2.5 \%$ reactivity decrease was found. This result indicates that the homogeneous modeling approach in the current work leads to a conservatively high estimate of excess reactivity due to the reduced fuel self-shielding in the homogeneous approach. While not quantified, this increased selfshielding also means the intra-assembly power peaking will be larger than predicted by this model.

For non-final calculations, or final calculations that were focused on core-wide behavior, the fuel cylinder's internal coolant channels and their $0.01 \mathrm{~cm} \mathrm{ZrC}$ cladding were homogenized with the fuel material. The outer cladding and coolant channel were not homogenized.

Most analyses in this work were performed at a temperature profile consistent with hot-fullpower conditions. This was important because the thermal feedback can shift power away from the bottom of the reactor where the coolant is the hottest. Factoring in this shift will provide a more realistic perspective of the small thermal margin that is present. In the OpenMC models, 10 axial bins were used to represent the axial variation of temperature. That is, if the core is 150 $\mathrm{cm}$ tall, then there are 10 bins of $15 \mathrm{~cm}$ each where within that $15 \mathrm{~cm}$ region all temperatures are the same. The temperatures and pressures used for these hot-full-power conditions are provided in Figure B-1 and Figure B-2, respectively. The bulk, clad, and fuel temperatures and pass 2 pressures are consistent with average material temperatures obtained via the thermal-hydraulic analyses within $20-50 \mathrm{~K}$. This is more than sufficient for the accuracy required for this project. The remaining temperatures (insulators, their coolant gaps, and the moderator block) and pass 1 pressure were based on engineering judgment. 


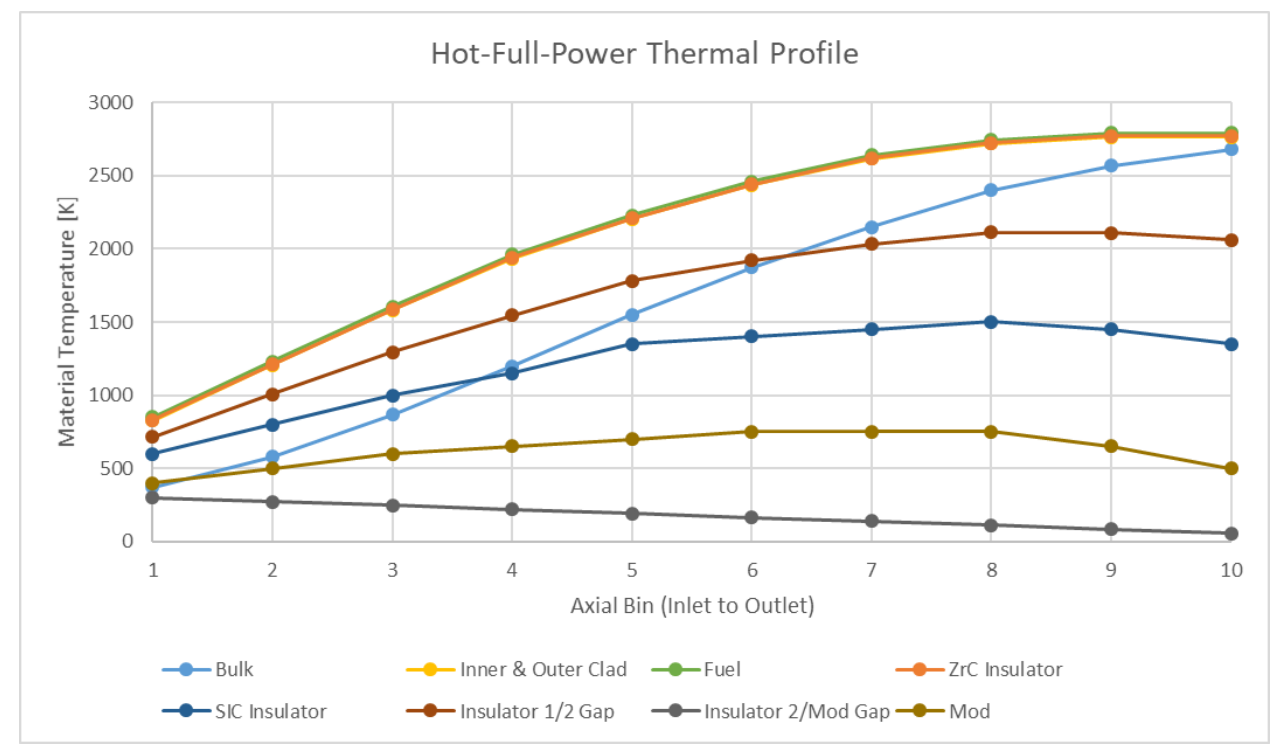

Figure B-1. Assumed Hot-Full-Power Temperature Profile

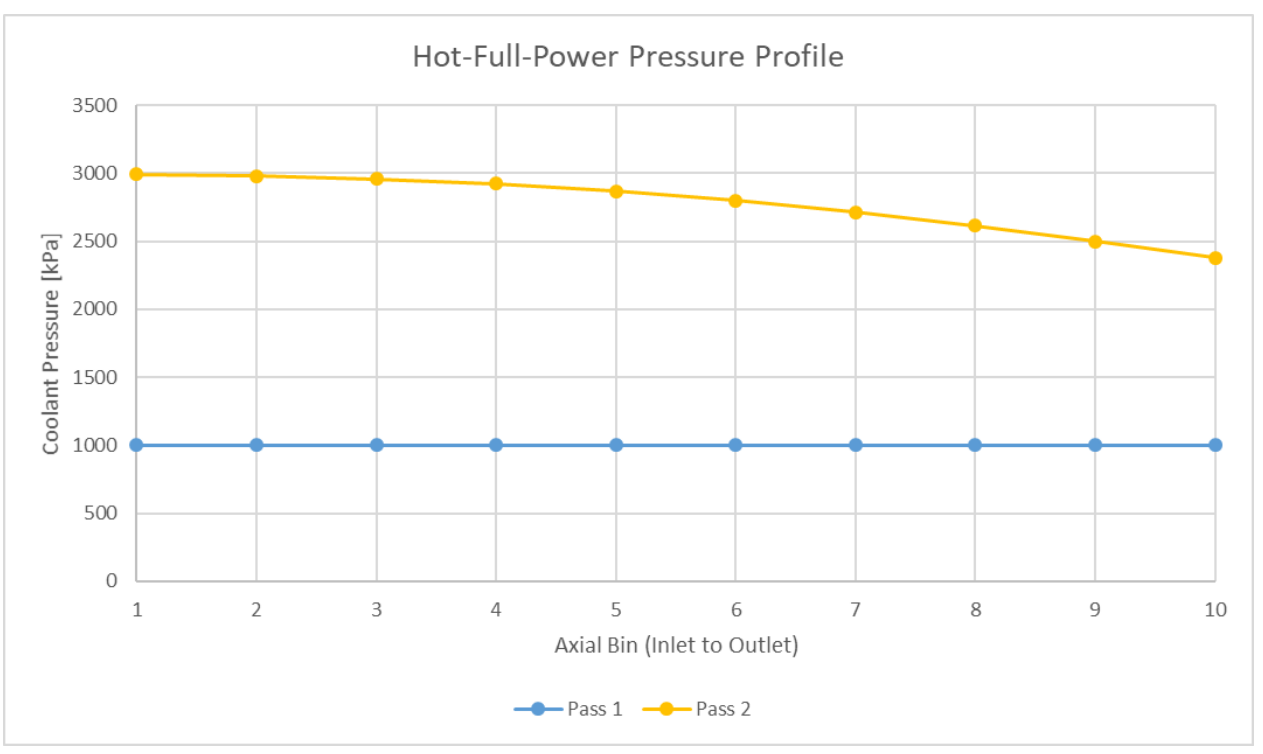

Figure B-2. Assumed Hot-Full-Power Pressure Profile

Finally, in depletion calculations only fuel and the control drum absorber materials were allowed to deplete. The other materials were kept at their initial inventories. This significantly reduces the already expensive computation time of a depletion calculation. When performing these depletion computations, each fuel assembly and control drum absorber was discretized in to ten axial regions. Each of these was modeled as a unique material composition so the materials could deplete according to the local flux magnitude and energy spectra. 


\section{B.5: Geometric Modeling}

An example OpenMC model used for 2D infinite-lattice analyses is shown in Figure B-3. The innermost region of this model is the coolant channel holes (and their $\mathrm{ZrC}$ cladding), and the $\mathrm{ZrC}+\mathrm{UN}$ CERCER fuel meat. The position and radii of the coolant channels in these models are determined by the $\mathrm{ZrC}$ cladding thickness, the number of rings of holes in their circular lattice and the coolant channel volume fraction. The number of rings of holes directly sets the total number of coolant channel holes. The radii of the holes are all assigned the same radius. This radius is determined with the number of holes, the coolant channel volume fraction, and the $\mathrm{ZrC}$ cladding thickness. For this, the individual coolant hole (coolant and cladding) radius is determined with the number of rings and the coolant channel volume fraction. Then, the $\mathrm{ZrC}$ cladding thickness is removed from this outer radius to yield the actual coolant radius. These radii and the number of rings are then used to determine the intra-hole spacing that is then used to compute the positions of the centers of the holes.

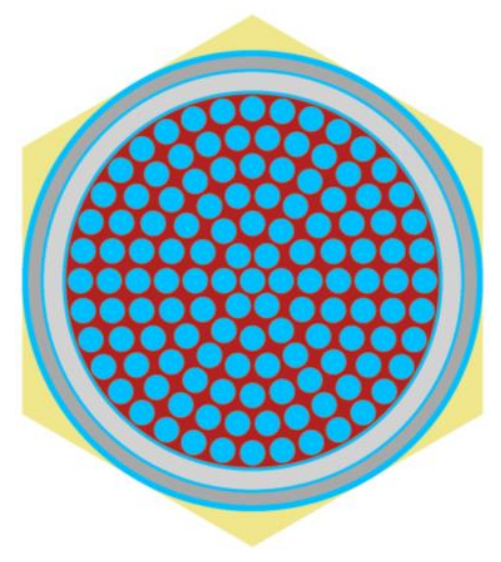

Figure B-3. Assembly Model

Note that some analyses at all phases of the design do not explicitly model these coolant channel holes. These analyses were those concerned only with the core reactivity and not with the specific power distribution within an assembly. In this case the number of unique surfaces, regions, and materials are reduced by homogenously mixing the coolant channel, cladding, and fuel meat. Note that the outer cladding and all materials outside the cladding are still explicitly represented. Finally, some earlier analyses (primarily Phase 1 analyses) utilized a hexagonal layout of the coolant channel holes. This is not expected to have any significant impact on the conclusions of these early stages.

Outside the outer coolant channel is the outer coolant gap (part of the second pass coolant), the low-density $\mathrm{ZrC}$ insulator, a second pass coolant channel gap, the $\mathrm{SiC} / \mathrm{SiC}$ insulator, a first pass coolant, and finally the moderator. The moderator web thickness discussed in this report is the thickness of the moderator at its thinnest dimension. Note that there are no coolant channels within the moderator, nor is there any structural material present. This is a design simplification that would have to be addressed at later stages of analysis, however, additional excess reactivity was included in the design margin to reflect that the final core will be less reactive than this one due to the removal of moderator and some replacement with structural material. 
The outer periphery of this moderator is modeled as a hexagon consistent with the hexagonal lattice layout of the entire reactor core. As a 2D infinite lattice model, the outer edges of the hexagonal and the axial boundaries are applied a reflective boundary condition.

A top-view of the full-core model is shown in Figure B-4. Figure B-5 is the same full-core case but from a side view sliced through the x-axis. In this model, the hexagonal layout of the fuel assemblies is shown. As stated elsewhere, this is an analysis simplification to reduce the number of free variables during the design. That is, only the number of rings and the assembly material thickness needs to be set to uniquely set the assembly positions in the lattice. With a circular lattice layout there are more degrees of freedom, impacting the depth of the design search to be performed. While a circular lattice allows for additional optimization, the authors judge that the differences due to the choice of hexagonal or circular lattice will have no bearing on the overall conclusions of this work.

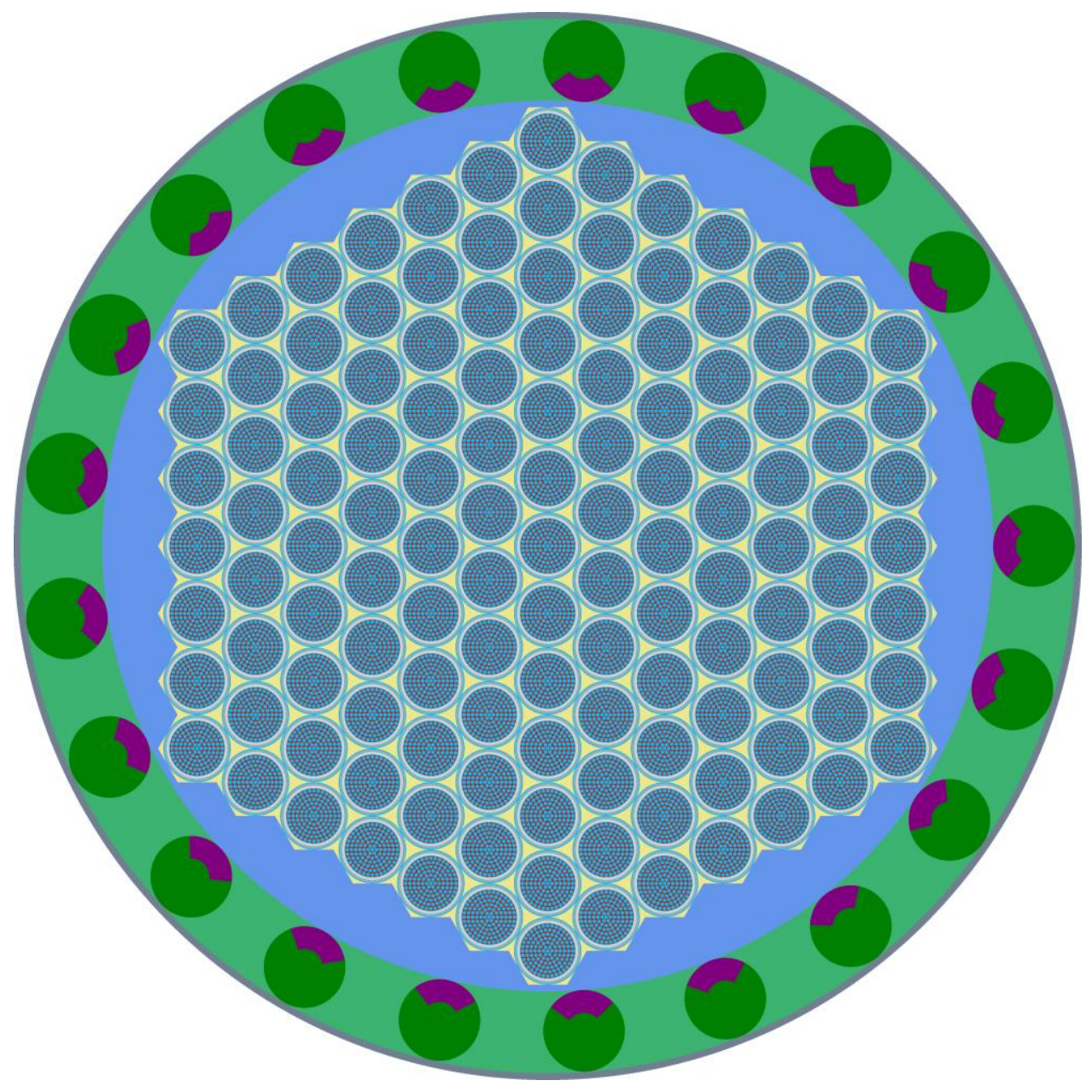

Figure B-4. Full-Core Model

The radial region surrounding the reactor core but inside the radial reflector is modeled effectively as a void $\left(\mathrm{H}_{2}\right.$ gas with a density of $\left.10^{-10} \mathrm{~g} / \mathrm{cm}^{3}\right)$. This was done specifically to minimize the differences between the hexagonal lattice core and the more optimum circular 
lattice. More specifically, a circular lattice allows for close reflection of the core by the reflector, and reducing the gap material to a void simulates this close reflection.

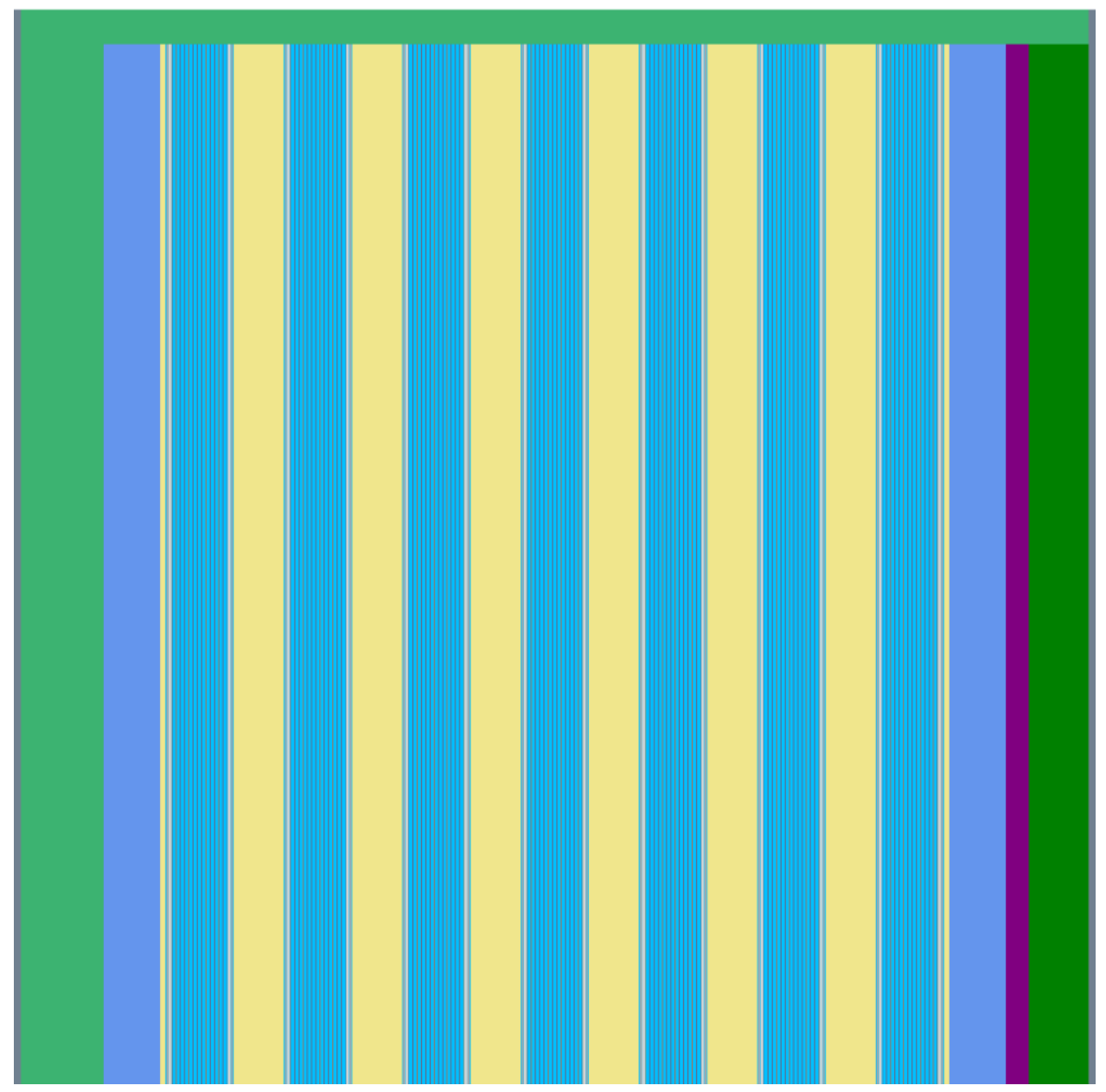

Figure B-5. Full-Core Side View

Outside this gap is the radial reflector and the control drums. The radial reflector is composed of the reflector material (determined in Phase 1 to be beryllium) and 15\% (by volume) of $\mathrm{H}_{2}$ gas as coolant. In hot-full-power conditions the beryllium and $\mathrm{H}_{2}$ gas are modeled as $800 \mathrm{~K}$ and $1 \mathrm{MPa}$ (for the $\mathrm{H}_{2}$ ). This radial reflector is as tall as the fueled region of the core and aligned with the fuel.

The control drums are modeled as cylinders at the same height as the radial reflector and the fueled region of the core and aligned with the fuel. The radius of each control drum is slightly less than half the thickness of the reflector. The radius is slightly less than half the thickness to avoid surface overlaps and aborted histories in the Monte Carlo simulation. The drum contains two material: the reflector and coolant combination described above, and the absorber material itself. The absorber material is not mixed with coolant as it is assumed that some of the $15 \%$ reflector coolant could be redirected around the surface of the control material. This would be a small effect so long as the absorption optical thickness of the absorber is preserved. 
The control drum's material is defined by two parameters: the thickness and the span. The thickness is self-explanatory. The span represents the angle between the center of the drum and the edges of the absorber. A span of 360 degrees means the control material is covering the entire control drum.

\section{B.6: Tally Specification}

The main outputs of interest in neutronics computations are the value of $\mathrm{k}_{\mathrm{eff}}$ and the flux/reaction rate distributions for a particular case or an evolution of that case in time. These results are also required in this analysis. All deterministic and Monte Carlo eigenvalue solvers inherently output the $\mathrm{k}_{\mathrm{eff}}$ of a model; OpenMC is no different. Monte Carlo solvers do not directly output the flux and reaction rate distributions. Instead, these need to be explicitly requested so that the solver can tally the necessary results to produce the requested output.

For this work, a few different tally types were required. These were primarily axially discretized assembly flux and power distributions and fine-mesh (on a Cartesian mesh) flux and power distributions. Both of these types were scored using tracklength estimators. A tracklength estimator can significantly reduce the stochastic uncertainty of a Monte Carlo by scoring a tally every time a history enters a region/mesh element of interest. The flux result is typical in Monte Carlo solvers and needs no further discussion.

The power distribution does, however, require explanation. For the purposes of this work, the power distribution was determined solely with OpenMC's 'kappa-fission` score type. The result of this score type is the recoverable energy production rate due to fission. This recoverable energy includes the fission product kinetic energy, the prompt and delayed neutron kinetic energies, prompt and delayed $\gamma$-ray total energies, and the total energy released by the delayed $\beta$ particles. This is score assumes all the energy is deposited where the fission event occurs. The $\gamma$-rays and $\beta$ particles do not transport their energy to other locations in the core. This is an approximation chosen for expediency, as explicitly treating the $\gamma$-ray would significantly increase the runtime. The result is that the local power generation rate at the peak power location would be larger than it would be if $\gamma$-ray were modeled. Since this is conservative it is considered acceptable for this work.

\section{References}

[1] P. K. Romano, N. E. Horelik, B. R. Herman, A. G. Nelson, B. Forget, and K. Smith, "OpenMC: A State-of-the-Art Monte Carlo Code for Research and Development," Ann. Nucl. Energy, 82, 90-97 (2015).

[2] M. B. Chadwick, M. Herman, P. Oblozinsky, et al., "ENDF/B-VII.1 nuclear data for science and technology: Cross sections, covariances, fission product yields and decay data", Nuclear Data Sheets, 112(12):2887-2996 (2011).

[3] K. S. Kim, "Specification for the VERA Depletion Benchmark Suite", CASL-U-2015-1014000, Rev. 0 (2016).

[4] L. Snoj and M. Ravnik, "Effect of Fuel Particles' Size Variations on Multiplication Factor in Pebble-Bed Nuclear Reactor," proceedings of Nuclear Energy for New Europe 2005, Bled, Slovenia, Sep. 2005. 
[5] M.-J. Wang, J.-J. Peir, D.-S. Chao, and J.-H. Liang, "Effects of Homogeneous Geometry Models in Simulating the Fuel Balls in HTR-10," JPES, vol. 6, no. 3, pp. 394-401, (2012). doi: 10.1299/jpes.6.394. 


\section{Appendix C: Thermal-Hydraulic Analysis Model}

This appendix describes the thermal-hydraulics (TH) models used in the design of the proposed NTP reactor cores. Due to time constraints and a broad, open-ended parameter space, onedimensional models were utilized to accelerate analysis.

Two one-dimensional models were used in the analysis. The primary model considers a coolant channel in a conservatively high-power region of a fuel cylinder. This model is referred to hereafter as the "bounding hole model". With it, viable combinations of fuel cylinder radius, height, power, and coolant volume fraction were determined. This model is described in the first section.

The second model, used for scoping and analysis of assumptions, inverts the fuel cylinder and coolant holes and models them as a rod bundle, preserving volume fractions. This model relies on the same 1D compressible flow and heat transfer relationships as the bounding hole model but utilizes different geometric abstractions. The differences between the pin and bounding hole models are described in the second section.

Both models treat the fission energy as being deposited locally at the fission site. That is, the neutrons, charged particles, and photons do not carry energy from the fuel to the other reactor components. Since this analysis only evaluates the fuel temperature this is approach is conservative in a moderated system by at least $2 \%$ (the fraction of fission energy released as kinetic energy of the neutrons).

\section{C.1: Bounding hole model}

Each fuel assembly in the reactor is comprised of a cylinder of fuel bearing ceramic and is traversed by coolant channels, hereafter referred to as "holes". Hydrogen gas enters the fuel at $300 \mathrm{~K}$ and exits at $2700 \mathrm{~K}$. The "hole model" studies the central cooling hole and the fuel immediately around it. By assuming the coolant hole removes the heat generated in the fuel in its immediate vicinity, adiabatic boundary conditions can be placed halfway between the coolant hole and its neighbors. A conceptual diagram of this system is shown in Figure C-1, where the dotted line indicates the adiabatic boundary that surrounds the modeled system. 


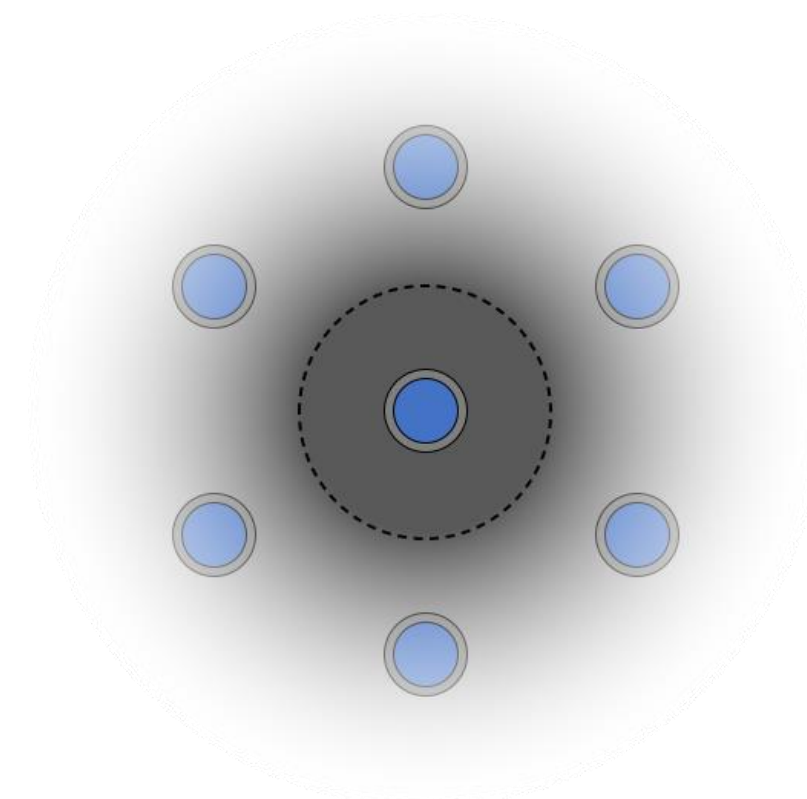

Figure C-1. Bounding hole model conceptual diagram

The system is modeled as three concentric cylinders. The inner cylinder is the coolant, modeled as a flowing compressible fluid with appropriate correlations for $\mathrm{H}_{2}$ gas. Surrounding the coolant is the cladding material, within which no heat generation is assumed. Finally, surrounding the cladding is the fuel material, where heat is generated.

The model requires user input for fuel assembly height, radius, total power, coolant volume fraction, and the number of coolant holes. First, a cosine power distribution is generated based on assembly height. Then, the coolant flow rate required to remove the all power in the assembly is determined based on numerical solution of $Q=m C_{p} d T$ such that the desired coolant $d T$ is achieved and where $C_{p}$ is allowed to vary with increasing temperature. Here, pressure is kept fixed at the inlet pressure. With the coolant mass flow rate for the assembly determined, the mass flow rate required for each coolant hole is obtained after dividing by the requested number of coolant holes. The power attributed to each hole is calculated in the same way. Coolant flow and heat removal through the outer coolant channel that surrounds the fuel assembly is neglected.

The model then steps axially through the system to calculate coolant, clad, and fuel temperatures. A coarse axial mesh is used for the power distribution; within each coarse mesh, 100 fine meshes are used to further resolve temperatures and pressures. This discretization is shown in Figure C-2, which demonstrates the coarse and fine meshing. 


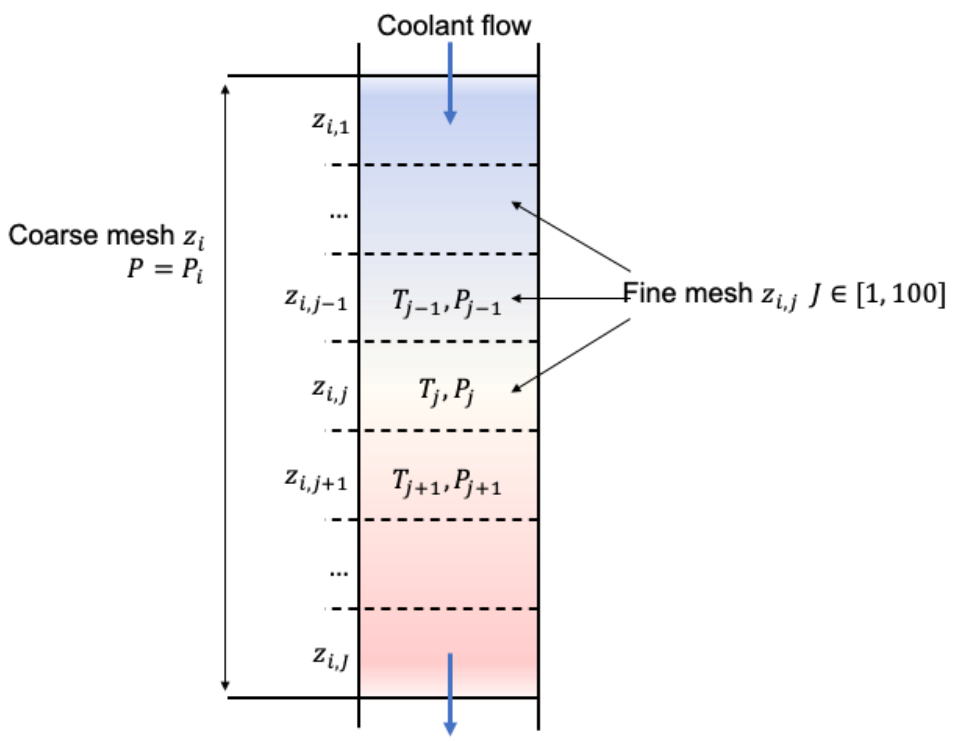

Figure C-2. Coarse and fine meshing used in the axial sweep

The solution of bulk coolant temperature and pressure is carried out via the procedure outlined in Ref. [1]. The governing equations are the conservation of mass and momentum, shown below in the differential form in Equations C.1-1 and C.1-2, respectively.

$$
\begin{gathered}
\frac{d \rho}{\rho}+\frac{d A}{A}+\frac{d u}{u}=0 \\
\frac{d \rho}{P}+\frac{\gamma M^{2}}{2} \frac{f d x}{D_{H}}+\gamma M^{2} \frac{d u}{u}=0
\end{gathered}
$$

The area of the coolant holes is constant, so the second term of Equation C.1-1 can be eliminated. In Equation C.1-2, $f$ is the Darcy friction factor, calculated as four times the Fanning friction factor, which in turn is obtained based on the approach shown in Eqs. 3 and 4 in Ref. [2]. $M$ is the Mach number, defined in Equation C.1-3.

$$
M(T, P)=\frac{u}{C}=\frac{\frac{\dot{m}}{\rho A}}{\sqrt{\frac{\gamma P}{\rho}}}
$$

That the Mach number remain below unity is critical to prevent the formation of shock waves that could disrupt the reactor core. Generally, as the coolant temperature increases and pressure decreases, the Mach number increases. The calculation is aborted if at any point during the sweep the Mach number exceeds 0.999 .

The change in Mach number across each axial fine mesh is used to evaluate the resulting temperature and pressure. This quantity can be evaluated as shown in Equation C.1-4 by 
combining Equations C.1-1-C.1-3 and the definition of stagnation temperature, $T_{0}$, which is shown in Equation C.1-5 in terms of the static temperature $T$.

$$
\begin{gathered}
\frac{d M}{d z}=\frac{M}{2\left(1-M^{2}\right)}\left(1+\frac{\gamma-1}{2} M^{2}\right)\left(\gamma M^{2} \frac{4 f}{D}+\frac{1+\gamma M^{2}}{T_{0}} \frac{d T_{0}}{d z}\right) \\
T_{0}=T\left(1+\frac{1}{2}(\gamma-1) M^{2}\right)
\end{gathered}
$$

Equation C.1-4 is different from Eqn. 3 presented in Ref. 1. It seems Eqn. 3 in Ref 1 is in error, based on initial attempts to recreate the results presented therein. It was determined that Eqn. 3 in Ref [1]. is missing a factor of 2 on the friction transfer term in the second set of parentheses; this factor is apparent in other references, such as in Table 5.3 (pg. 263) and Table 6.2 (pg. 315) of Ref [3].

The stagnation temperature, $T_{0}$, is evaluated with $T=T_{i, j-1}$. The change in stagnation temperature over the axial step, $d T_{0} / d z$, is evaluated by approximating $T_{i, j}$ using $Q=m C_{p} d T$. Given that the Mach number at the step inlet is known, the initial value problem posed by Equation C.1-4 is solved numerically to obtain the Mach number at the step outlet.

With the outlet Mach number known, the static temperature/e $T_{j+1}$ can be evaluated using Equation C.1-5. The outlet pressure is evaluated using Equation C.1-6.

$$
P_{i, j}=P_{i, j-1} \frac{M_{i, j-1}}{M_{i, j}} \sqrt{\frac{T_{i, j}}{T_{i, j-1}}}
$$

After the bulk coolant temperature and pressure have been determined, the cladding surface temperature, $T_{i, j}^{S}$ is calculated by iteration on the heat transfer coefficient. For each iteration, the Nusselt number is calculated based on an adjustment to the Dittus-Boelter correlation, presented Eqs. 5 and 7 in Ref. [2] and shown in Equation C.1-7 and C.1-8.

$$
N u_{b}=x\left[0.023 R e_{b}^{0.8} \operatorname{Pr}_{b}^{0.4}\right]
$$

Where $\mathrm{x}$ represents the entrance length treatment as follows:

$$
x=\left\{\begin{array}{lr}
\left(\frac{T_{i, j}^{S}}{T_{i, j}}\right)^{-0.57+1.59 D_{H} / z_{i, j}} & T_{i, j}^{S}>T_{i, j} \text { and } 2<\frac{z_{i, j}}{D_{H}}<252 \\
1 & \text { otherwise }
\end{array}\right.
$$

The heat transfer coefficient is obtained from the Nusselt number using the coolant thermal conductivity evaluated at its bulk temperature and pressure and the heated perimeter of the coolant hole as the characteristic length. 
With the clad surface temperature determined, one-dimensional radial conduction is used to calculate the clad inside temperature. The model considers the system to be a series of concentric, infinite cylinders, shown conceptually in the diagram in Figure C-3.

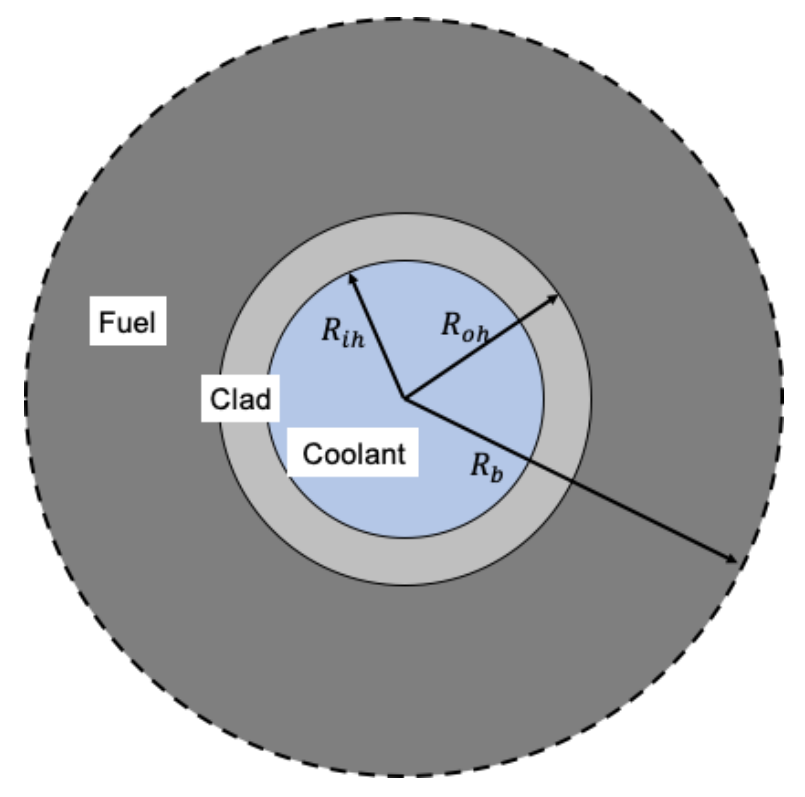

Figure C-3. Bounding hole conduction system

The heat flux through the cladding, $q^{*}$, is calculated based on the power density and the radii of the adiabatic boundary $\left(R_{b}\right)$ and cladding inside surface $\left(R_{o h}\right)$ as shown in Equation C.1-9.

$$
q^{*}=\frac{q^{\prime \prime \prime}\left(R_{b}^{2}-R_{o h}^{2}\right)}{2 R_{o h}}
$$

The clad inside temperature is determined iteratively using Equation C.1-10, evaluating the thermal conductivity of the clad at the average of the inner and outer temperatures until convergence is achieved. In Equation C.1-8, $R_{i h}$ is the radius of the outer surface of the cladding.

$$
T_{i, j}^{\text {clad }}=\frac{q^{*} R_{o h}}{k_{\text {clad }}} \ln \left(\frac{R_{o h}}{R_{\text {ih }}}\right)+T_{i, j}^{S}
$$

The maximum fuel temperature, which occurs at the adiabatic boundary, is obtained using a similar iteration scheme to update the fuel thermal conductivity at the average fuel temperature. The solution for the peak temperature is given by Equation C.1-11.

$$
T_{i, j}^{f u e l}=\frac{q^{\prime \prime \prime} R_{b}^{2}}{2 k_{f u e l}}+C_{1} \ln \left(R_{b}\right)+C_{2}
$$

Where: 


$$
\begin{gathered}
C_{1}=\frac{q^{\prime \prime \prime} R_{b}^{2}}{2 k_{f u e l}} \\
C_{2}=T_{i, j}^{c l a d}+\frac{q^{\prime \prime \prime}}{4 k_{\text {fuel }}}\left(R_{\text {oh }}^{2}-R_{b}^{2} \ln \left(R_{o h}\right)\right)
\end{gathered}
$$

The procedure described above is carried out over the length of the fuel assembly, collecting coolant, clad, and fuel temperatures at each step. The peak fuel temperature over the axial space is taken as the limiting temperature. To provide sufficient margin with the melting temperature, the maximum acceptable fuel temperature is $2800 \mathrm{~K}$.

\section{C.2: Pin model}

As an alternative to the bounding hole model, the assembly can be inverted and modeled as a fuel rod bundle. The same relationships and calculation procedure can be applied but need to be modified to the new geometry. Because these modifications are largely trivial, they are not expanded on here. Instead, this section briefly describes the geometry of the pin model and its relationship to the bounding hole model.

Rather than specifying the number of coolant channels, as is required for the bounding hole model, the pin model requires the number of pins, which are assumed to be arranged in a hexagonal lattice. The greater the number of pins, the greater the number of coolant flow paths. Just as the bounding hole model considered a single coolant hole, the pin model considers a single fuel pin and the coolant surrounding it. The pin radius is calculated based on the fuel particle volume fraction and the requested number of pins. One of the few differences between the bounding hole and pin models is that in the pin model, the outer coolant channel surrounding the fuel assembly is included in the coolant volume. Previous work [4] has found that for coolant volume fractions less than 0.6-0.7, the pin model should generally result in greater peak fuel temperatures than an inverted fuel geometry (as is modeled by the bounding hole model).

\section{References}

[1] A. Bandyopadhyay, A. Majumdar. "Modeling of Compressible Flow with Friction and Heat Transfer using the Generalized Fluid System Simulation Program (GFSSP)". Paper submitted to the Thermal Fluid Analysis Workshop, September 10-14, 2007. URL: https://tfaws.nasa.gov/TFAWS07/Proceedings/TFAWS07-1016.pdf

[2] M. Taylor. "Prediction of Friction and Heat-Transfer Coefficients with Large Variations in Fluid Properties". NASA-TM-X-2145 (1970).

[3] M. J. Zucrow, J. D. Hoffman. "Gas Dynamics - Volume 1". John Wiley \& Sons, 1976.

[4] P. Ferroni. "An Inverted Hydride-Fueled Pressurized Water Reactor Concept". PhD Thesis, Massachusetts Institute of Technology (2010). 


\section{Argonne}

Nuclear Science and Engineering Division

Argonne National Laboratory

9700 South Cass Avenue, Bldg. 208

Argonne, IL 60439

www.anl.gov

Argonne National Laboratory is a U.S. Department of Energy laboratory managed by UChicago Argonne, LLC 